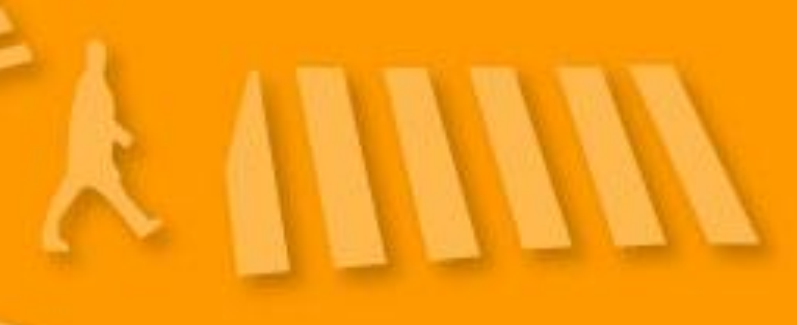

Seminario Urbanismo Internaciona 14 al 18 de Marzo 2005 


\section{CARTAGENA DE INDIAS}

Cinco siglos de evolución urbanística

\section{Maruja Redondo Gómez}

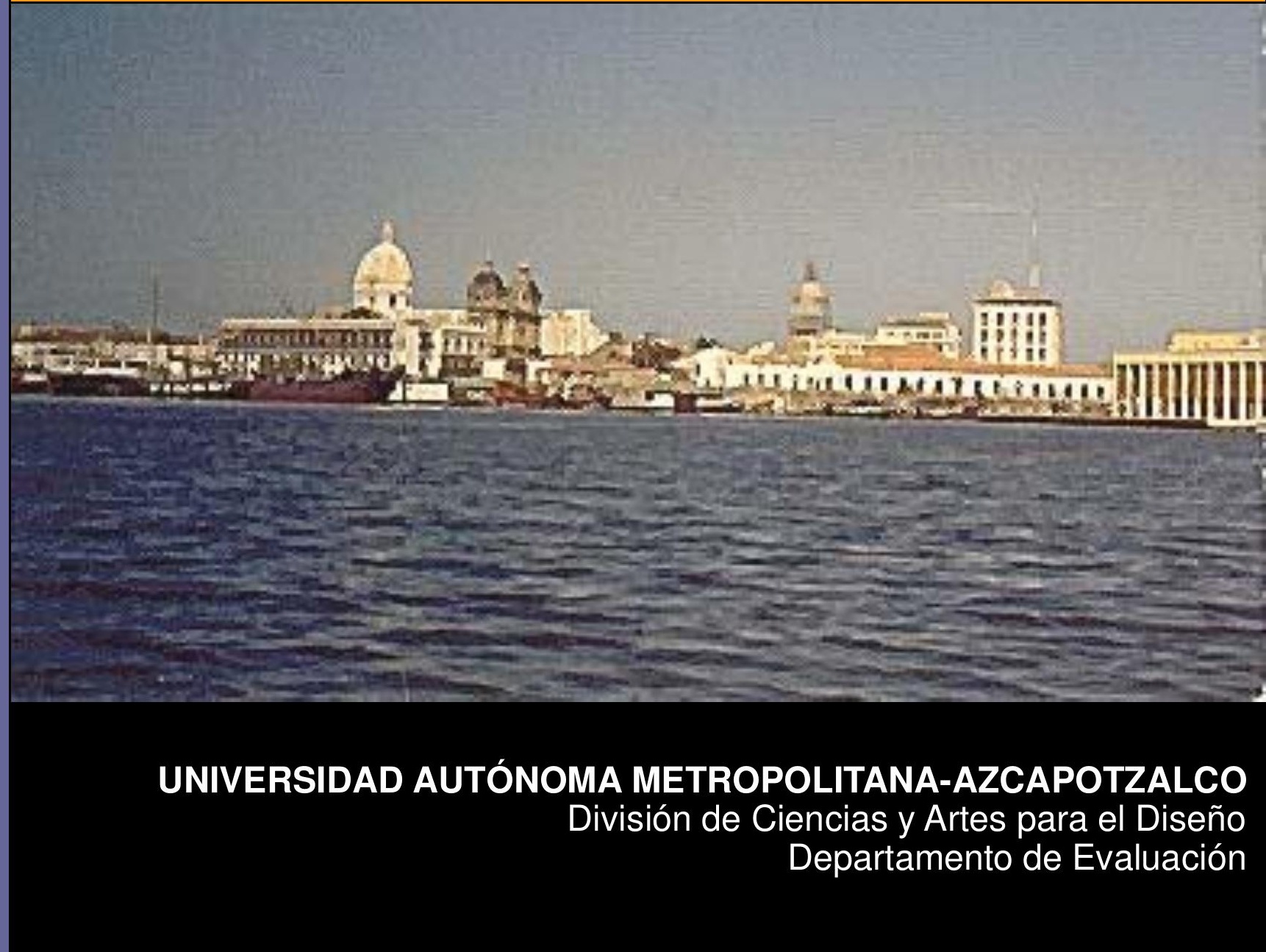




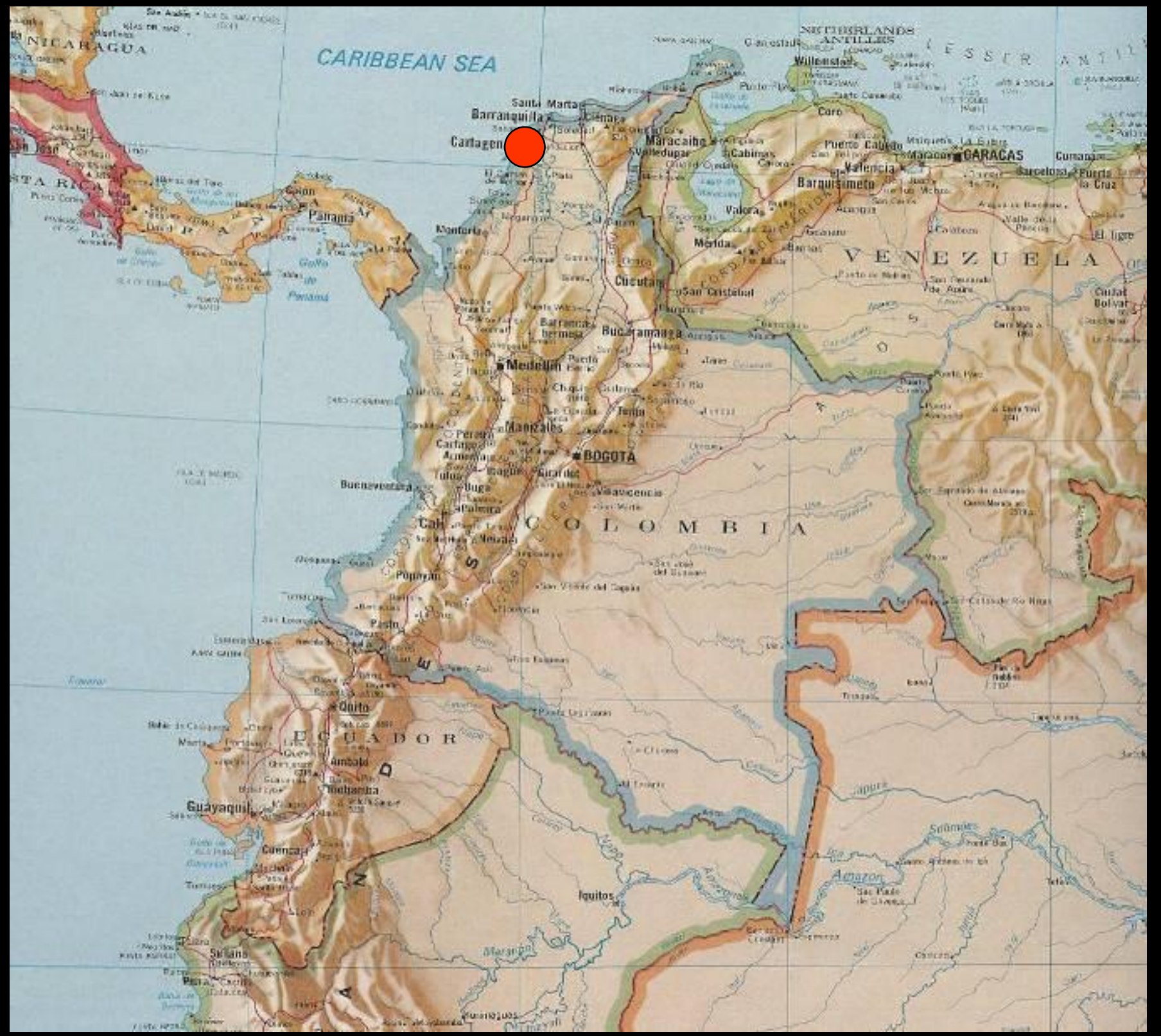

\section{SITUACION GEOGRÁFICA}




\section{EMPLAZAMIENTO}

Cartagena de Indias está asentada en dos islas bajas y arenosas que después fueron unidas. Rodeada por el Mar Caribe y una bahía interior que alimenta a un gran número de cuerpos de agua con un entorno rico en paisajes naturales.

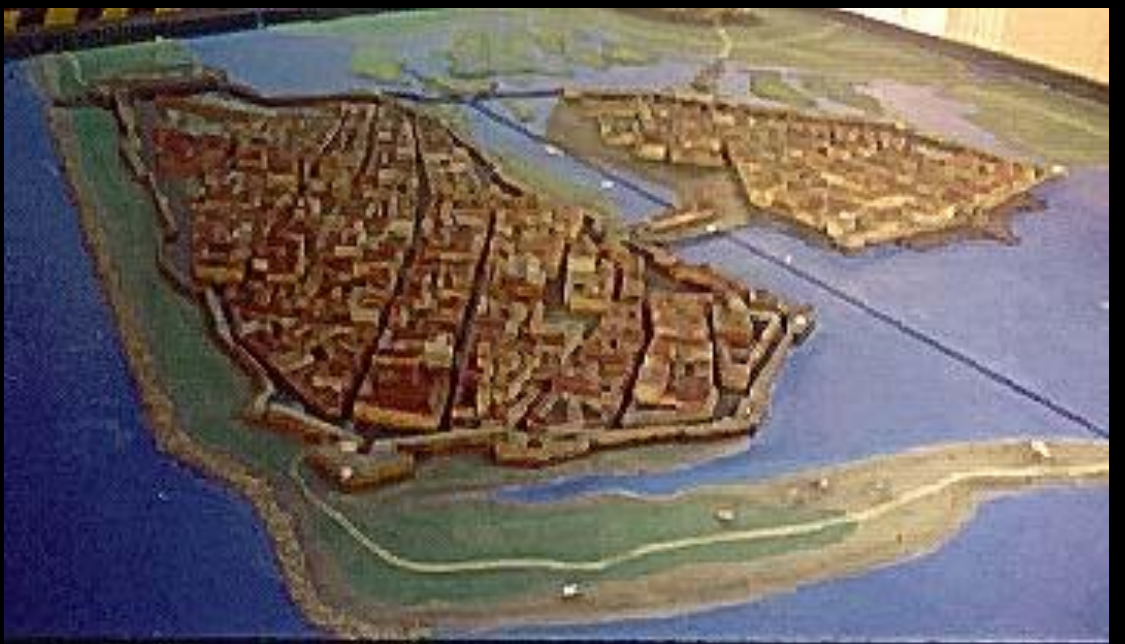

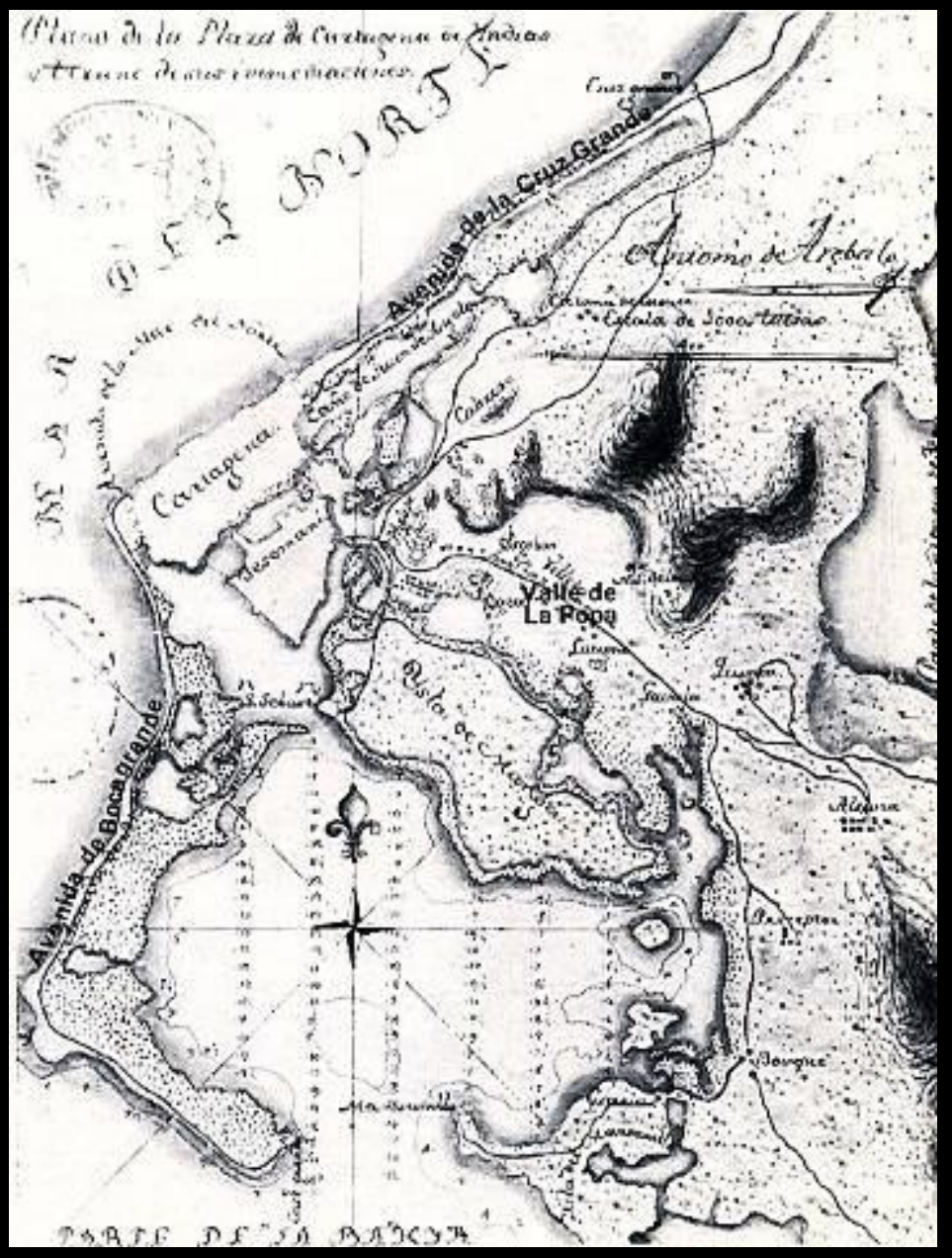

La bahía, factor decisivo en su fundación, está rodeada de islas que fungieron como puntos estratégicos para la defensa de la ciudad, en la etapa colonial. 


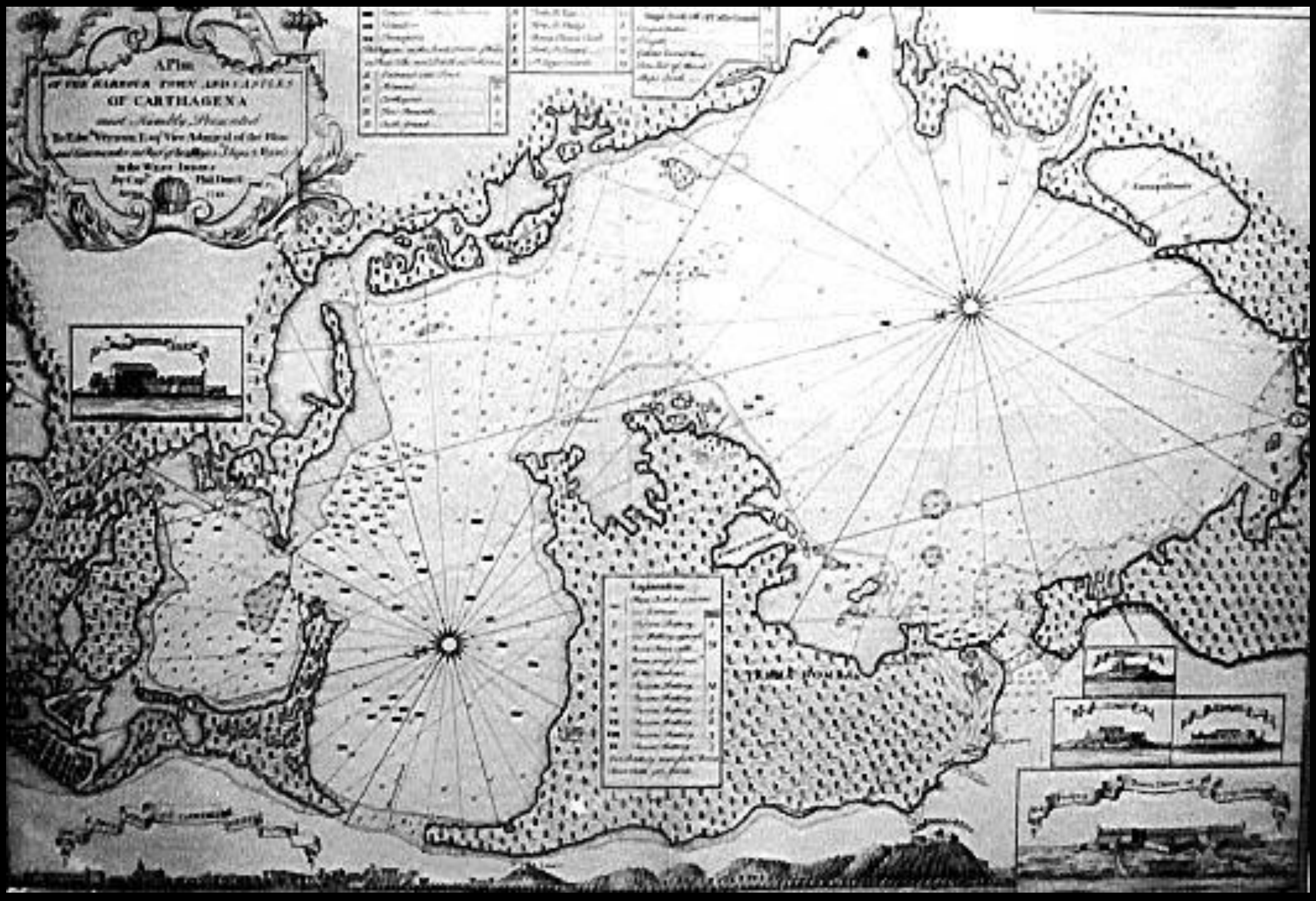

Plano de Phil D.A. 1742 


\section{- FUNDACIÓN}

Fundada por Don Pedro de Heredia en 1533. Calamar como se llamaba entonces, tuvo que salvar algunos inconvenientes básicos para la fundación:

- La escasez de agua de buena calidad y

- La carencia de espacios aptos para la crianza de ganado.

Los puntos a su favor fueron:

- Las condiciones que presentaba como puerto de enlace.

- Su situación geográfica.

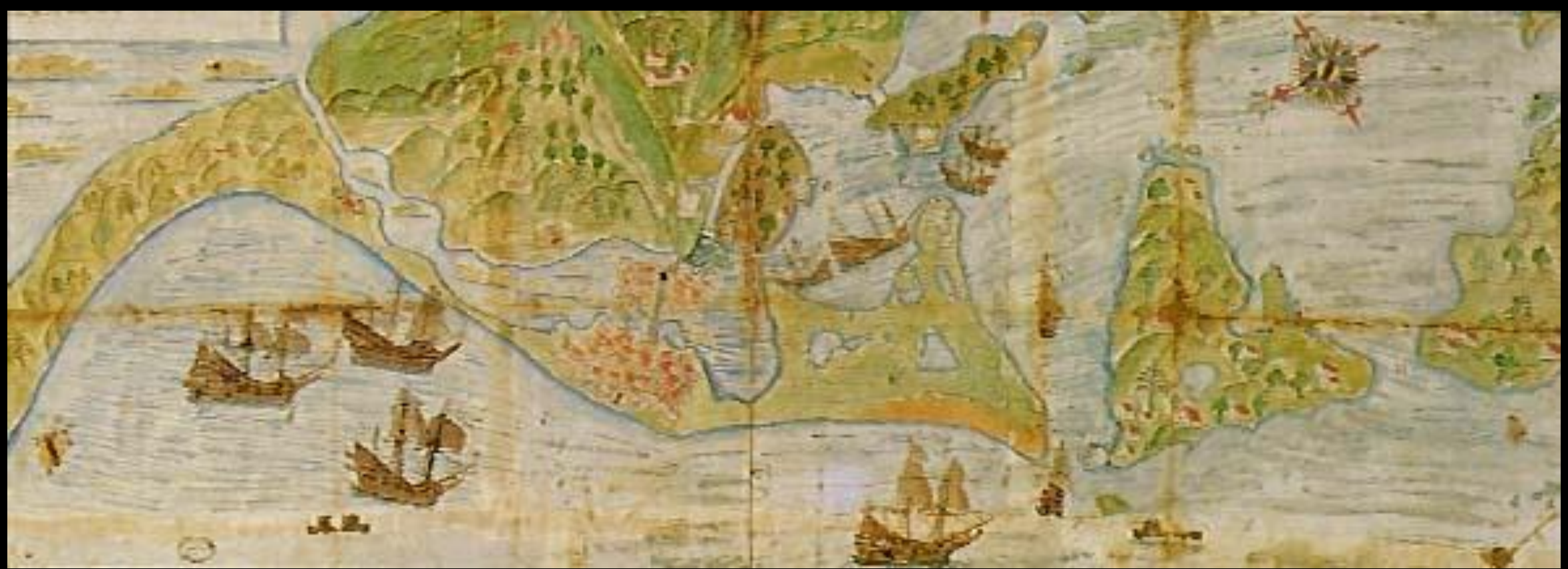




\section{EXPANSIÓN URBANA}

Esquema de organización territorial compacto inicialmente -pautas del poblado-.

Proceso de crecimiento: expansión de su área urbana

G en forma radial hacia el oriente siguiendo ejes del punto de origen del poblado: la Plaza de la Mar.

- 1533-1563 urbanización incipiente de la zona central

- 1586 expansión hacia el poniente

- 1595-1599 saturación de

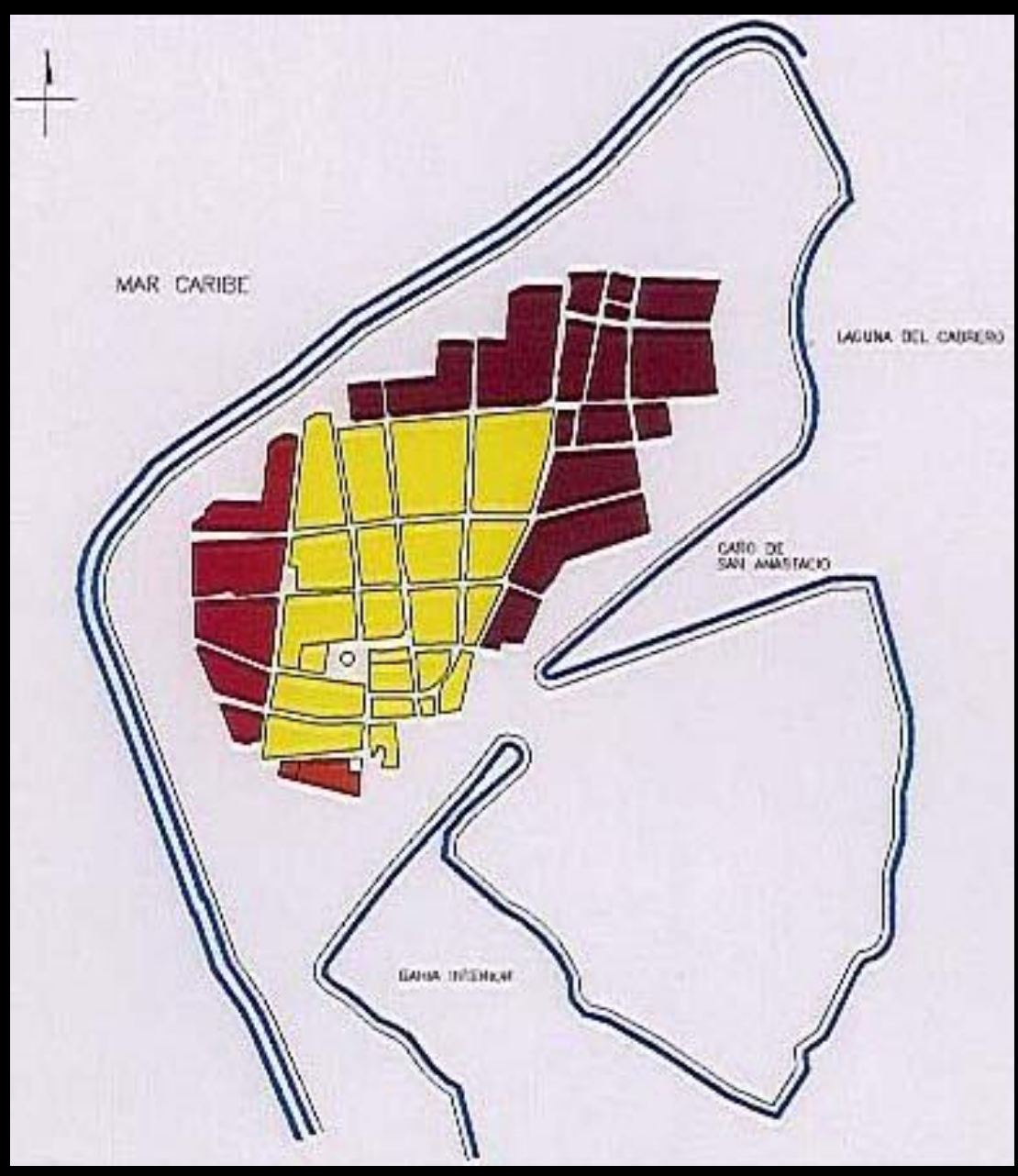
la isla principal 



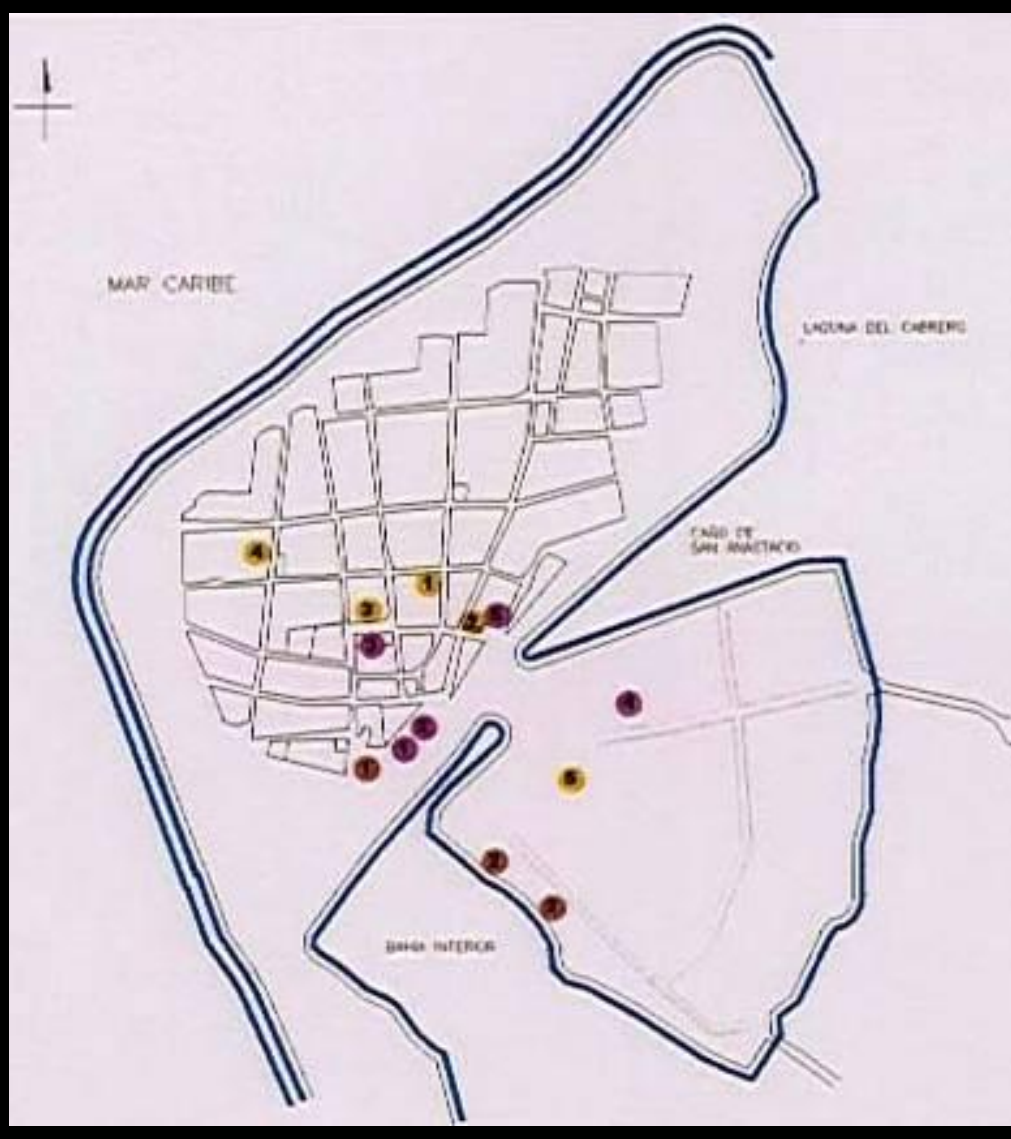

\section{ESTRUCTURA URBANA}

1535 primer intento de ordenación y transformación urbana: construcción de un templo de paja y trazado de algunos caminos. Se genera una incipiente dinámica de desarrollo impulsando algunas obras públicas.
La estructura era compacta y homogénea, inducida por la morfología de la isla. El equipamiento lo formaban: iglesias, conventos y oficinas administrativas que se conectaban con otras funciones urbanas a través de los ejes importantes.

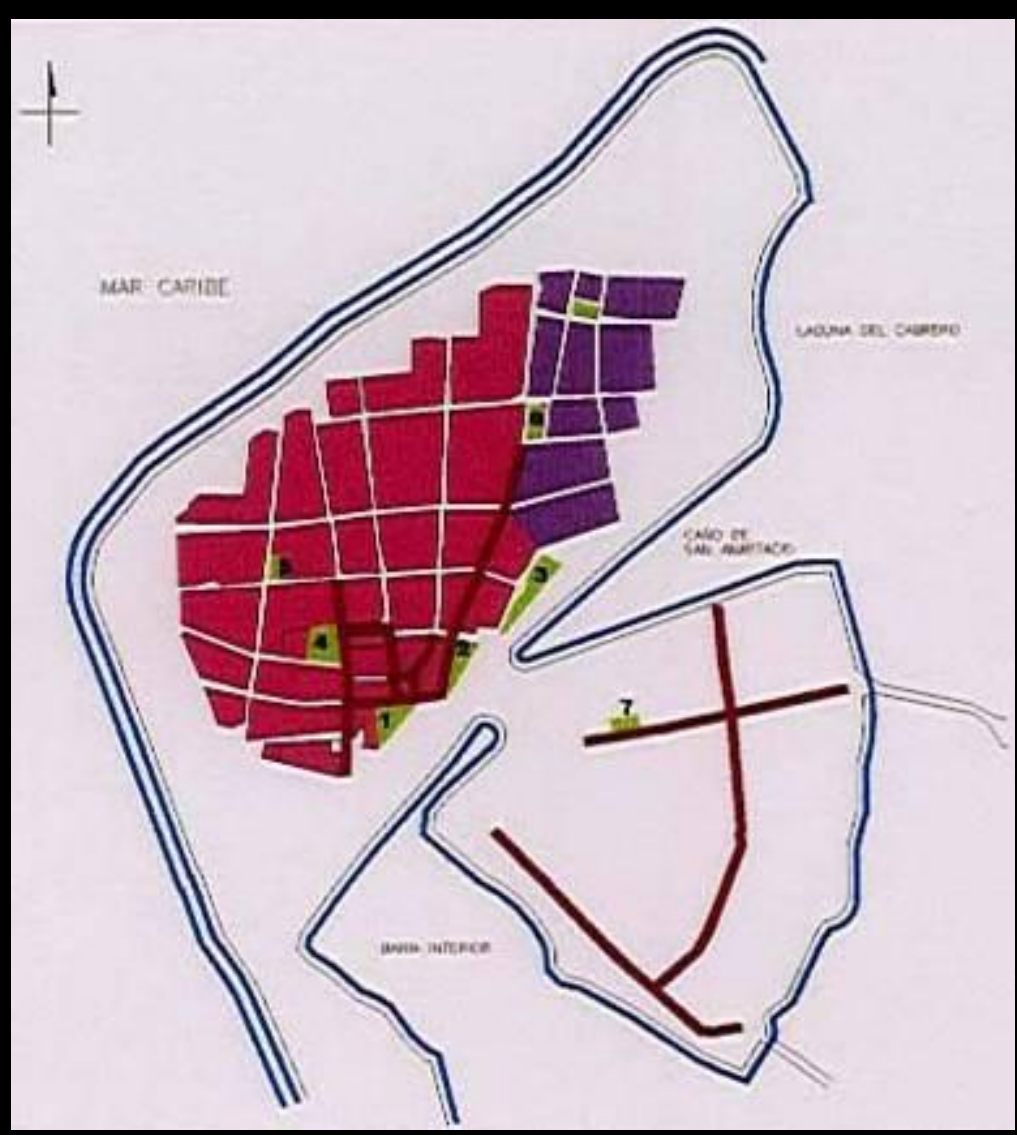




\section{EXPANSIÓN URBANA}

1633 Cartagena cumple su primer siglo de vida urbana; evoluciona de un período fecundo de experiencias e incierto de transformaciones urbanas a uno de consolidación y definición.

- Etapa de auge comercial que conlleva a una dinámica urbana. Cartagena es el puerto más importante y primer mercado de productos españoles en Sudamérica.

- Consolidación hacia el extremo oriente y urbanización de la isla vecina.

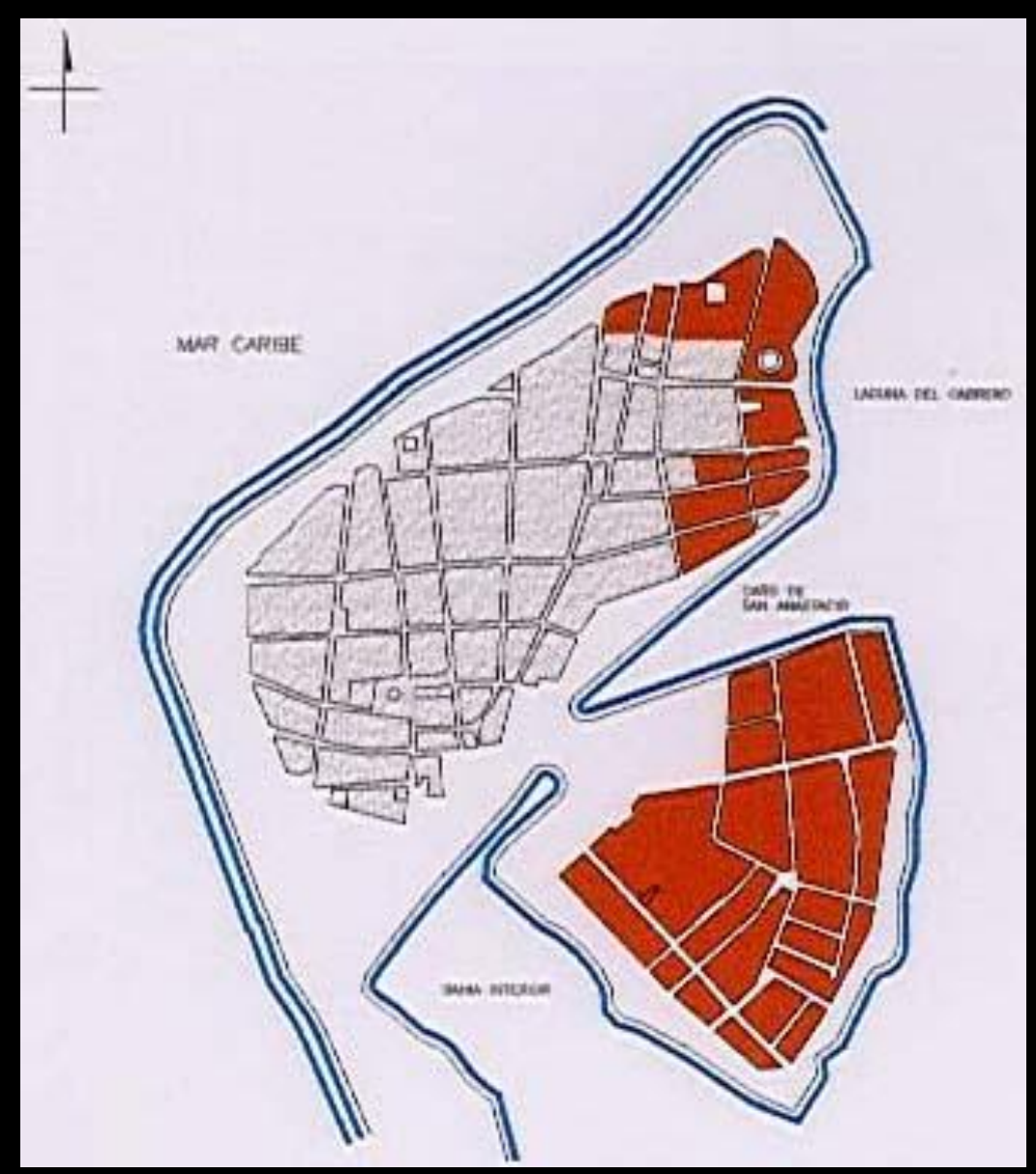




\section{ESTRUCTURA URBANA}

Siglo de transformación en su imagen urbana. sustitución de materiales; creación de nuevas tipologías y de un nuevo perímetro urbano conformado por murallas, y baluartes generando una nueva estructura.

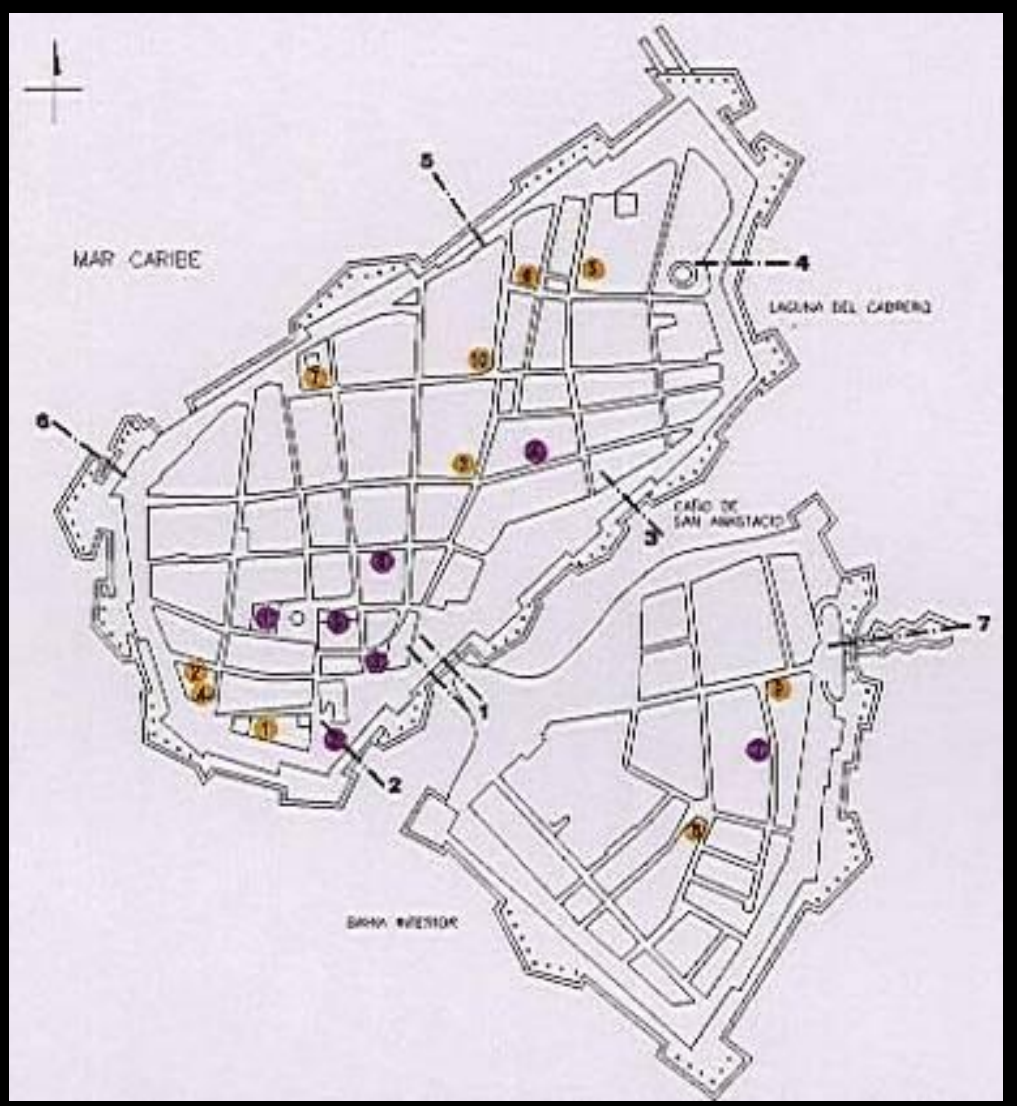

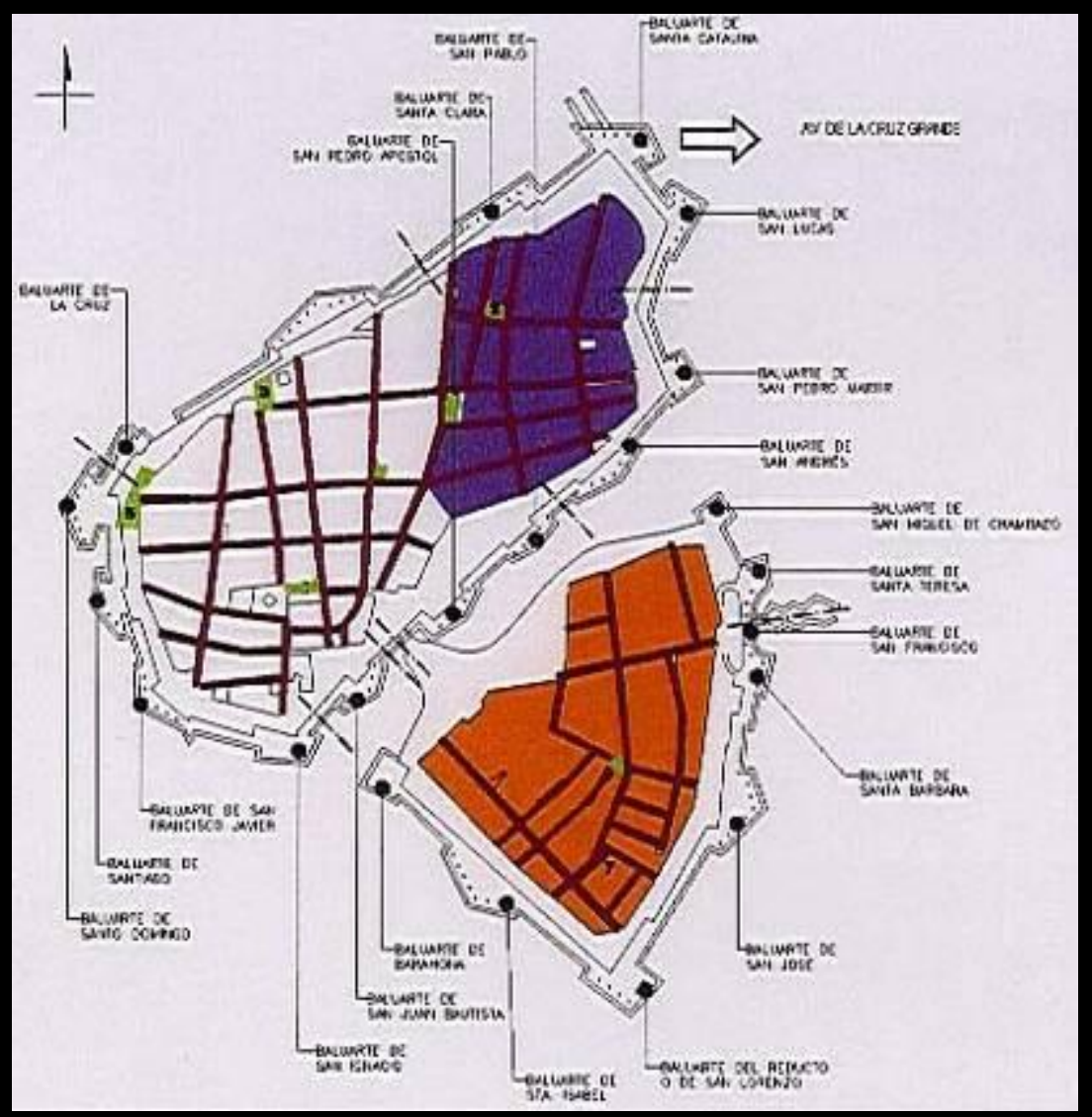

- Proyecto definitivo de fortificaciones.

- Construcción de la protección de la bahía.

- Inició del proceso de construcción y reconstrucción de murallas.

El equipamiento fue próspero en edificios religiosos y hospitales. 


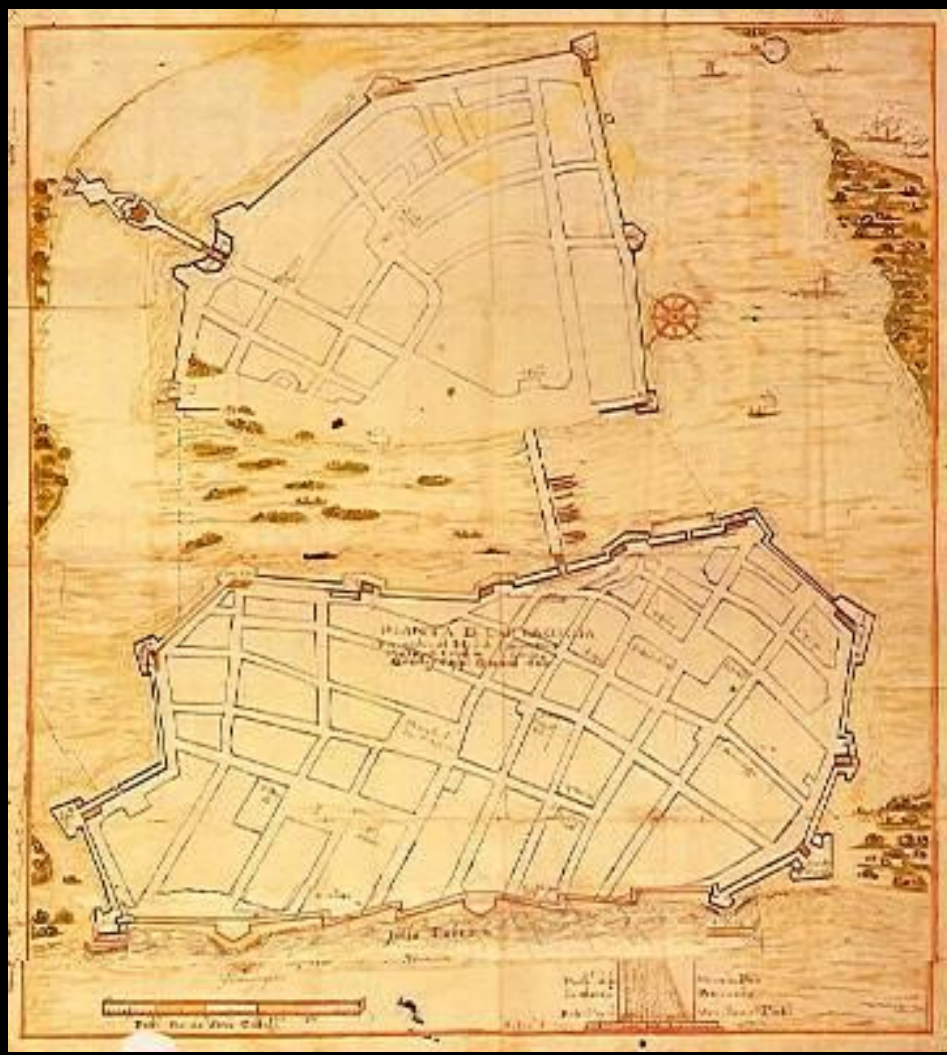

Francisco Picardo, 1688

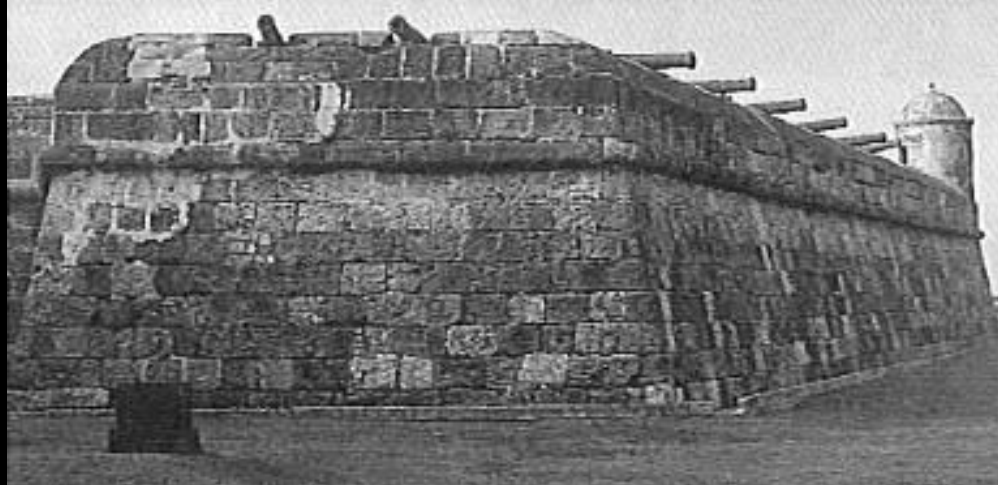

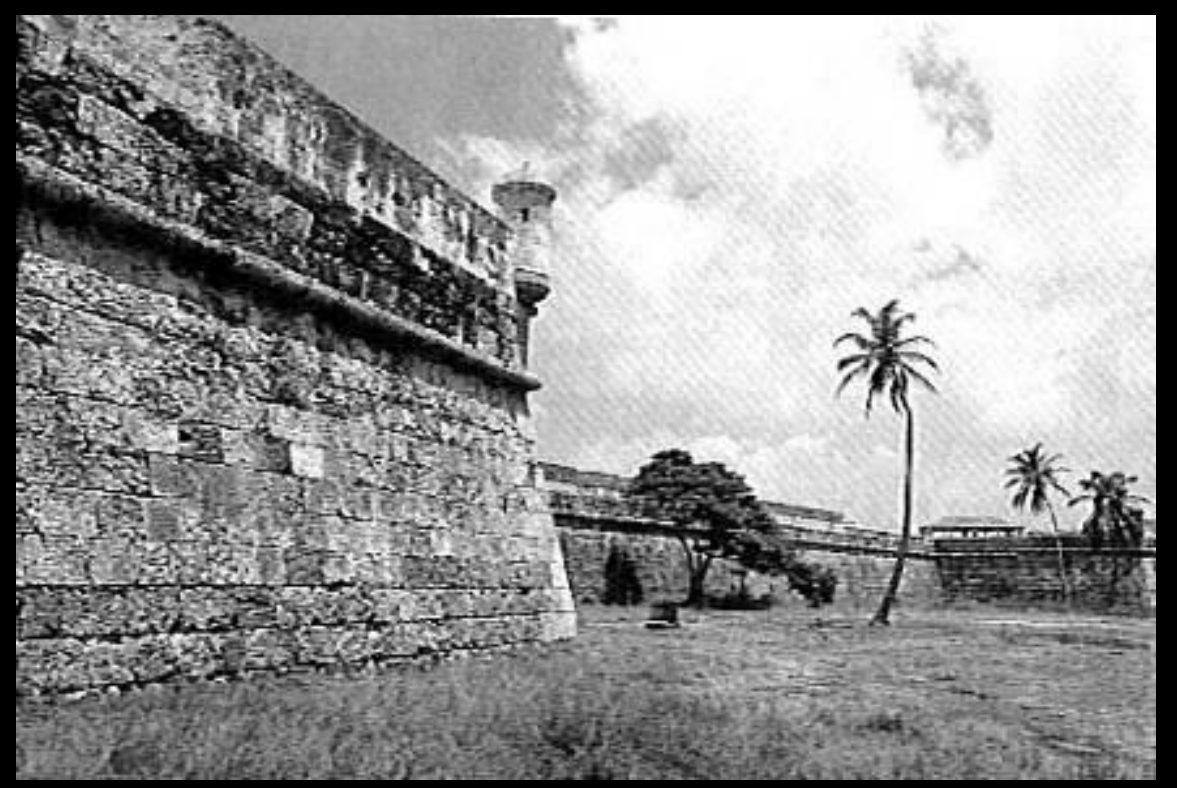

B. De Santa Catalina y

San Lucas

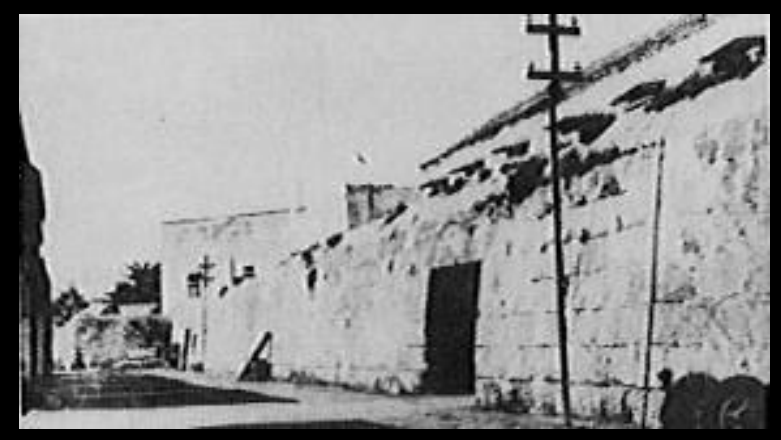

B. De Santo Domingo
B. De San Ignacio

Muralla entre baluartes

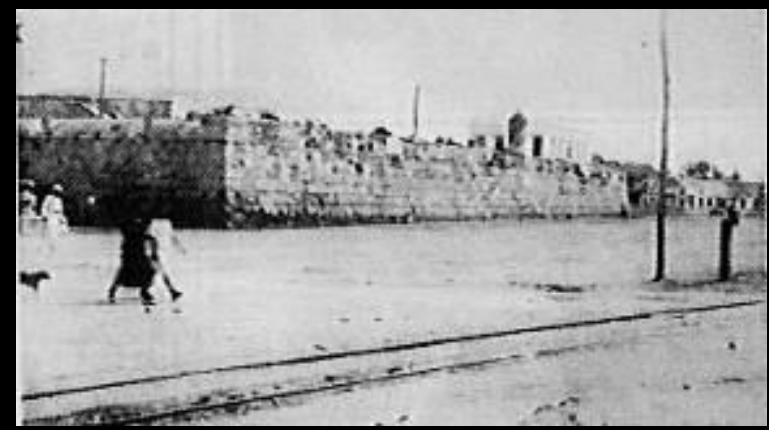




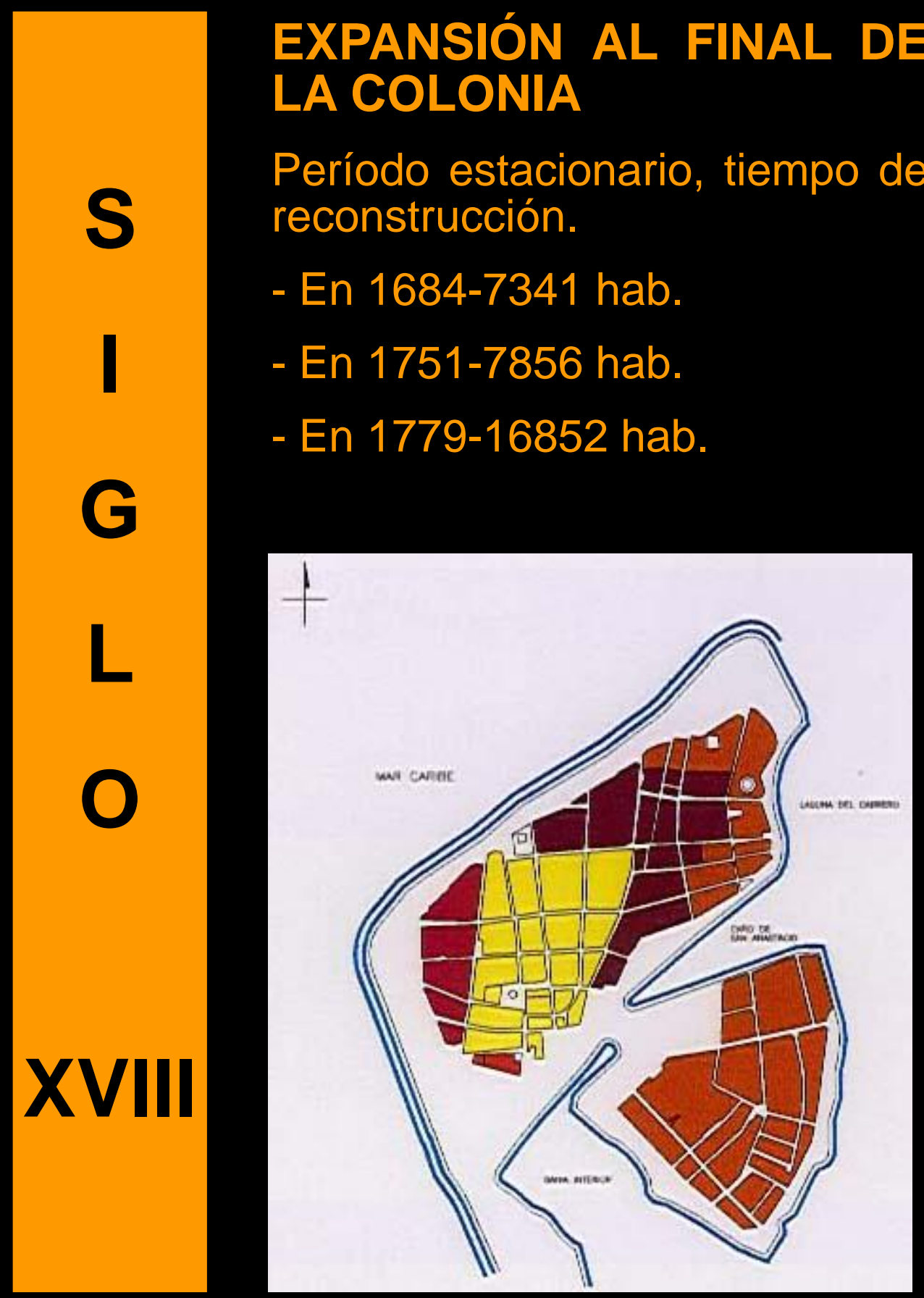

MODELO DE EXPANSIÓN

Esquema sectorial radio-concéntrico. Plaza de la Mar, elemento detonador del crecimiento.

-1er. Anillo - 1533

-2do. Anillo - 1563;

-3er y 4to. Anillo - 1595

- 5to. Anillo - siglo XVII.

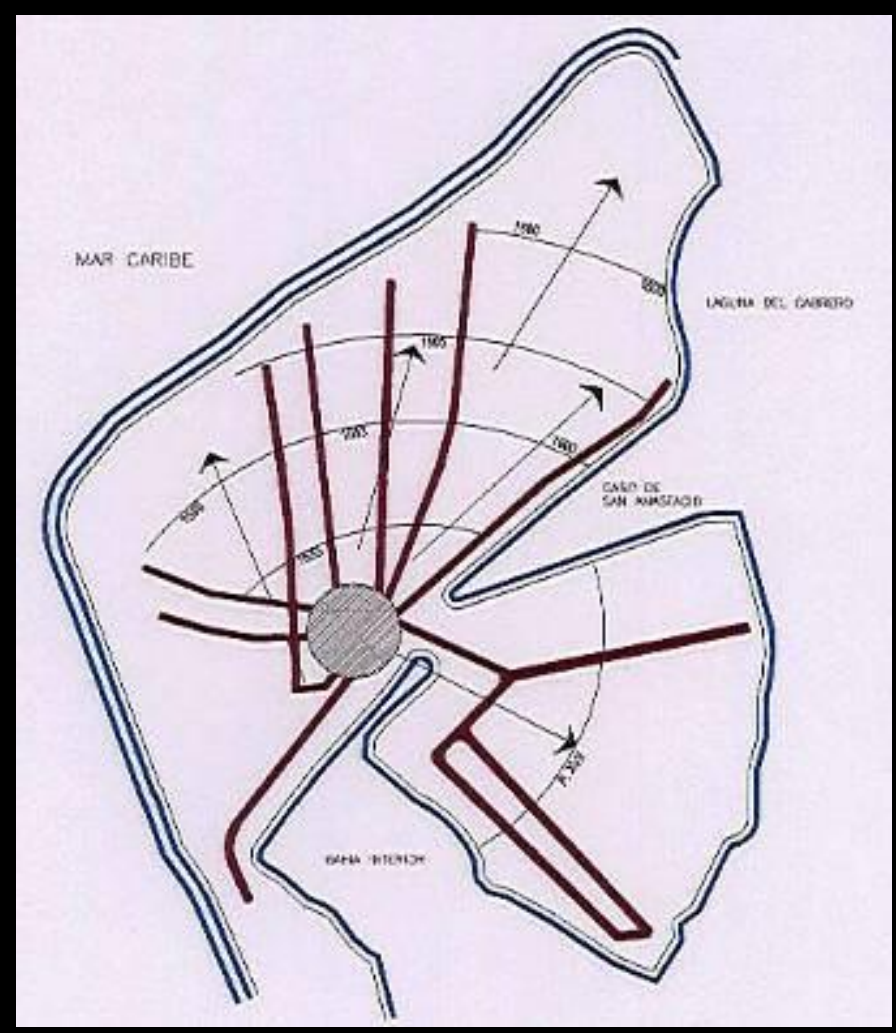




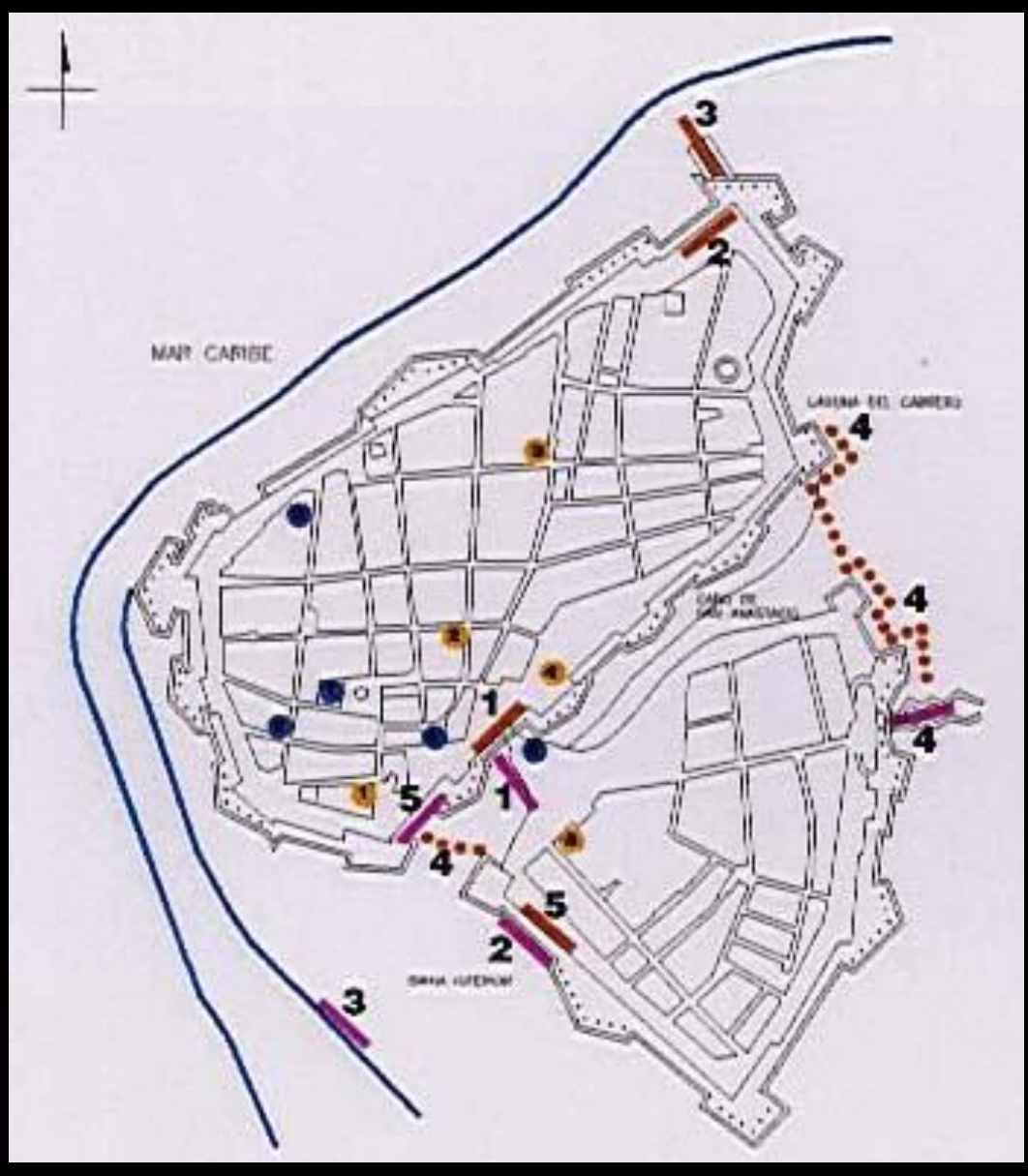

\section{ESTRUCTURA URBANA}

Al final de la colonia, la estructura logra su consolidación. Las obras de infraestructura impulsaron el comercio marítimo.
Las murallas y bastiones la convirtieron en una "Plaza Fuerte" e inexpugnable. La complejidad urbana alcanzada llevó a una demarcación de barrios con un carácter claramente administrativo:

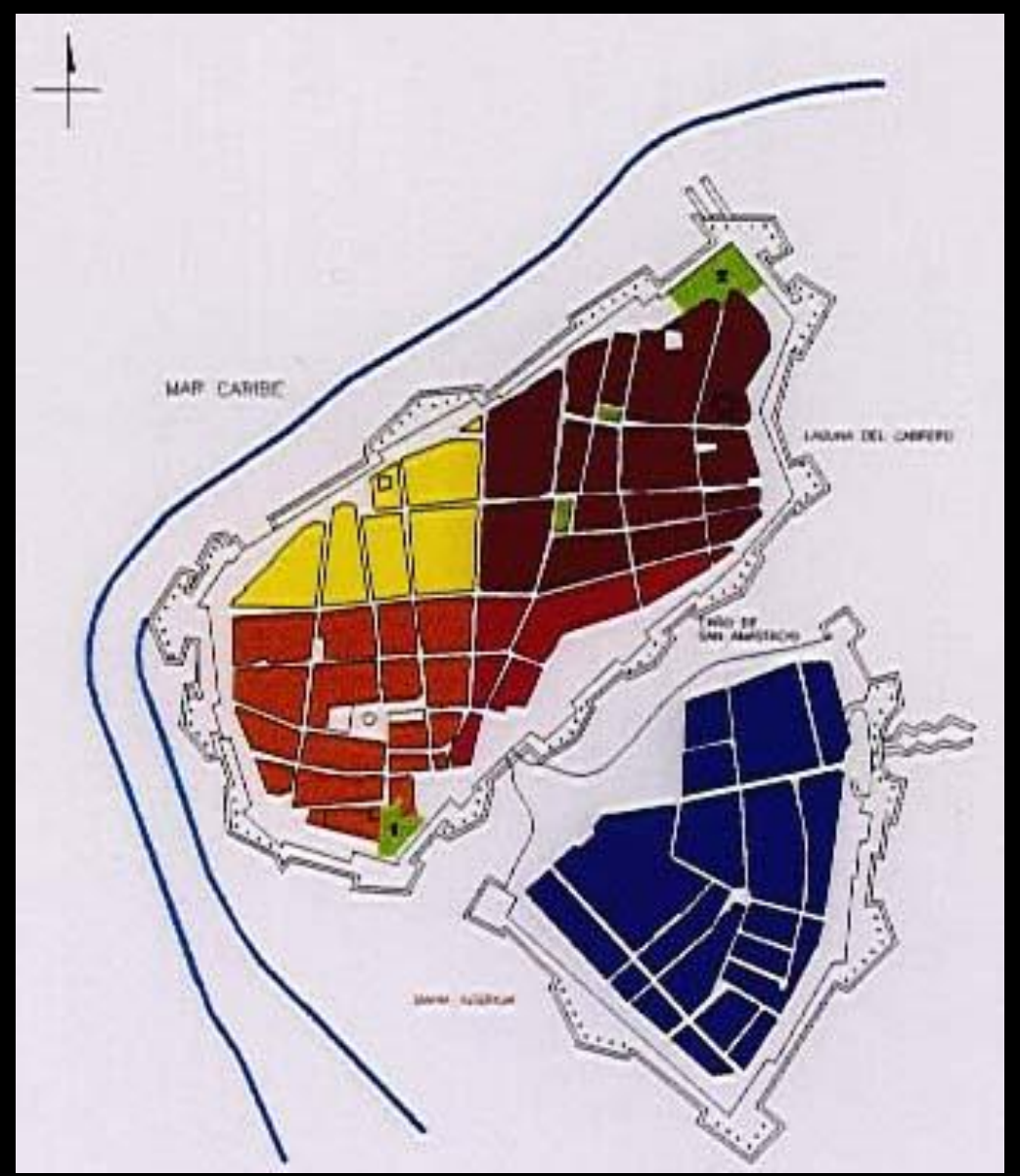




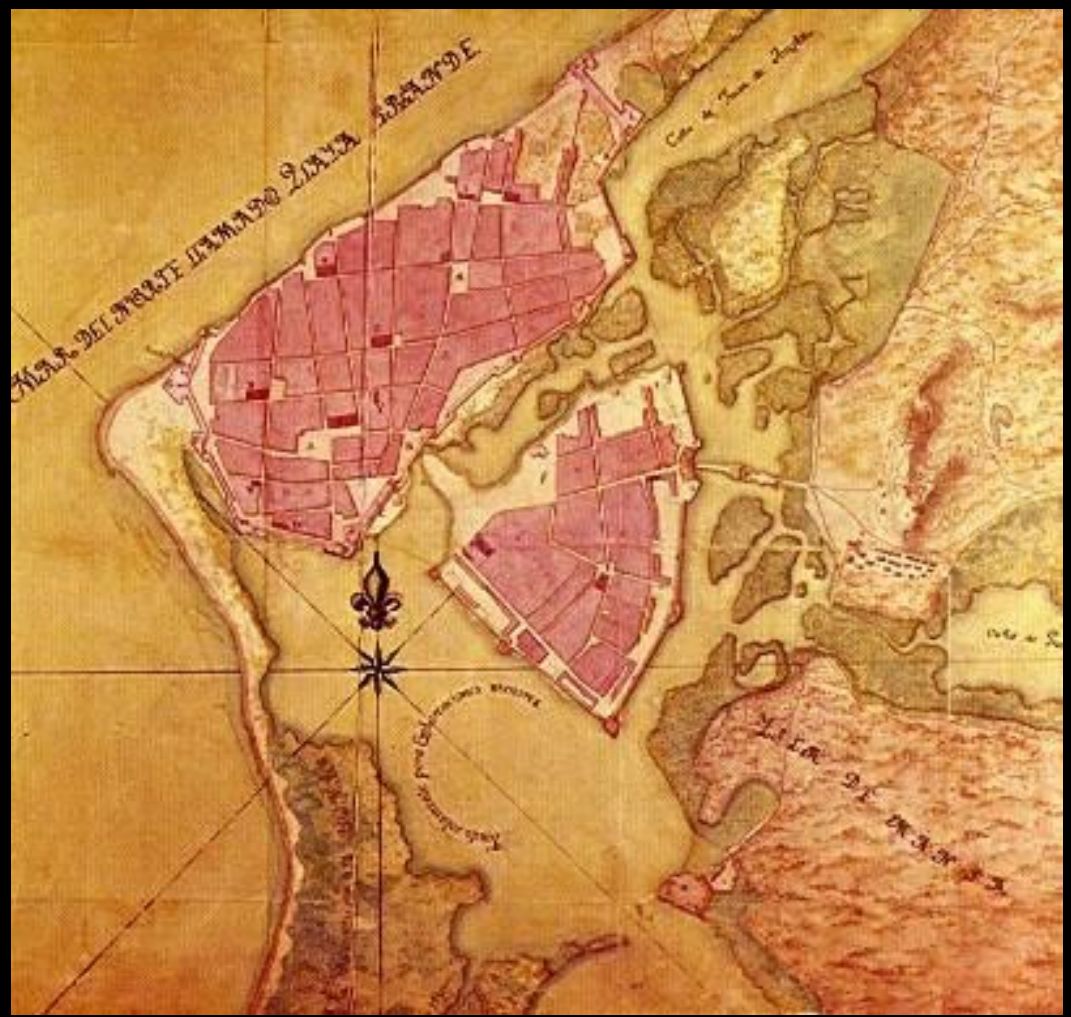

Antonio de Arevalo, 1769

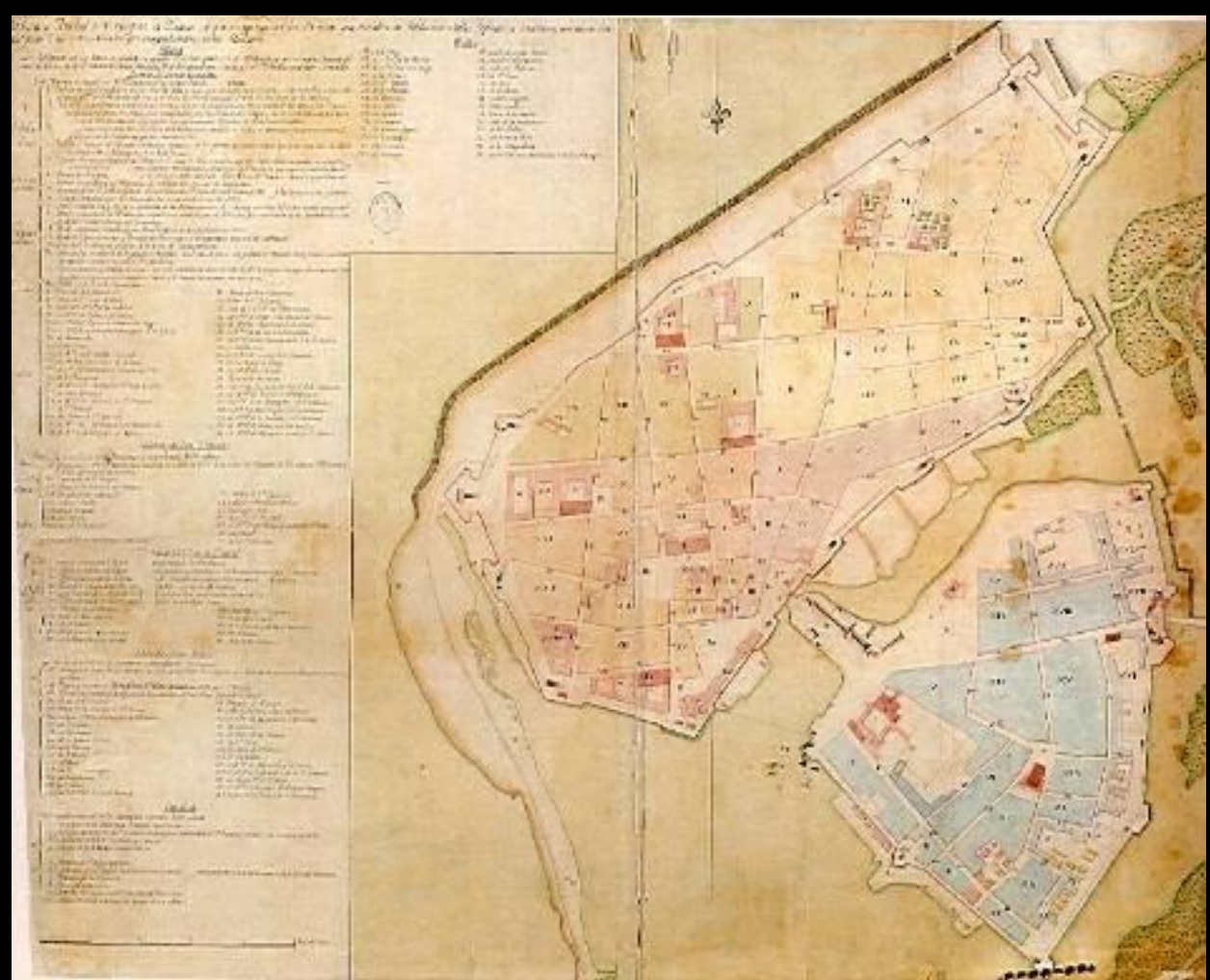

A. Anguiano, siglo XVIII

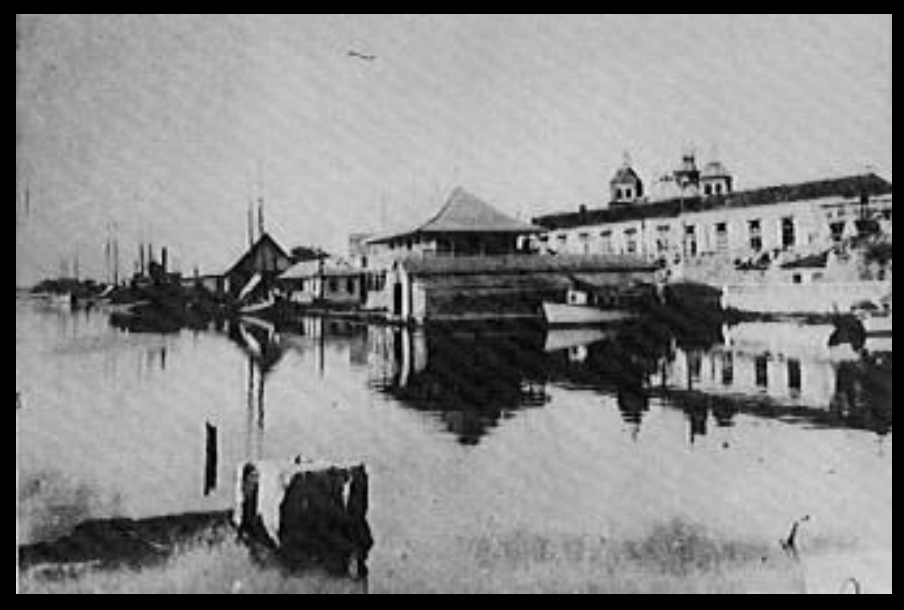

Muelle de la Bodeguita

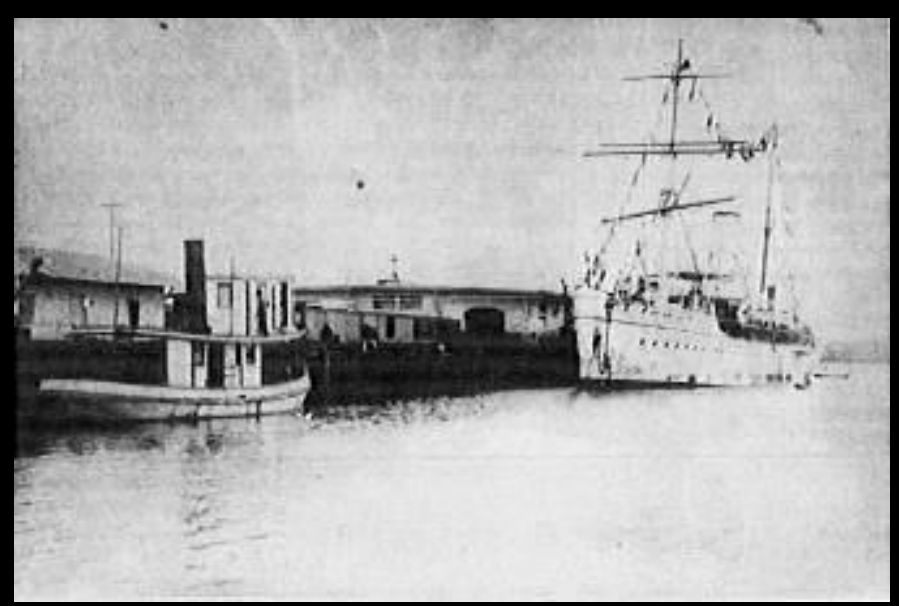

Muelle de la Machina 
MODELO DE ESTRUCTURA DE CAMINOS

\section{INTRAMUROS}

Las vías preexistentes condicionaron el sistema de puertas; se convirtieron en nodos de primer orden que se comunicaban entre sí, generando un esquema de calles convergentes en un punto: la Boca del Puente.

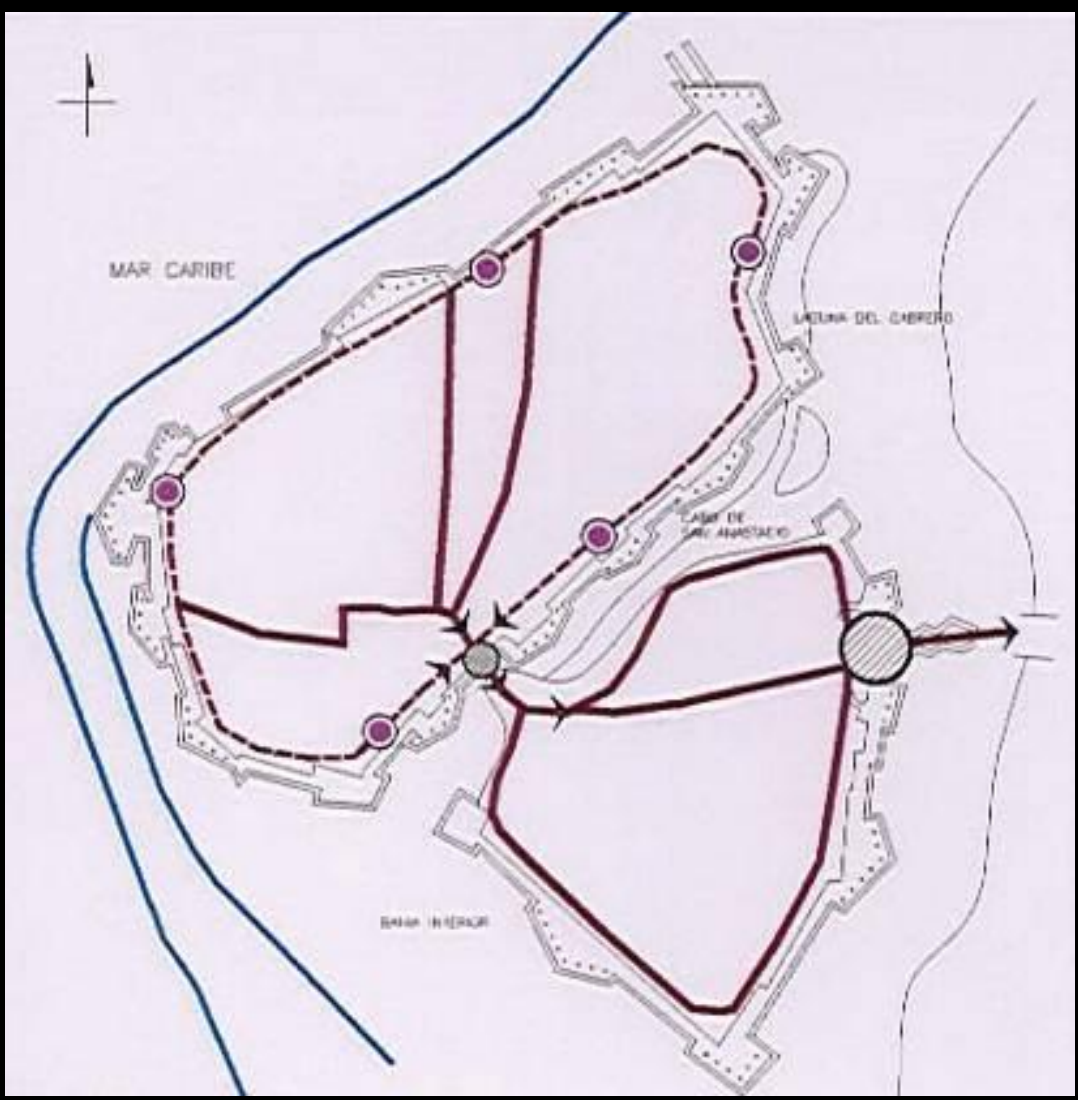

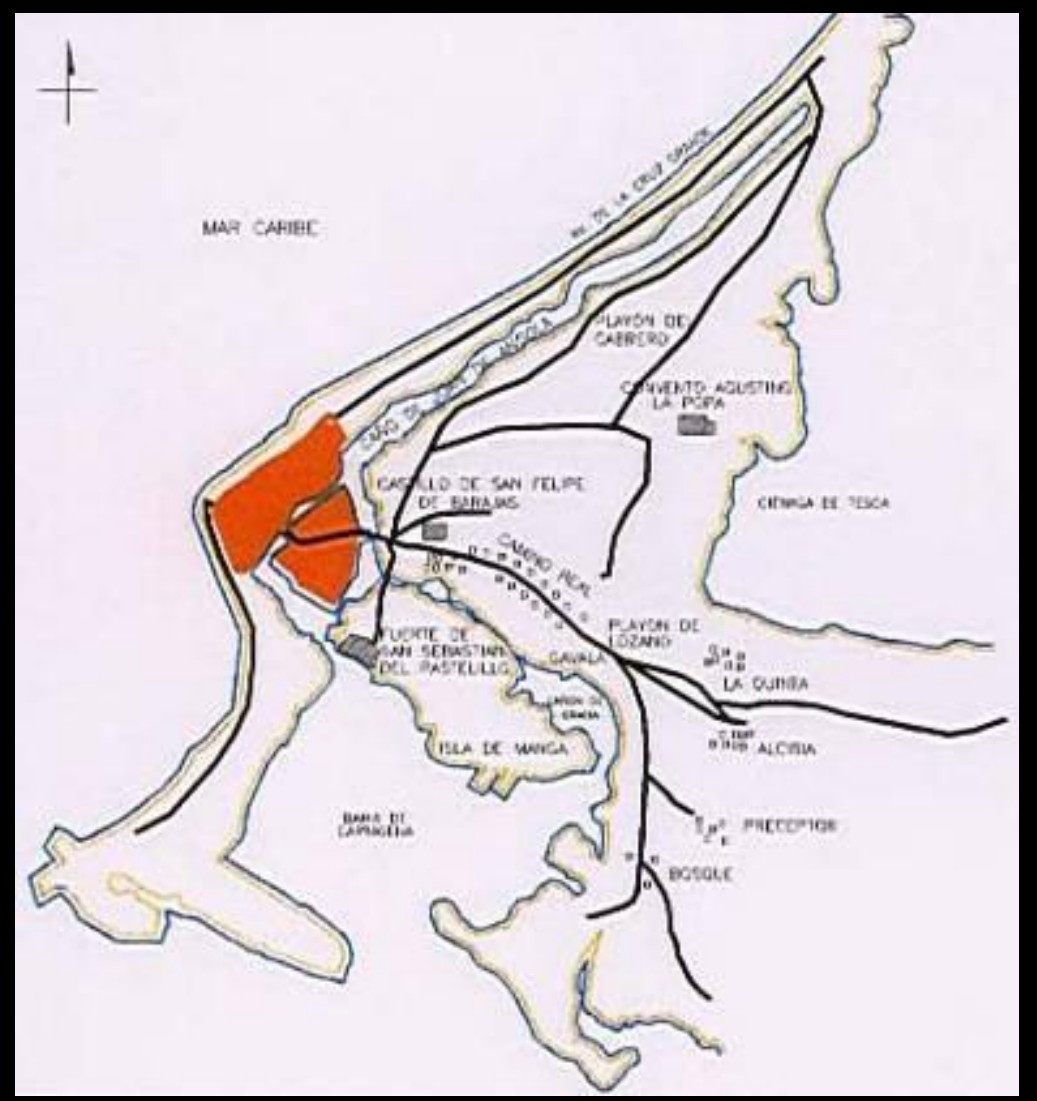

\section{EXTRAMUROS}

La ciudad se comunicaba hacia tierra firme a través de la puerta de la Media Luna que a su vez se ligaba con una serie de "Playones" que constituirían el área de futura expansión de la ciudad. 


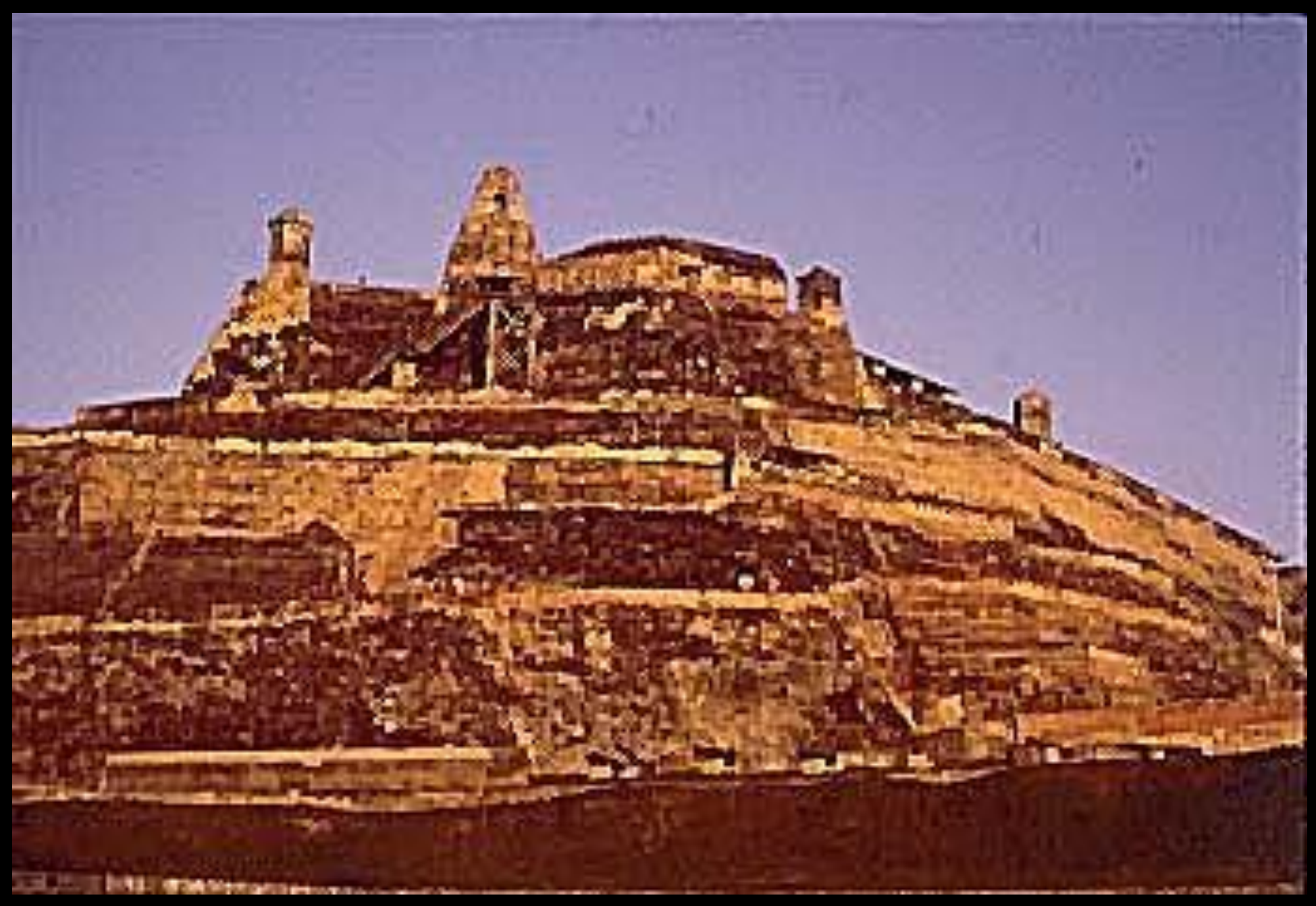

Castillo de San Felipe de Barajas 


\section{S MODELO DE EXPANSIÓN}

Siglo de decadencia y devastación. Asentamientos dispersos e incipientes surgían en las zonas extramuros iniciando el ensanche hacia tierra firme.

RETROCESO CRECIMIENTO Y DESARROLLO

( 1815-----20 a 22,000 hab.

1850----10,145 hab.

1881------9,681 hab.

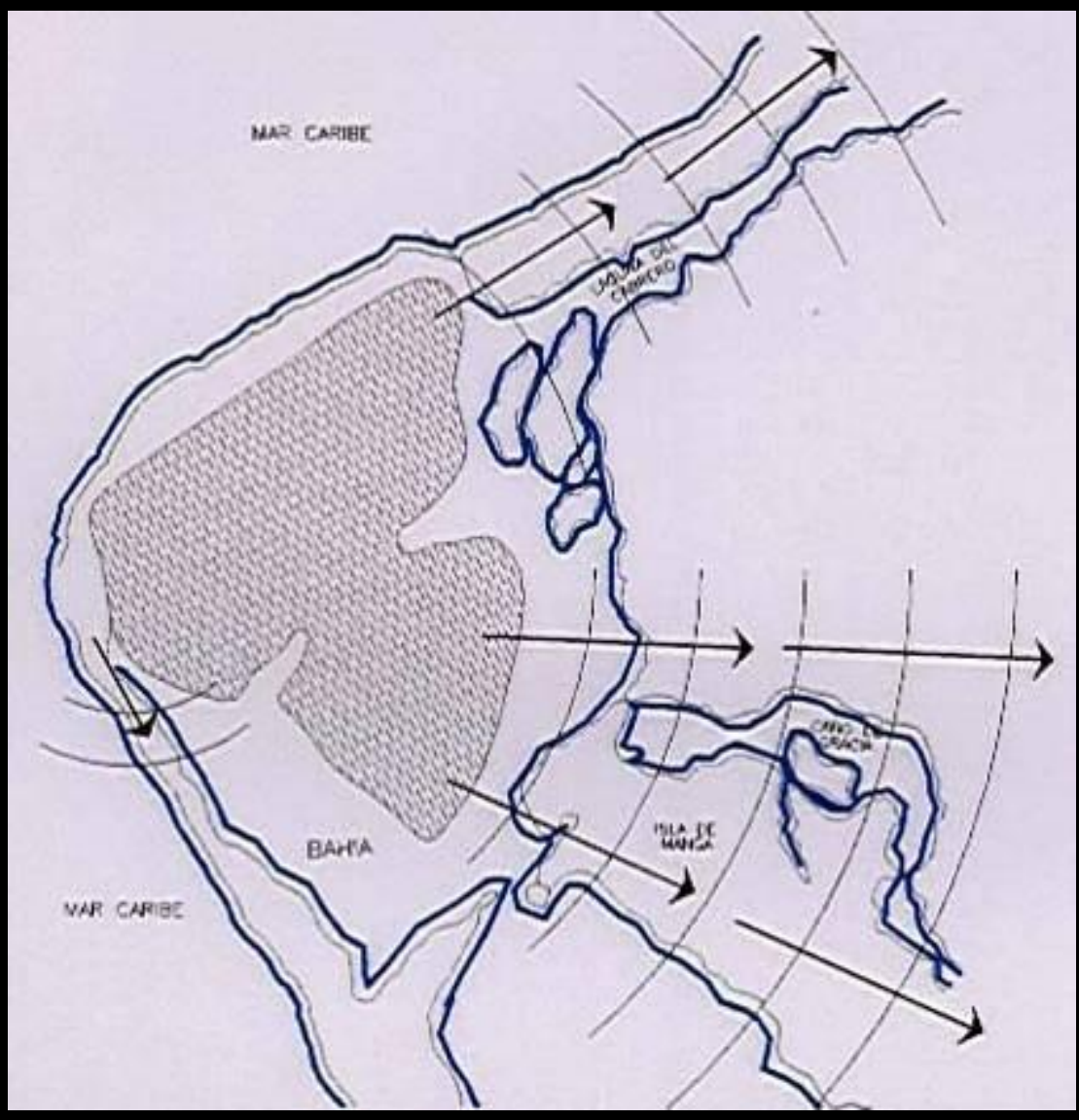




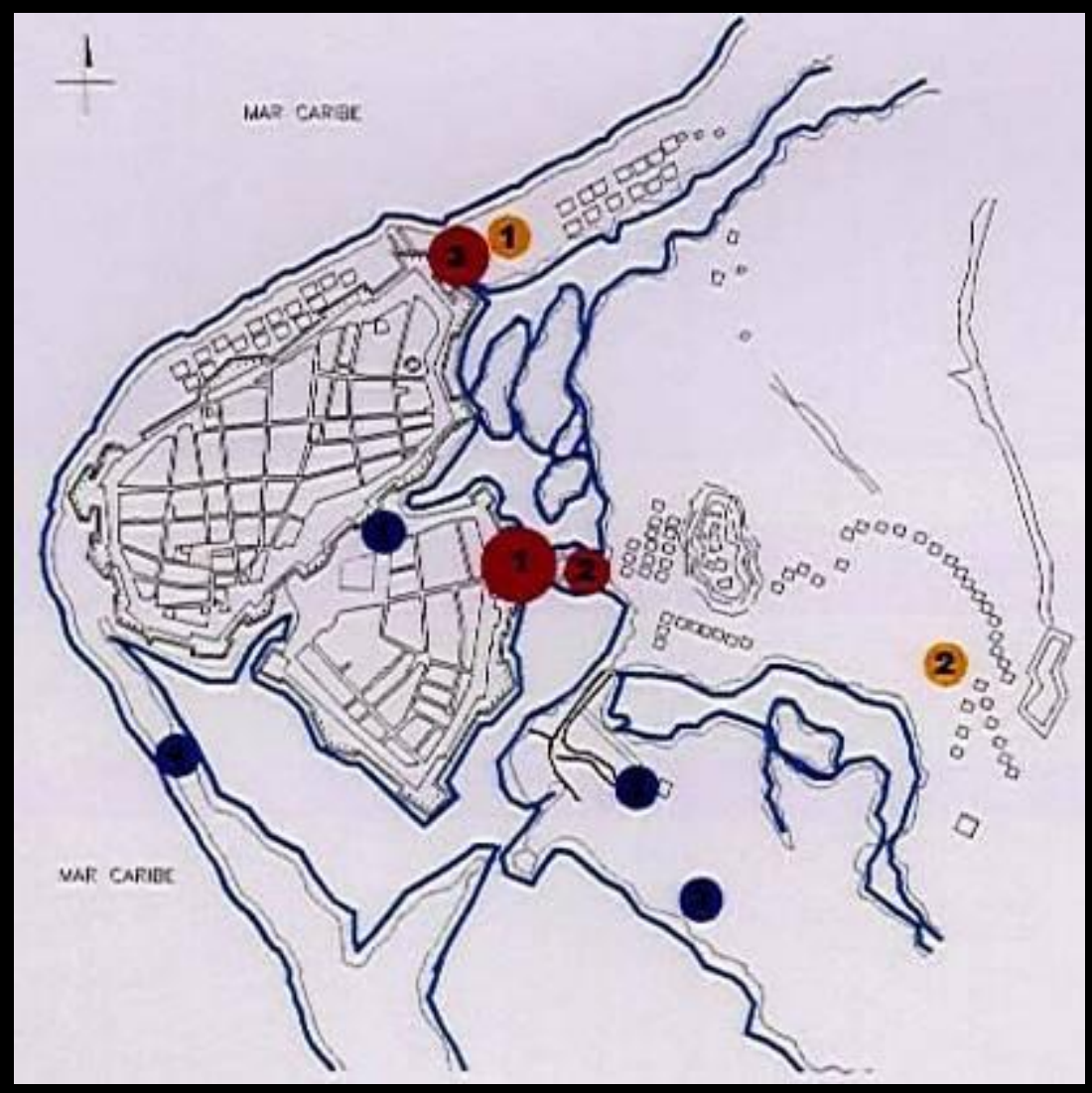

- Se reabre el Canal del Dique

- Se inaugura la Línea del ferrocarril Cartagena-Calamar

- Se rellena la calzada de la Media Luna

- Se inaugura la primera Planta Eléctrica.

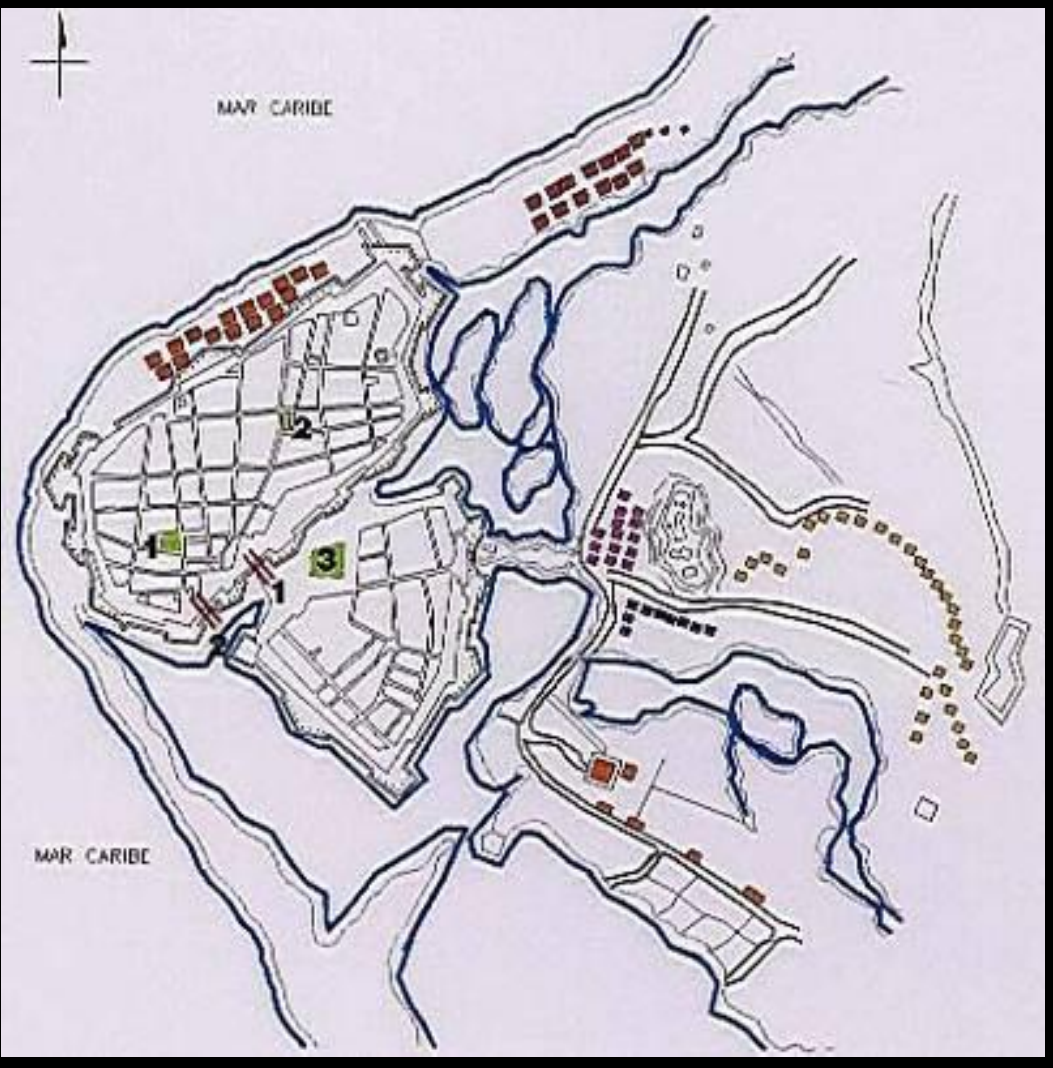

Conservaba el carácter colonial en su traza, tejido y paisaje; Aún después las modificaciones del tejido no fueron significativas para la estructura. Al final del siglo, inician las demoliciones en la muralla para dar paso al desarrollo; comienza la recuperación económica

\section{ESTRUCTURA URBANA}



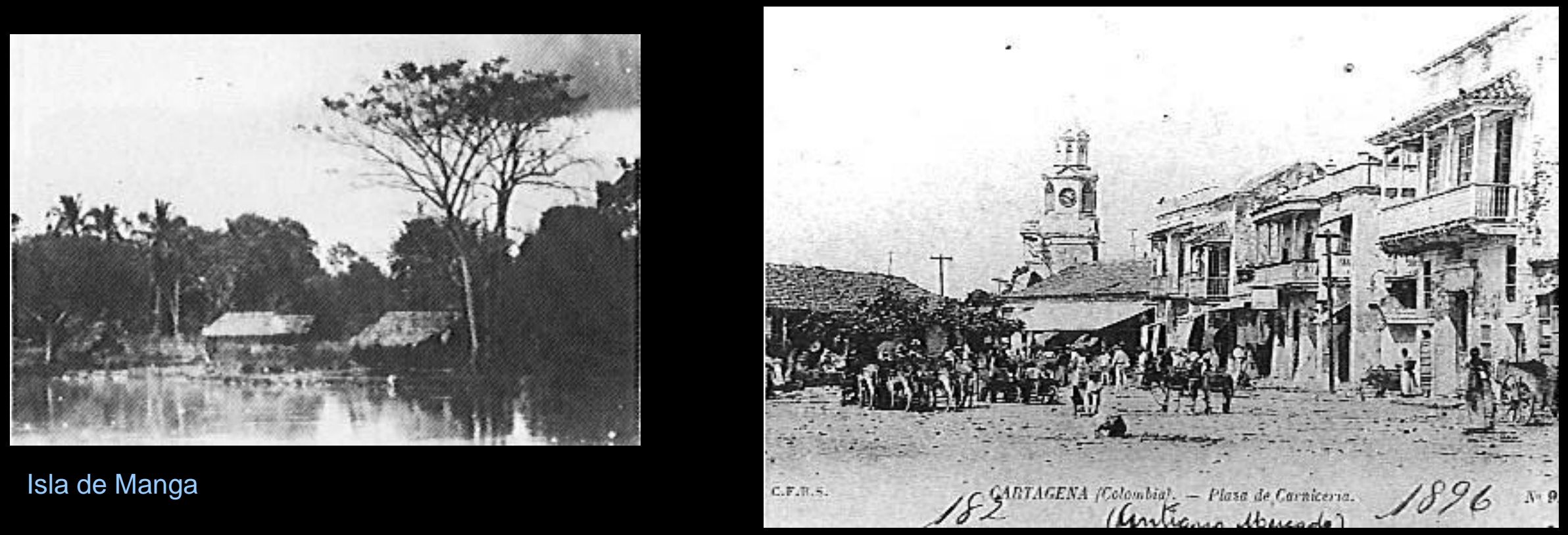

Isla de Manga

Plaza de la Carnicería

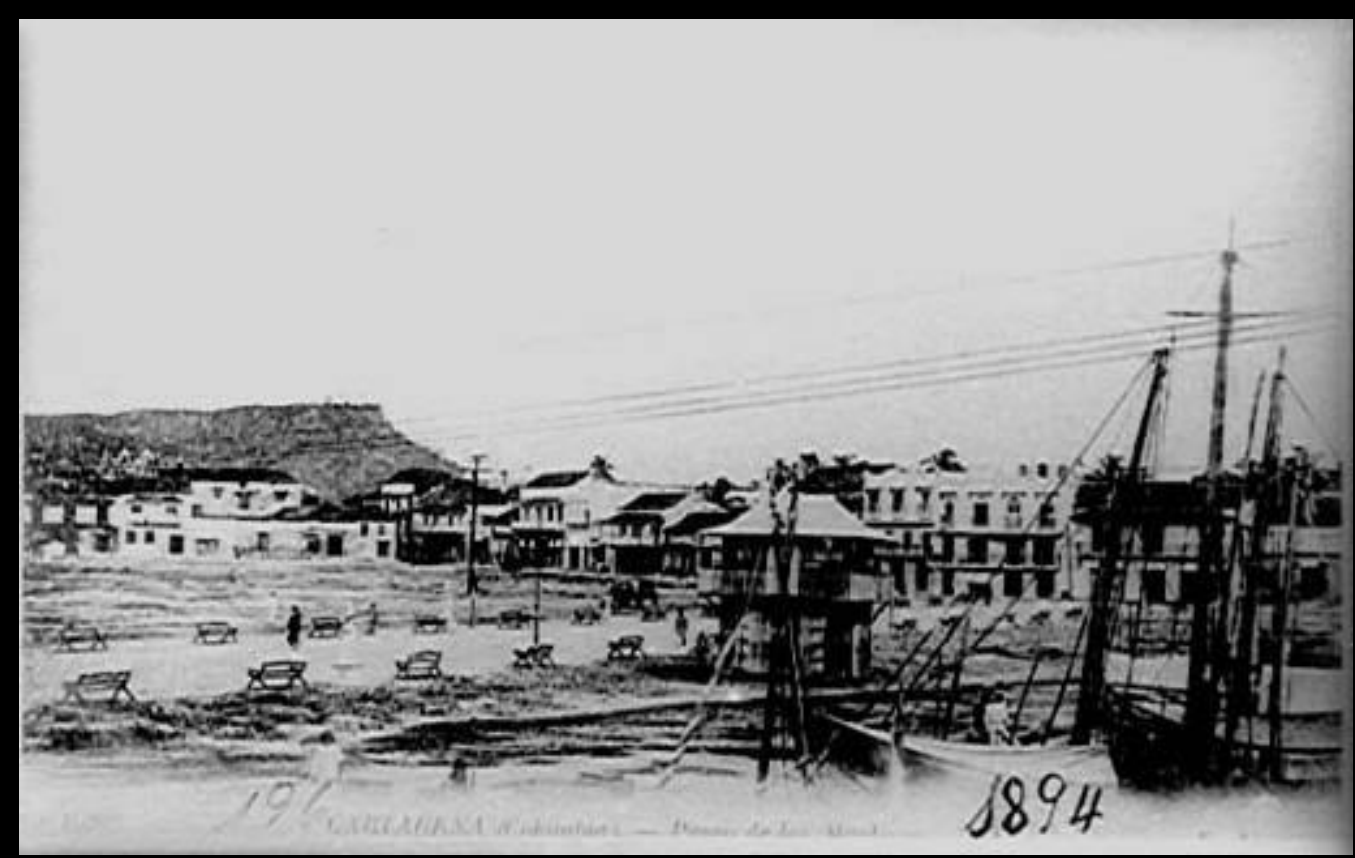

Plaza de la Independencia 


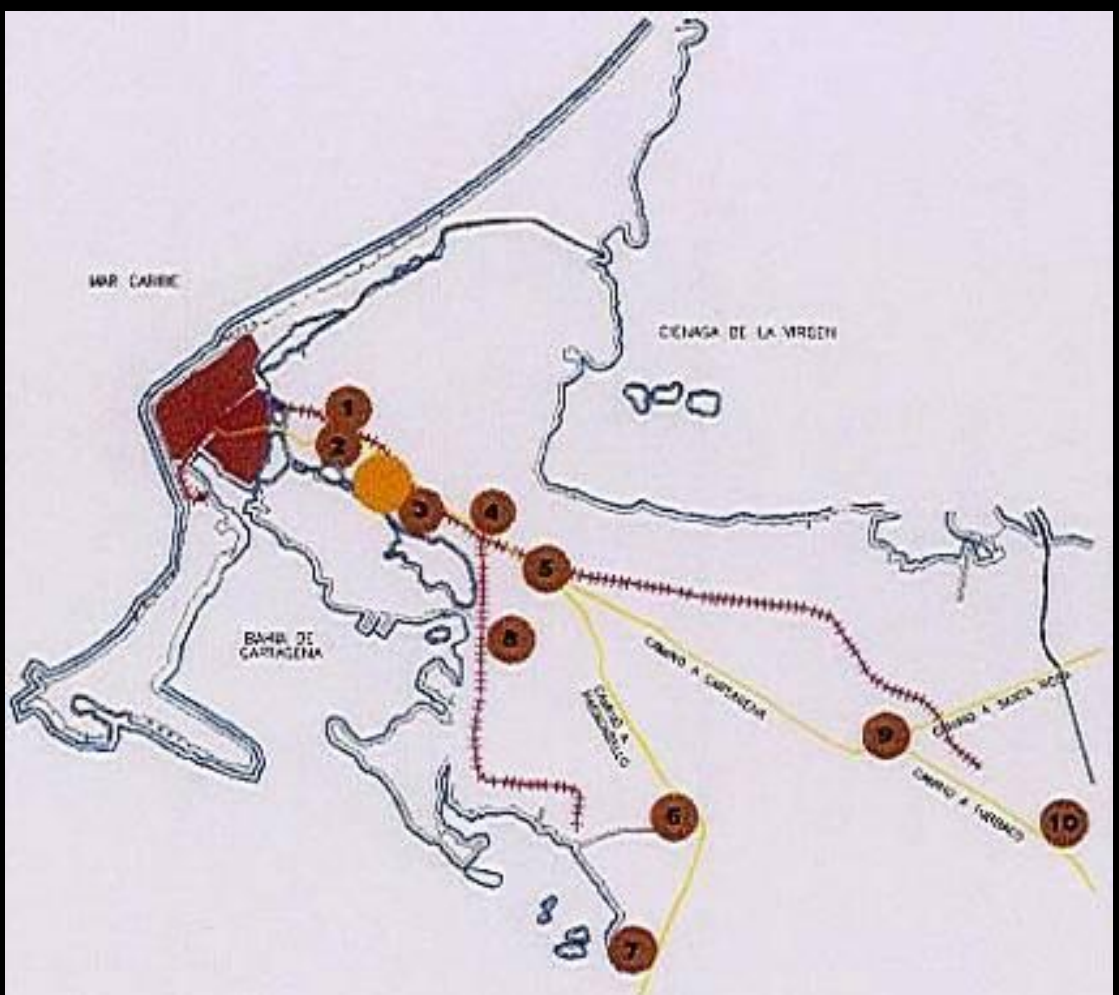

MODELO DE ESTRUCTURA GENERADO POR LA MURALLA

La ciudad hacia los extramuros generó un fenómeno de convergencia hacia el primer punto fijo de desahogo del núcleo y de divergencia en el segundo punto hacia el exterior repitiéndose una estructura de funciones y espacios.

\section{SISTEMA DE ORGANIZACIÓN EXTRAMUROS}

Los caseríos fungían como una unidad territorial y administrativa bajo una cabeza de distrito dividida en cinco veredas o partidas y en barrios y agregaciones; generando un complejo sistema de núcleos unidos por redes de caminos.

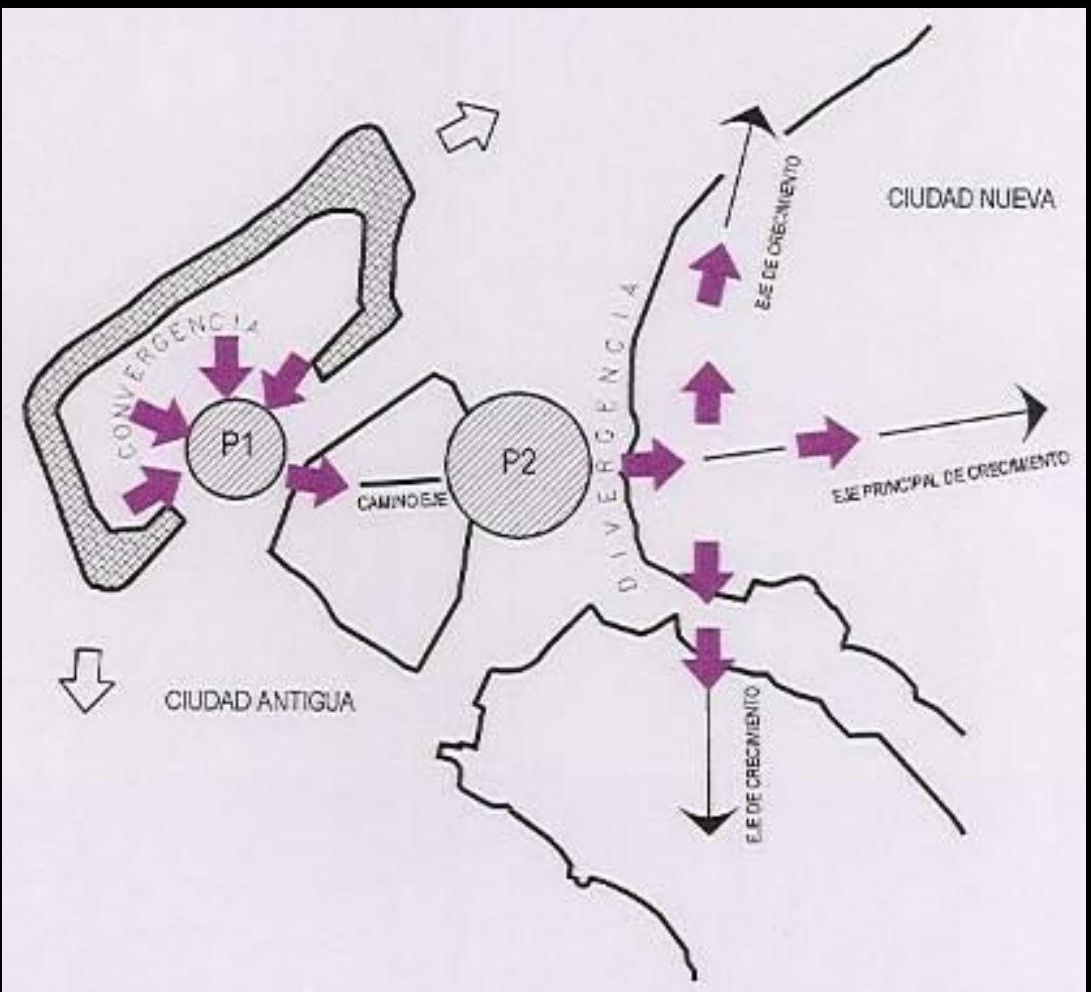




\section{CIUDAD ANTIGUA}

\section{ESTRUCTURA}

$\mathbf{S}$ ACTUAL

- Permanece aún el trazado colonial y edificios singulares con otras funciones.
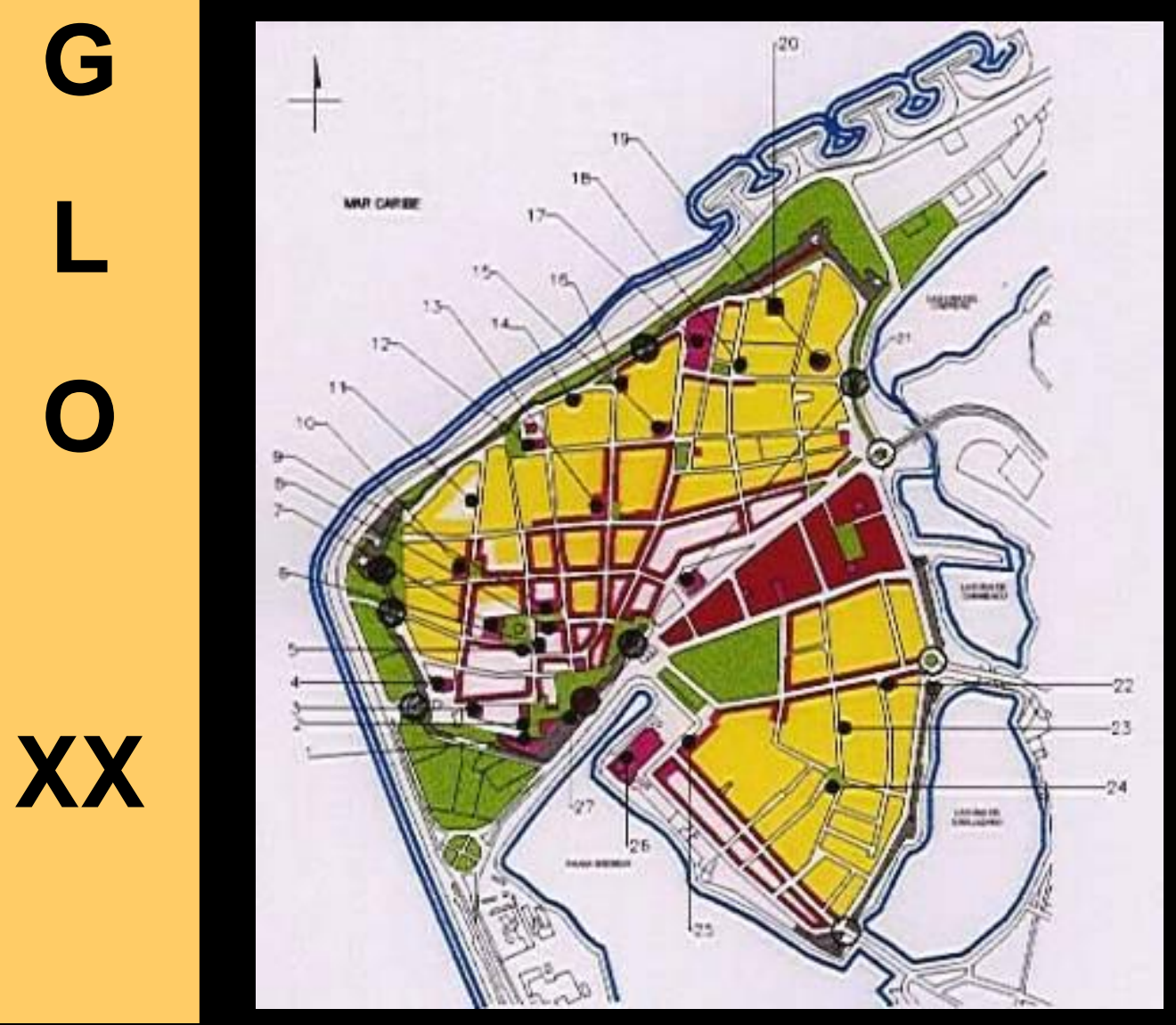

Surgen innovaciones en la arquitectura y procesos de rehabilitación urbana.

- Predomina el uso habitacional con uso comercial en las plantas altas.

- La estructura de barrios se simplificó.

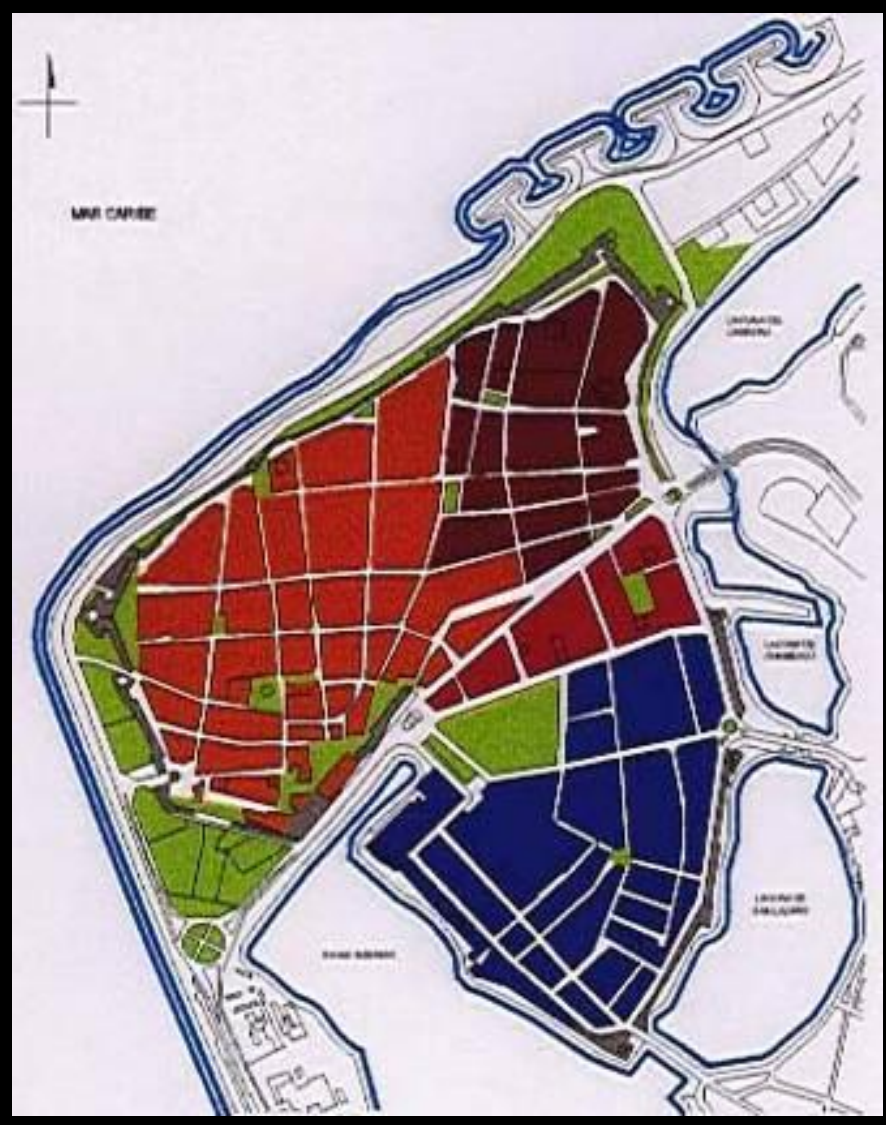



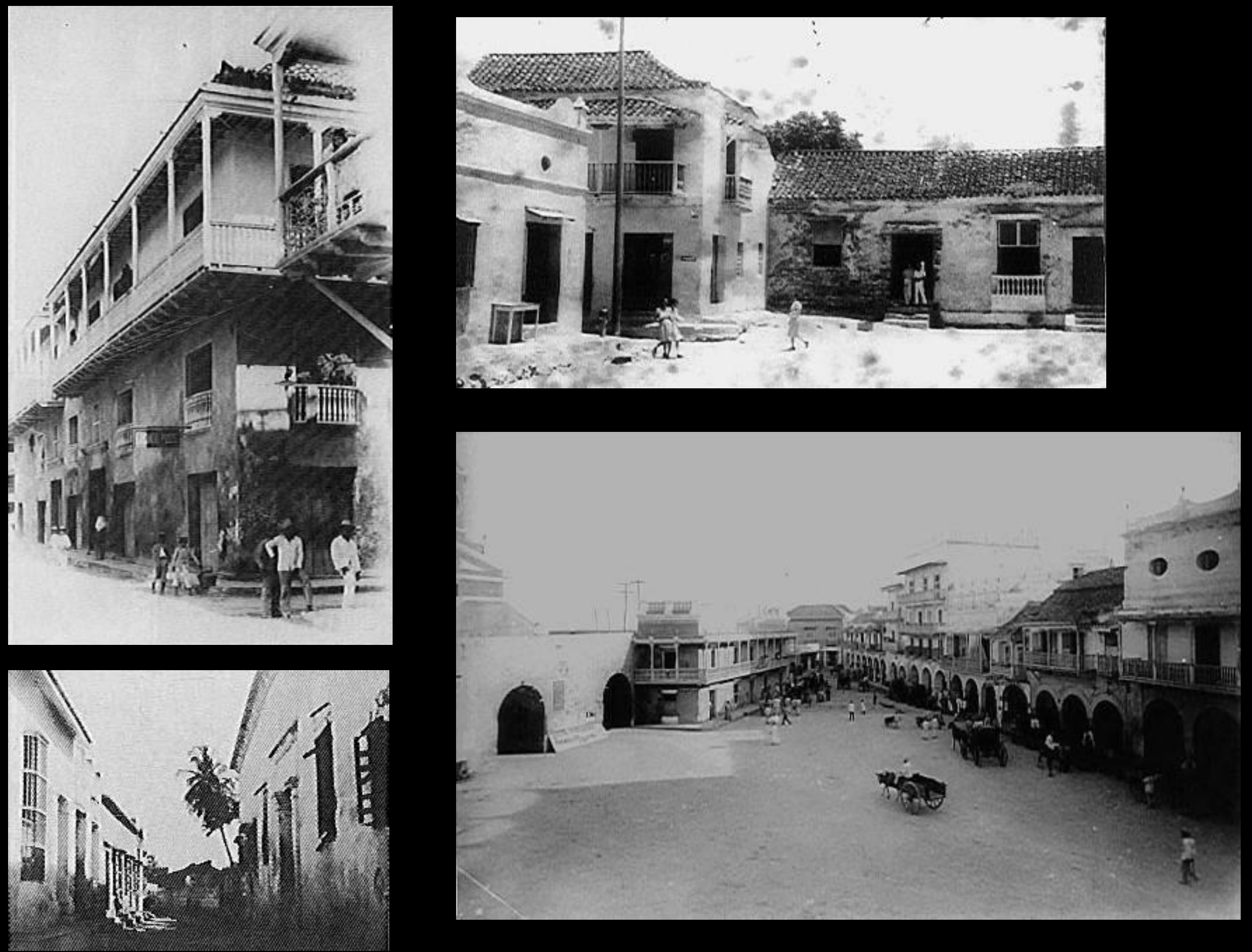

Calles y plazas en el sector amurallado a principios del siglo 

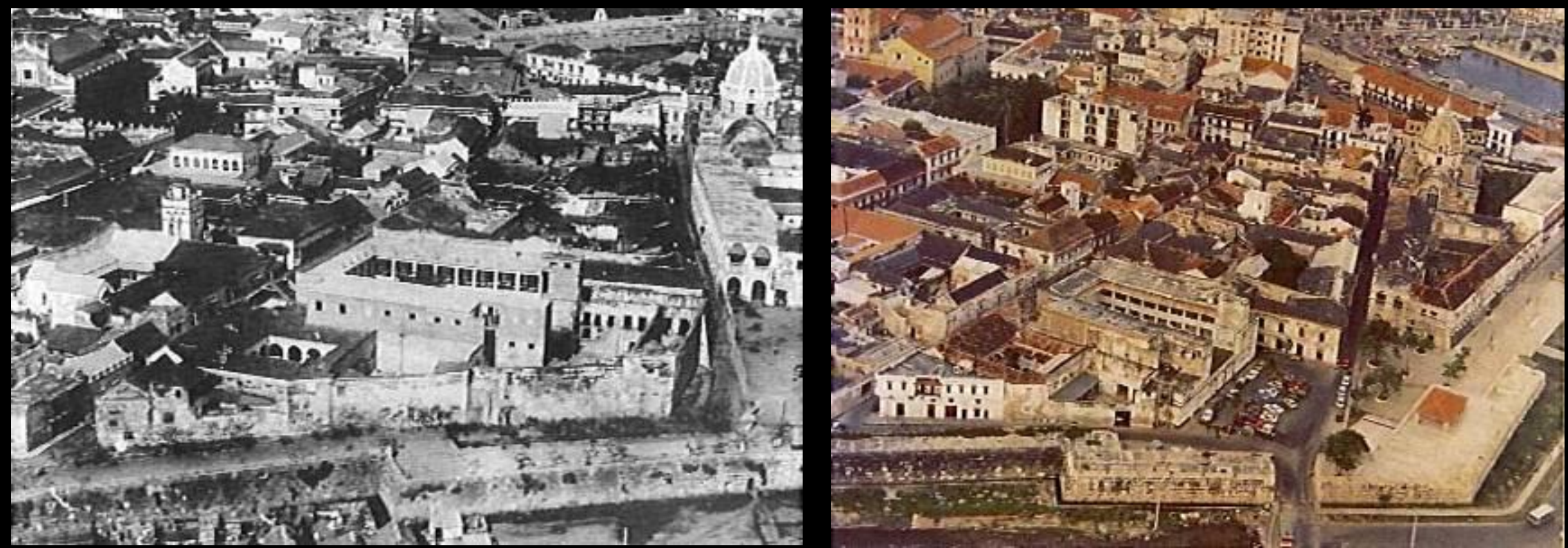

Plaza de Santa Teresa y San Pedro 1928
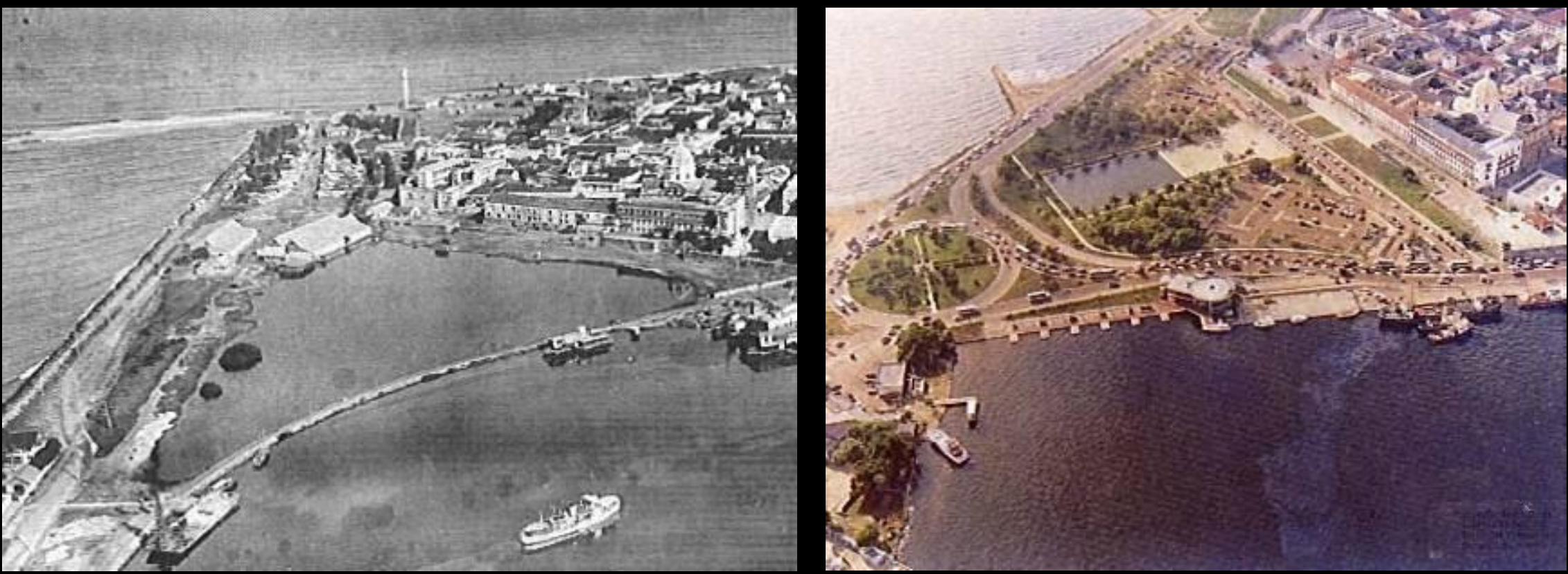

Carrilera del tren 1928

Parque de la mMarina 1994 

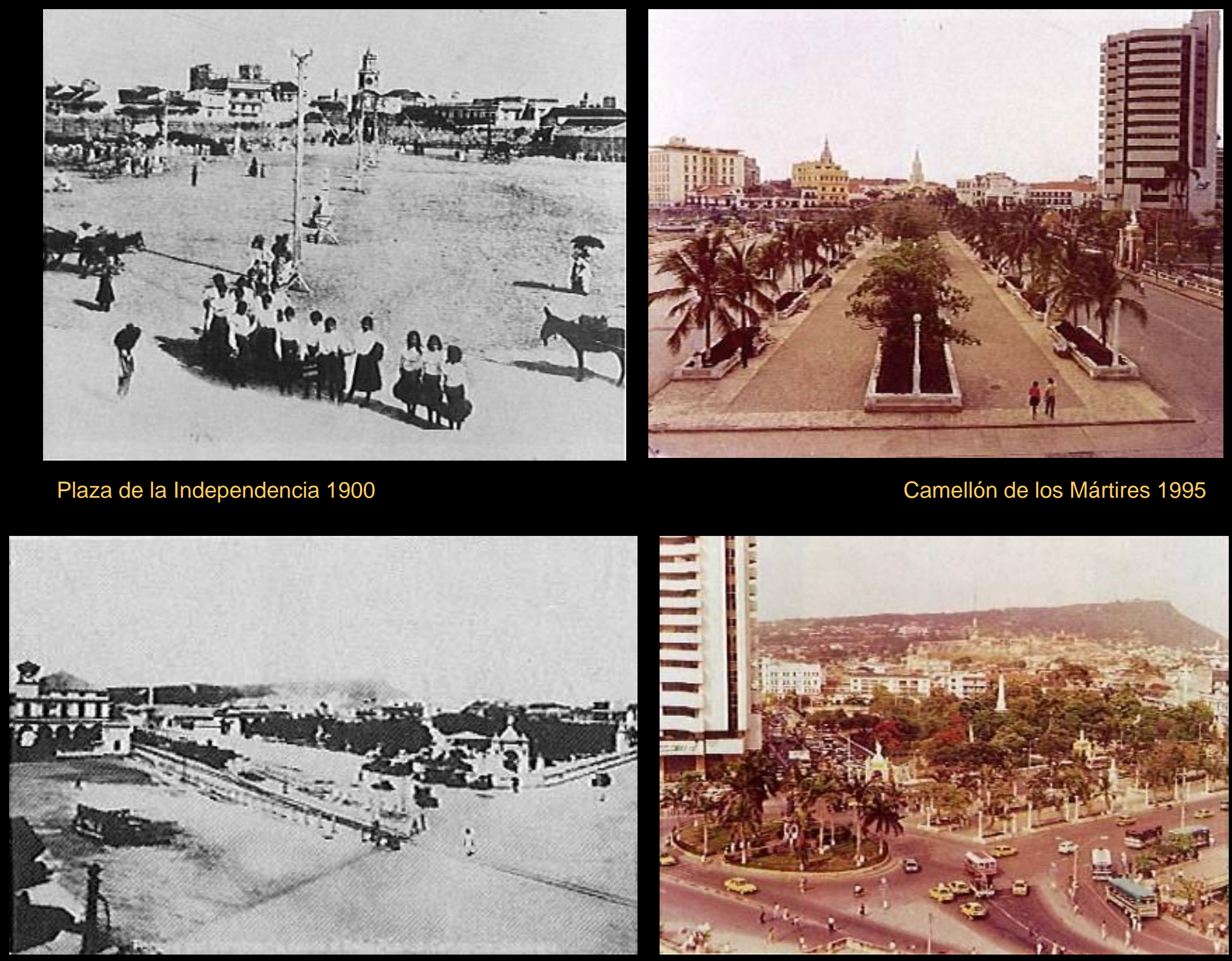

Estación del tren 1910

Parque del Centenario 1995 


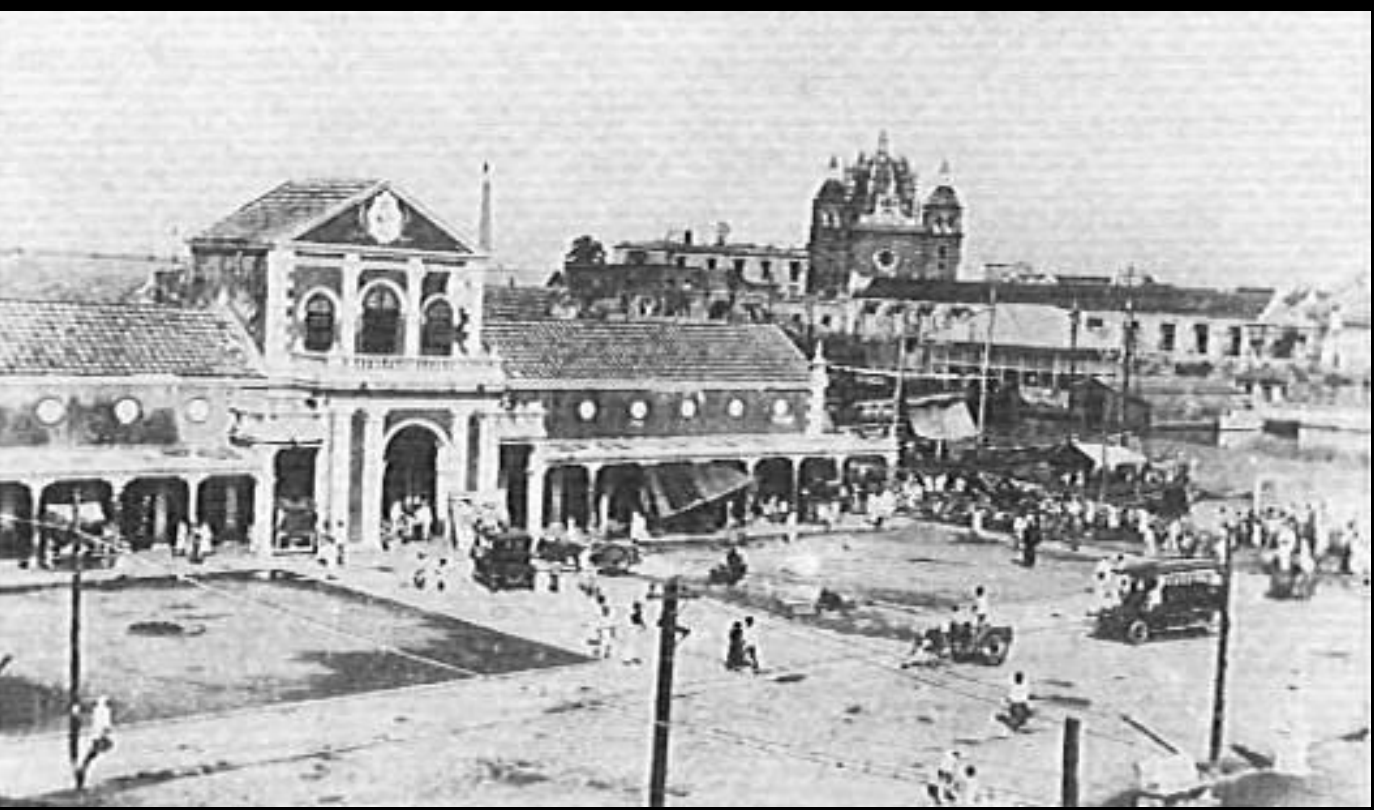

Mercado Público 1930

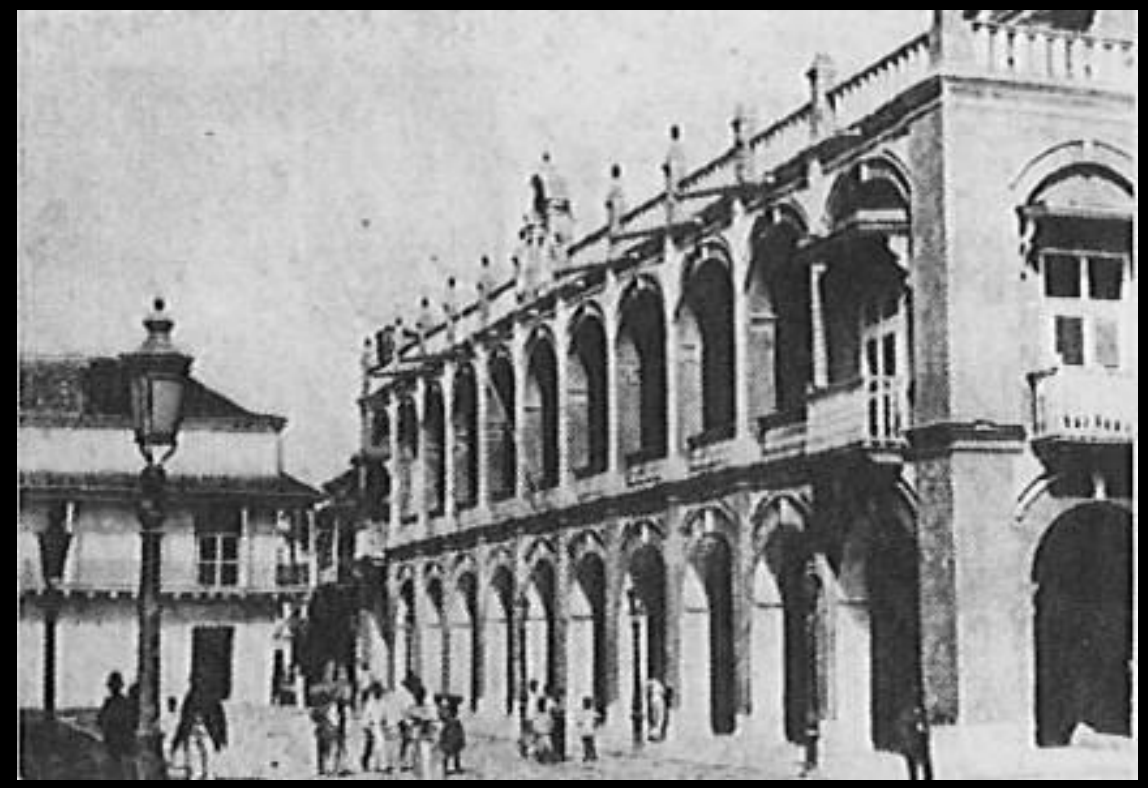

Palacio de Gobierno 1920

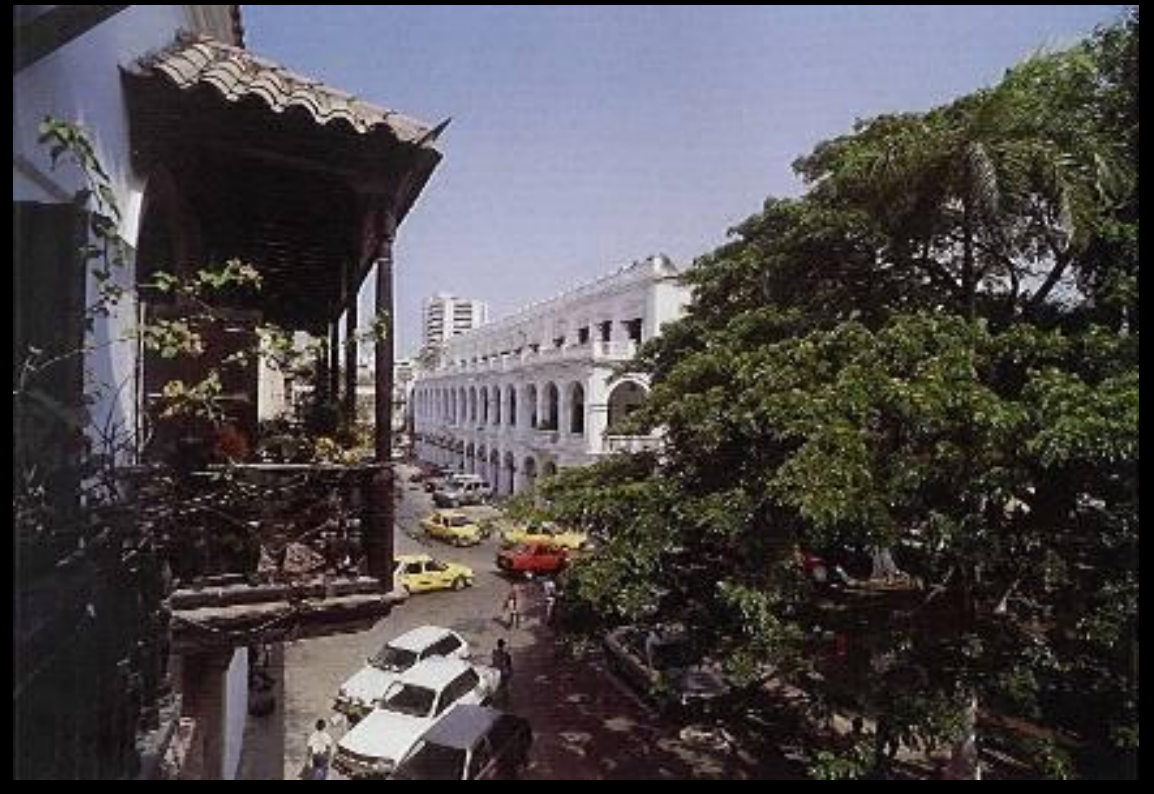

Parque de Bolivar y Palacio de Gobierno 1997 
El centro histórico es concentrador de actividades intensas y especializadas. Un nuevo proceso de expansión lineal se dio hacia zonas aledañas y la isla vecina.

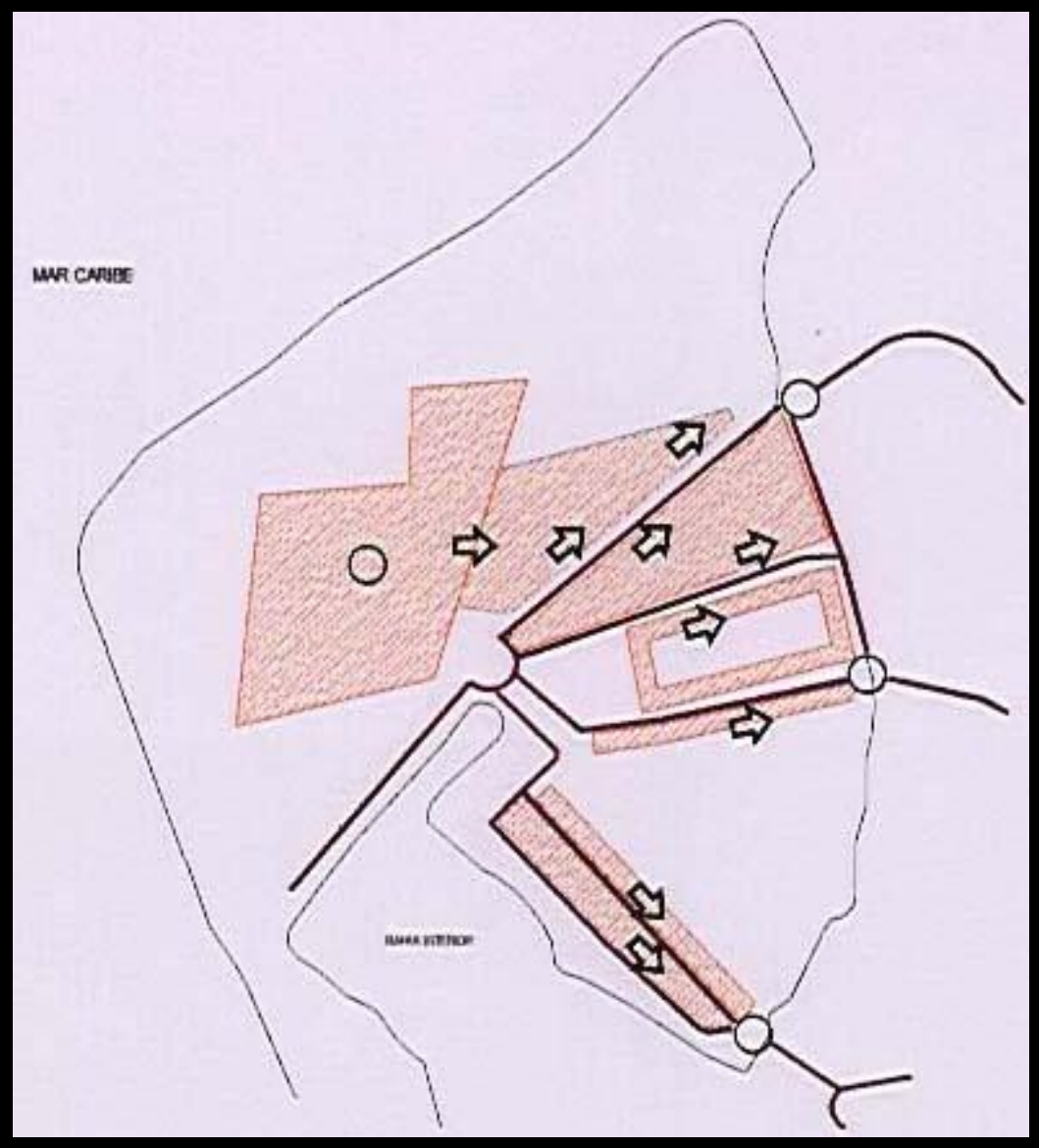

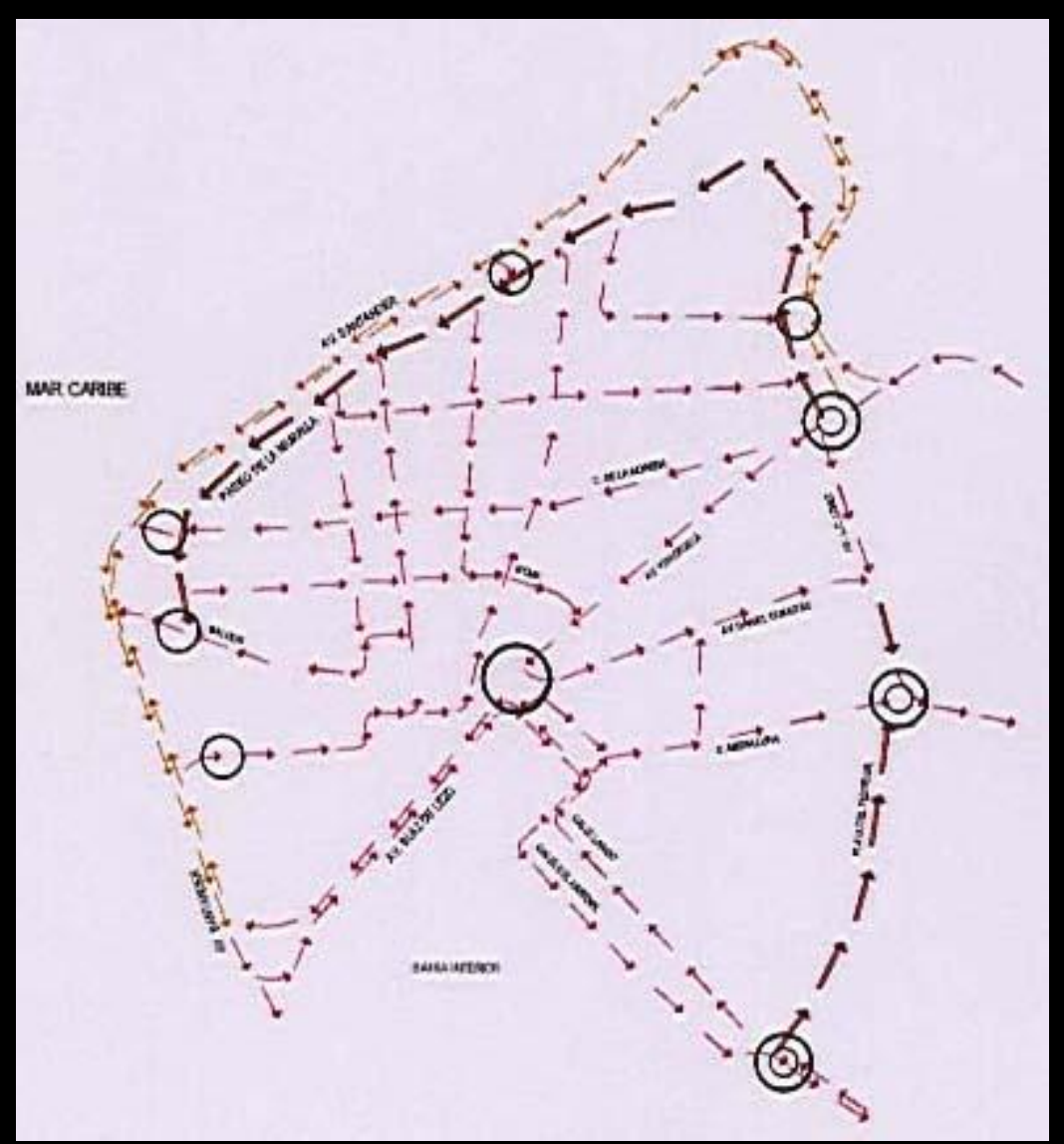

\section{MODELO DEL VEHICULAR \\ FLUJO}

Compuesto por un sistema de ejes que conducen a la puerta principal y hacia los extramuros a través de puertas o boquetes que conectados entre sí forman un circuito por el borde amurallado. 

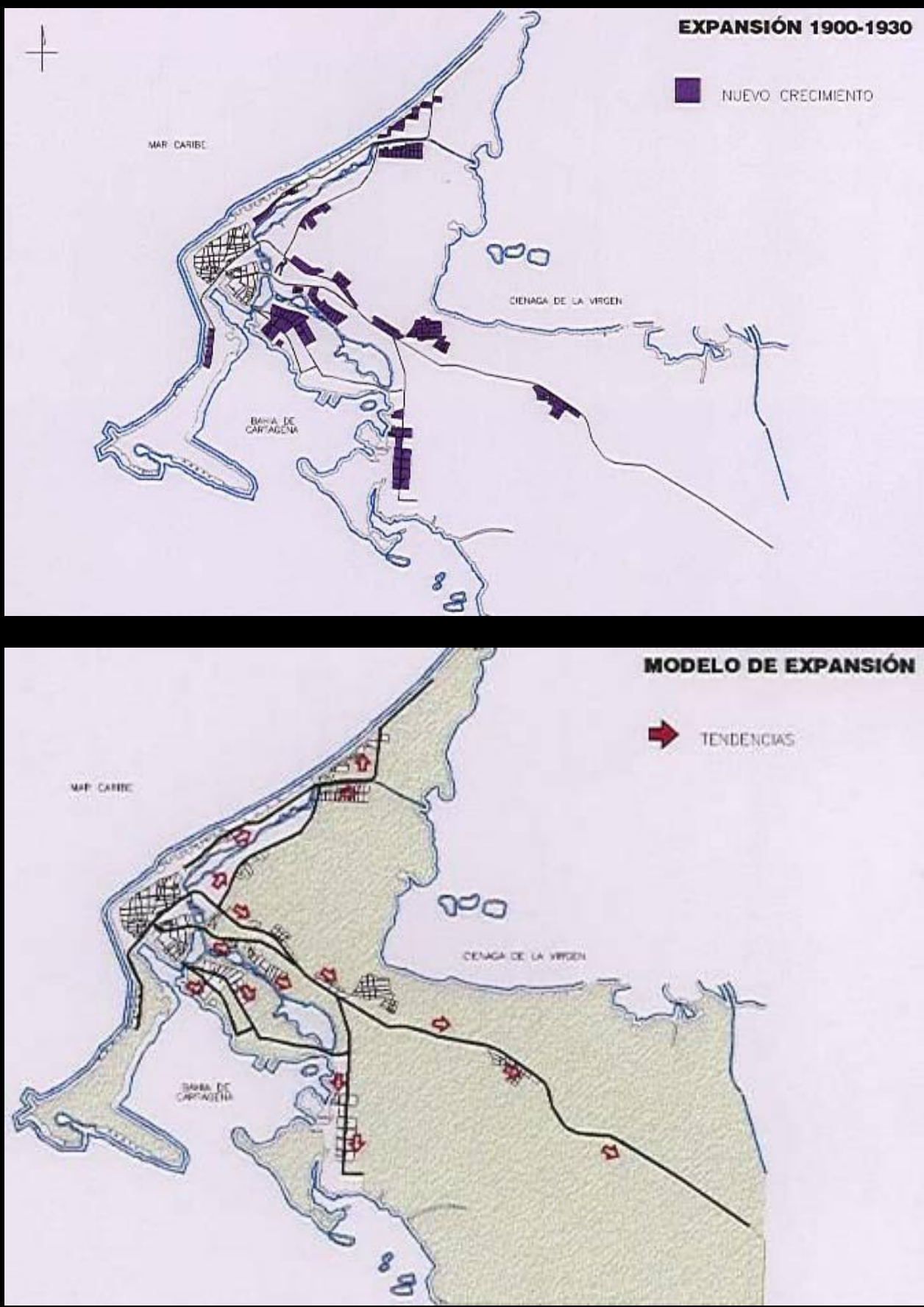

\section{CIUDAD MODERNA}

EXPANSIÓN URBANA 1900- 1930

Rápido crecimiento demográfico:

-Fines del siglo XIX 17,600 hab.

$-1912$

-Final del período 36,632 hab. 84,937 hab.

- Transformación y consolidación de los caseríos y nuevos núcleos a lo largo de la vía del tren y caminos al norte y sur.

\section{MODELO DE EXPANSIÓN}

- Se adopta nueva trama asegurando racionalidad en su organización básica.

- Definición de un modelo lineal que se ligaba con los ejes del núcleo antiguo. 

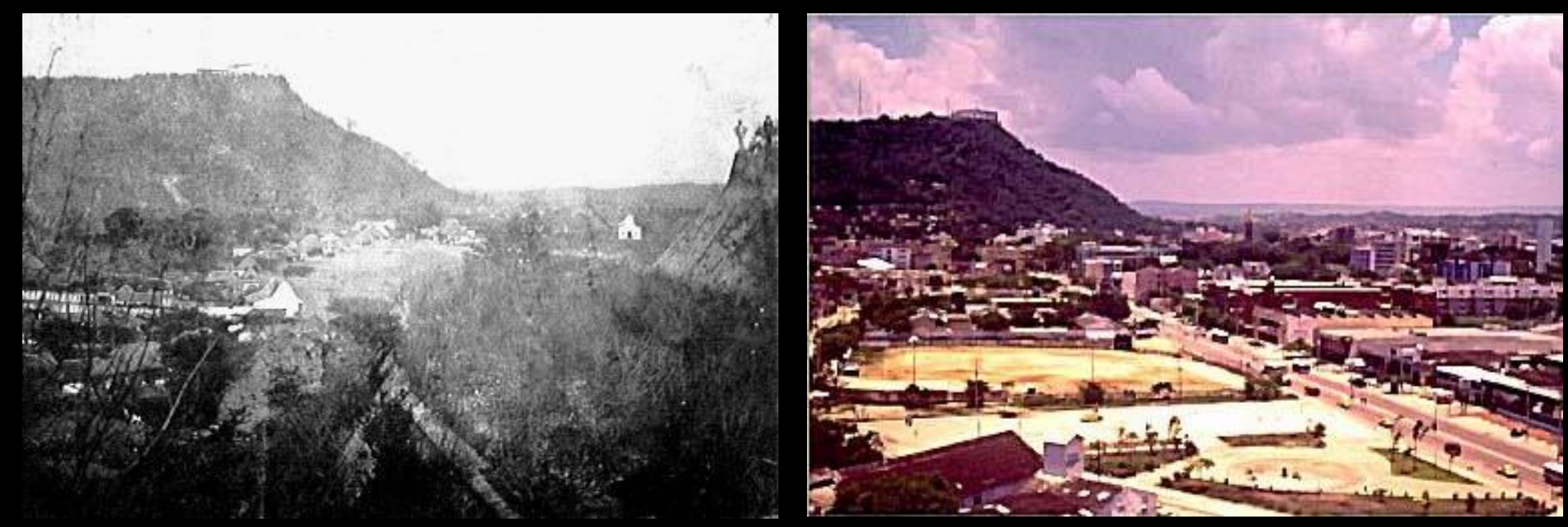

Pie de la Popa 1900
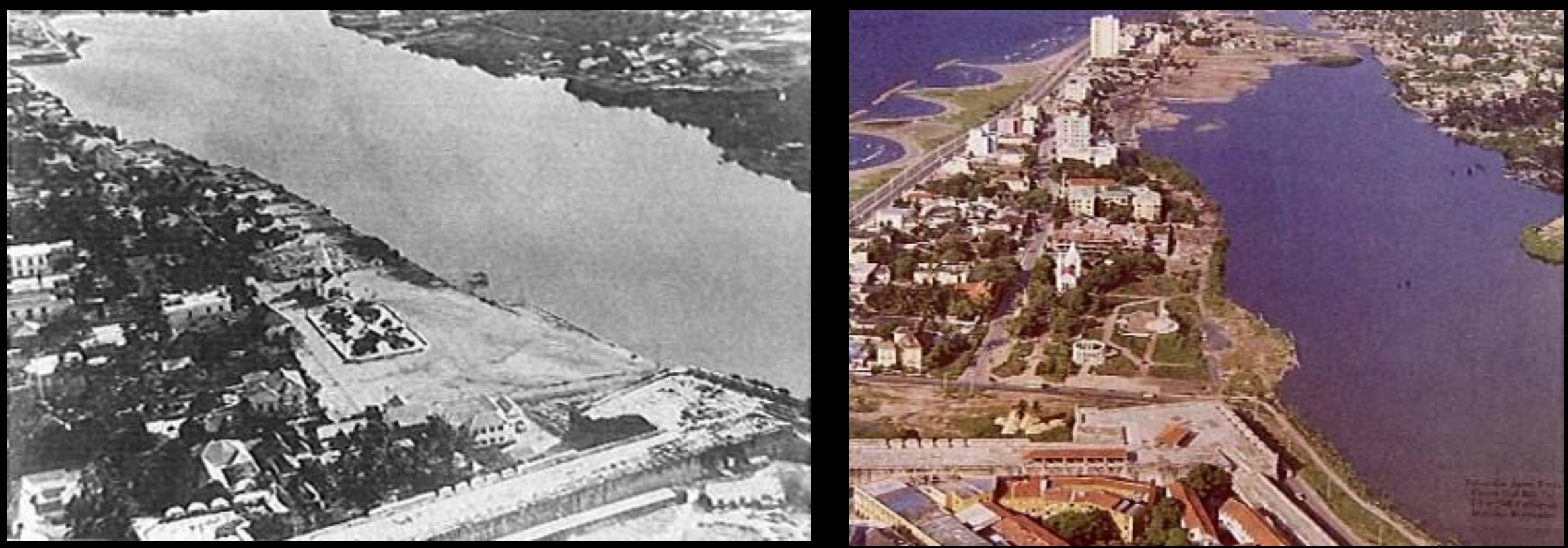

El Cabrero 1928 


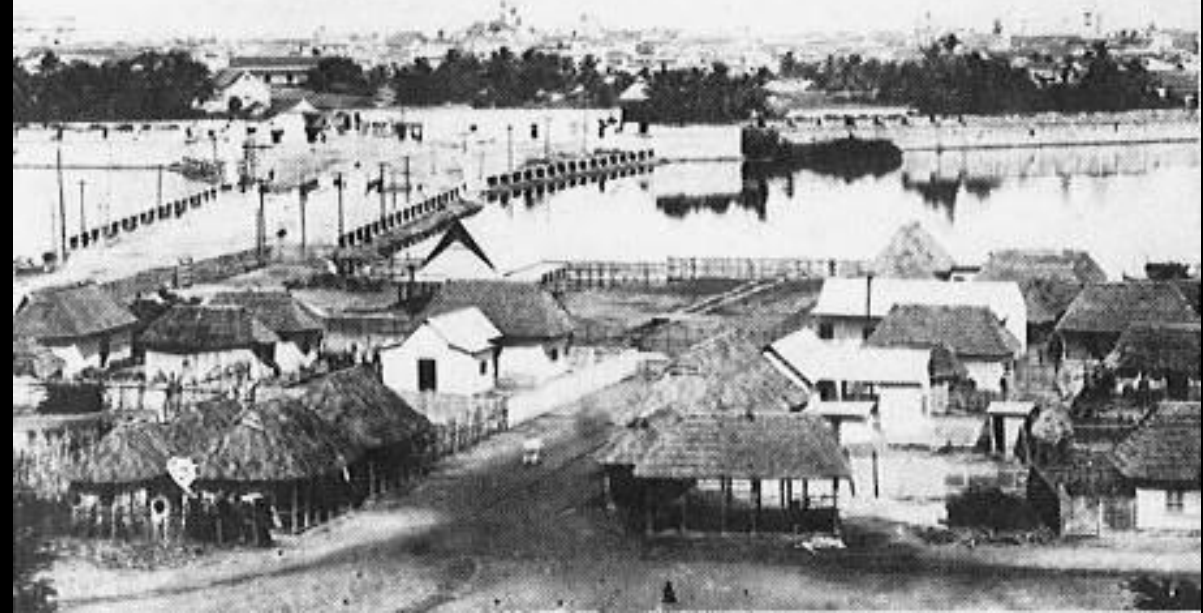

El Espinal 1910

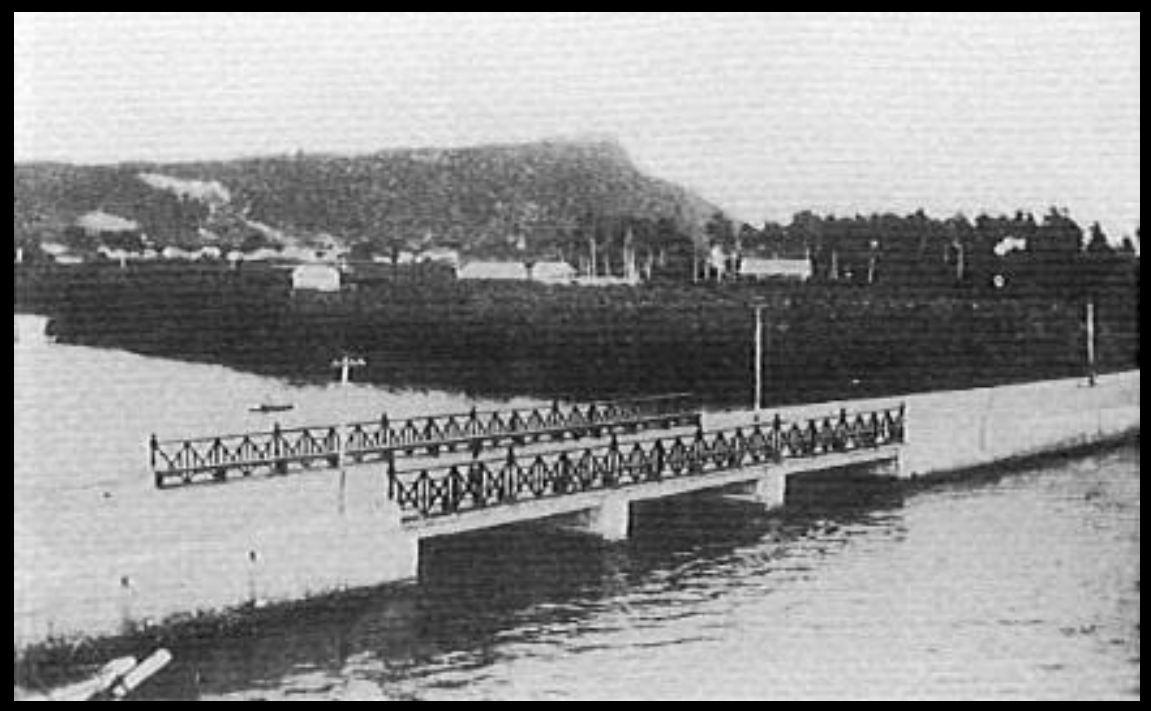

Puente Román 1906

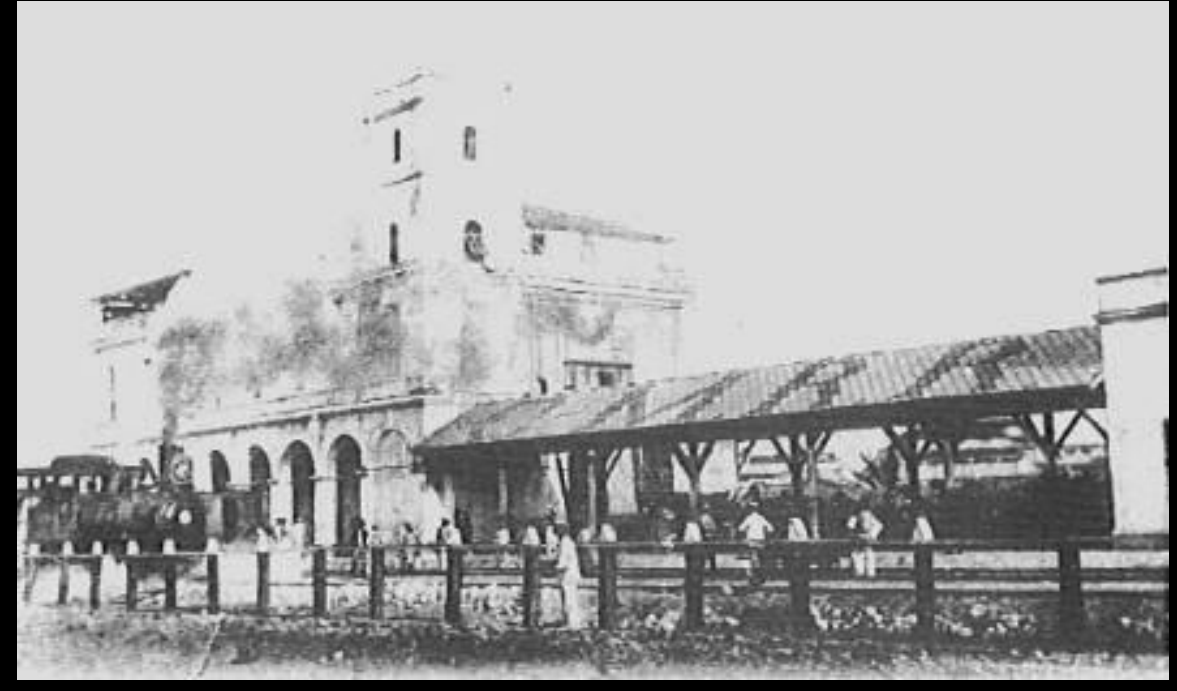

Estación del tren de Cartagena

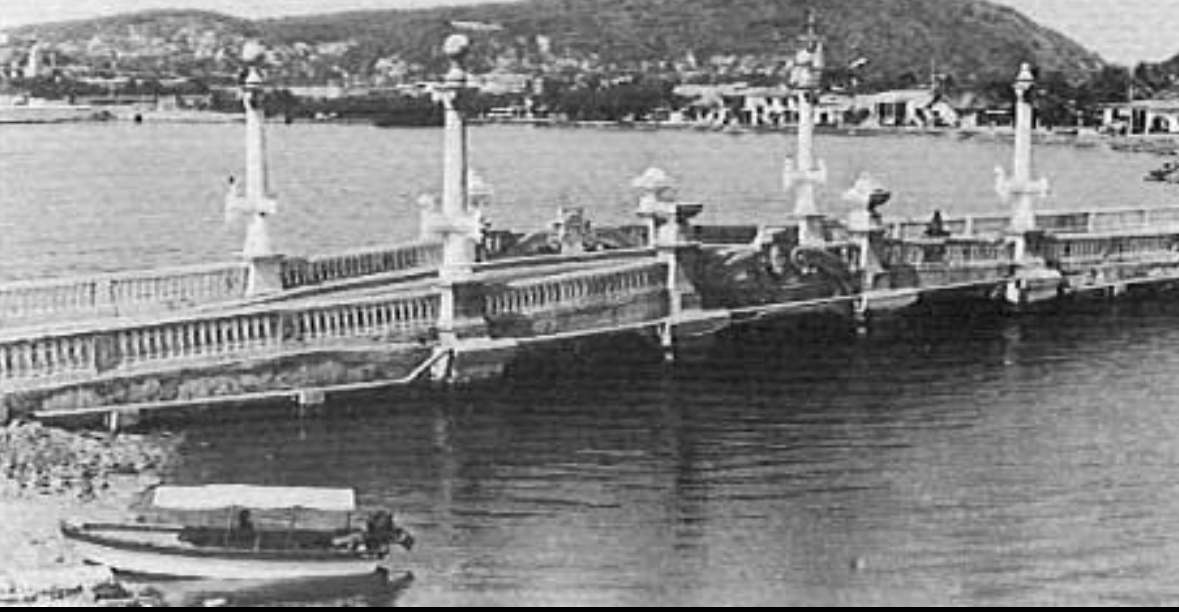

Segundo Puente Román 


\section{EXPANSIÓN URBANA 1930- 1940}

- Consolidación de los barrios del período anterior.

- Compactación de la mancha urbana a lo largo de la vía principal y surgimiento de nuevos barrios en la intersección con la nueva vía del bosque.

\section{MODELO DE EXPANSIÓN}

- Continuación del modelo lineal en una expansión menos dispersa.

- Adopción de una nueva estrategia para la consolidación de las diferentes zonas.
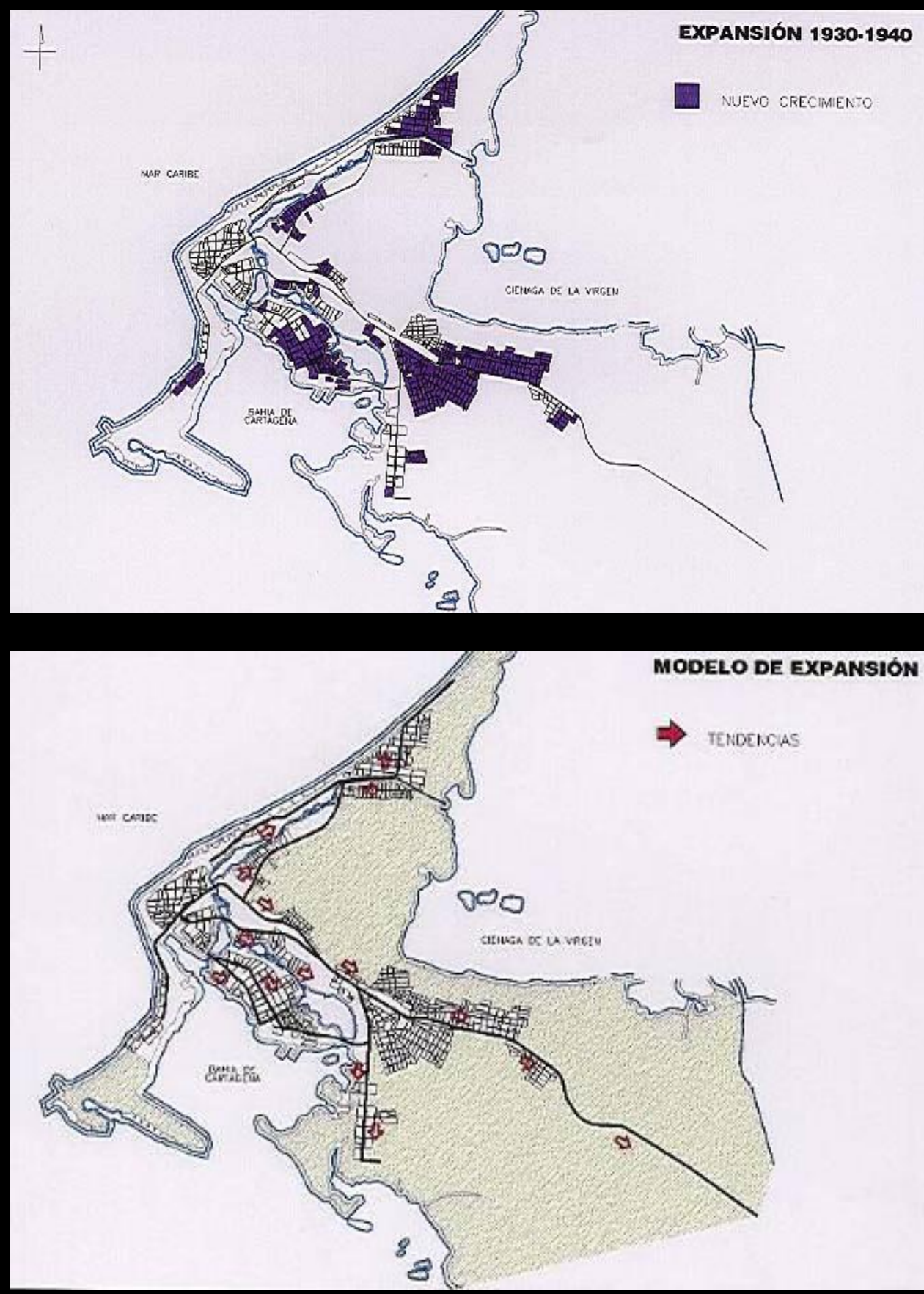

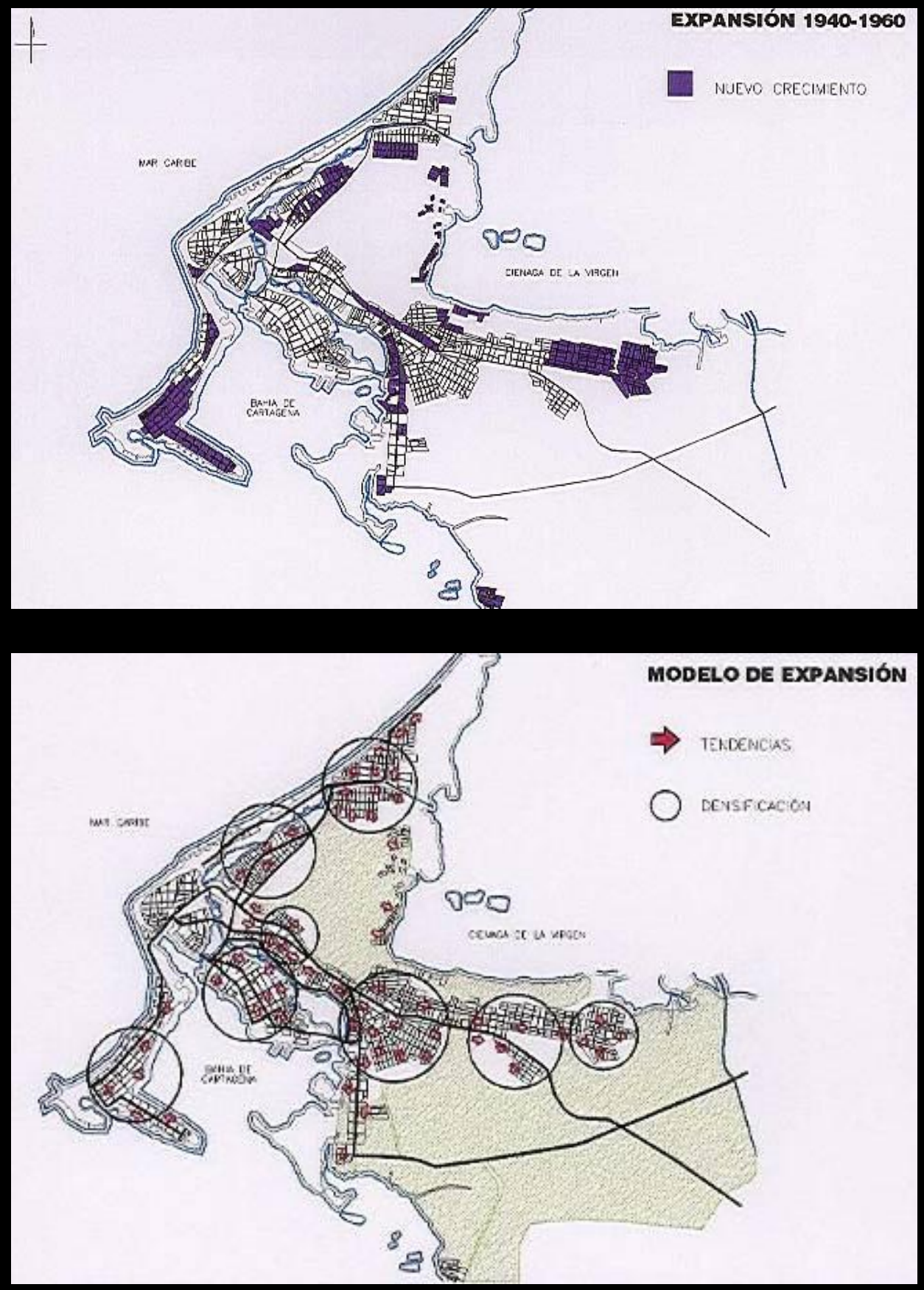

EXPANSIÓN URBANA 1940- 1960

- Crecimiento poblacional entre 1951 y 1964. La ciudad llega a los 200.000 hab.

- Densificación de la vía principal hasta el barrio 13 de junio.

- Surge el Instituto de Crédito Territorial (ICT) para incidir en el desarrollo urbano.

- Innovación de asentamientos irregulares y nueva zona de Chambacú.

\section{MODELO DE EXPANSIÓN}

- Período que se caracteriza por un proceso de alternancia entre el modelo lineal $y$ un modelo de compactación. 

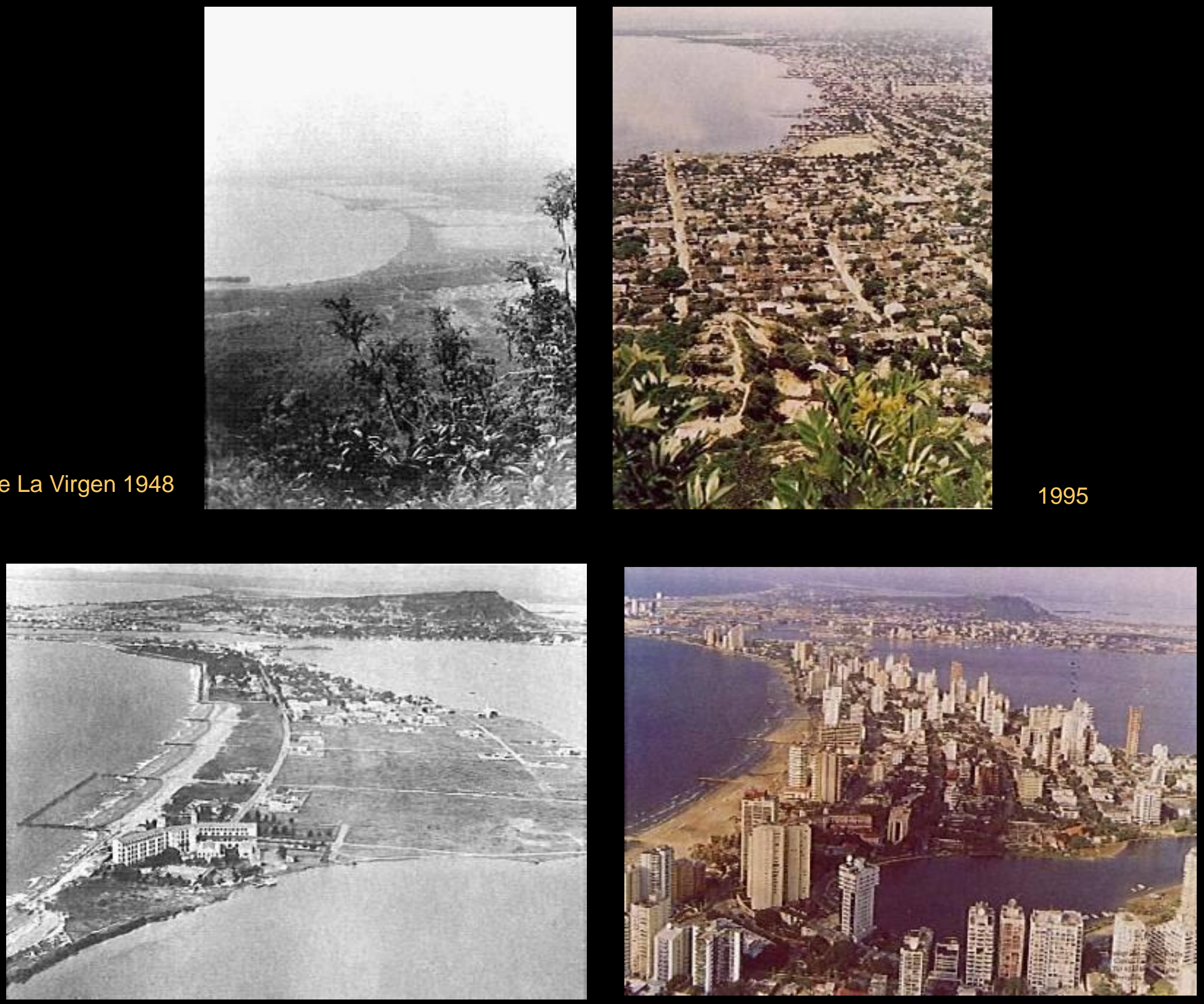


\section{EXPANSIÓN URBANA 1960- 1980}

- Continúa el aumento de población. De 1967 a 1973 creció a 311,664 hab. hacia 1974 se duplicó la población y generaron nuevas áreas de expansión.

- Se incrementan las acciones del ICT hacia el suroriente, norte y sur - Surgen los multifamiliares.

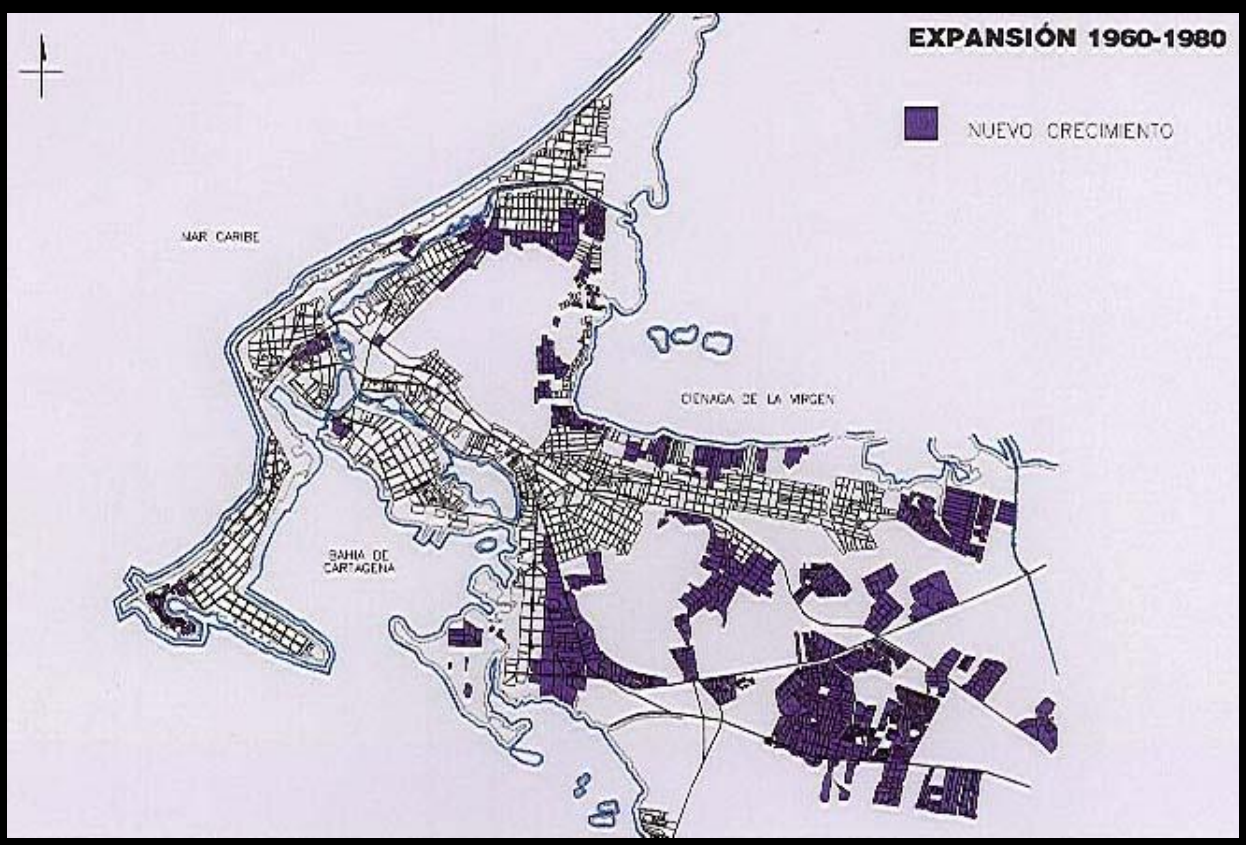

\section{MODELO DE EXPANSIÓN}

- Expansión de forma dispersa al suroriente rodeando las zonas con pendientes.

- Desarticulación de la traza generando una trama urbana desordenada.

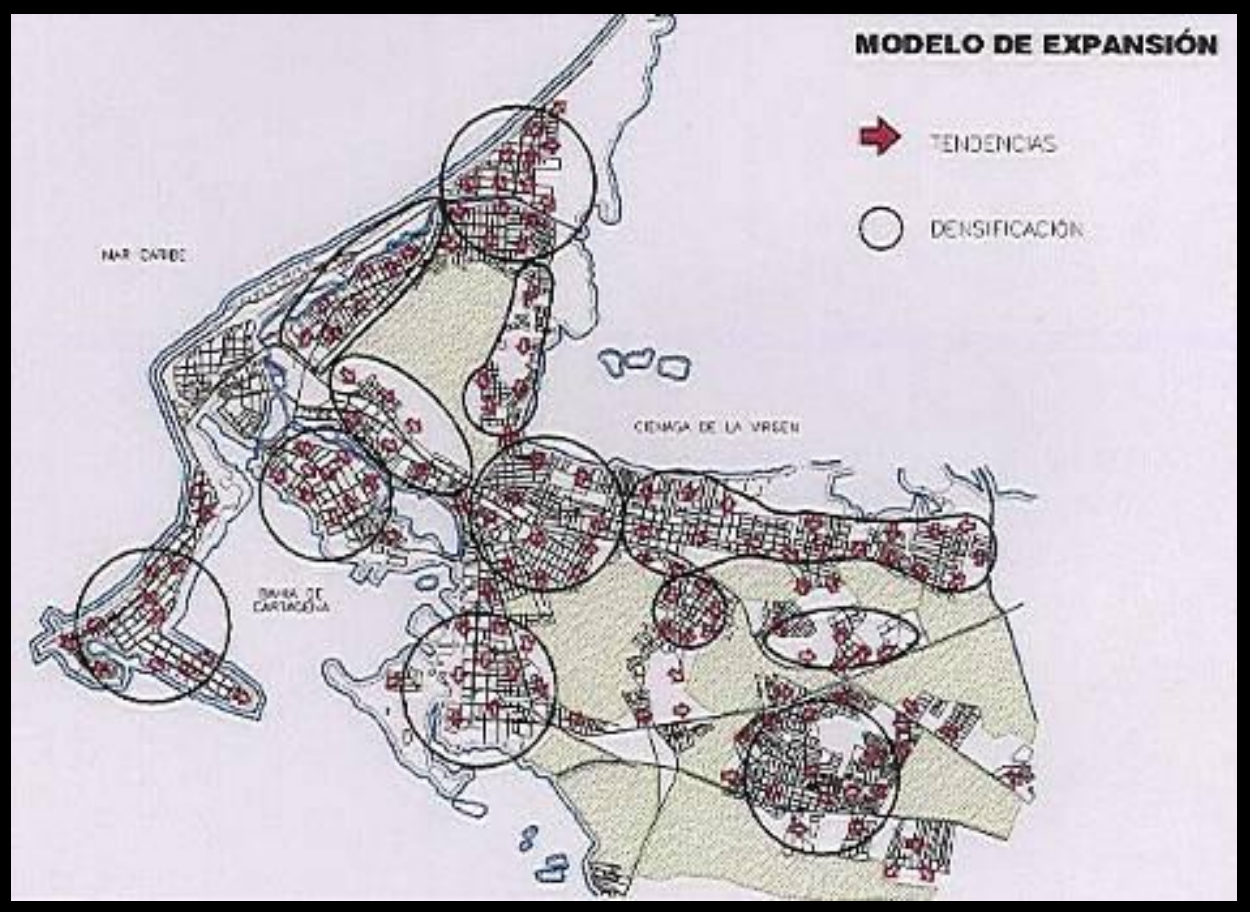



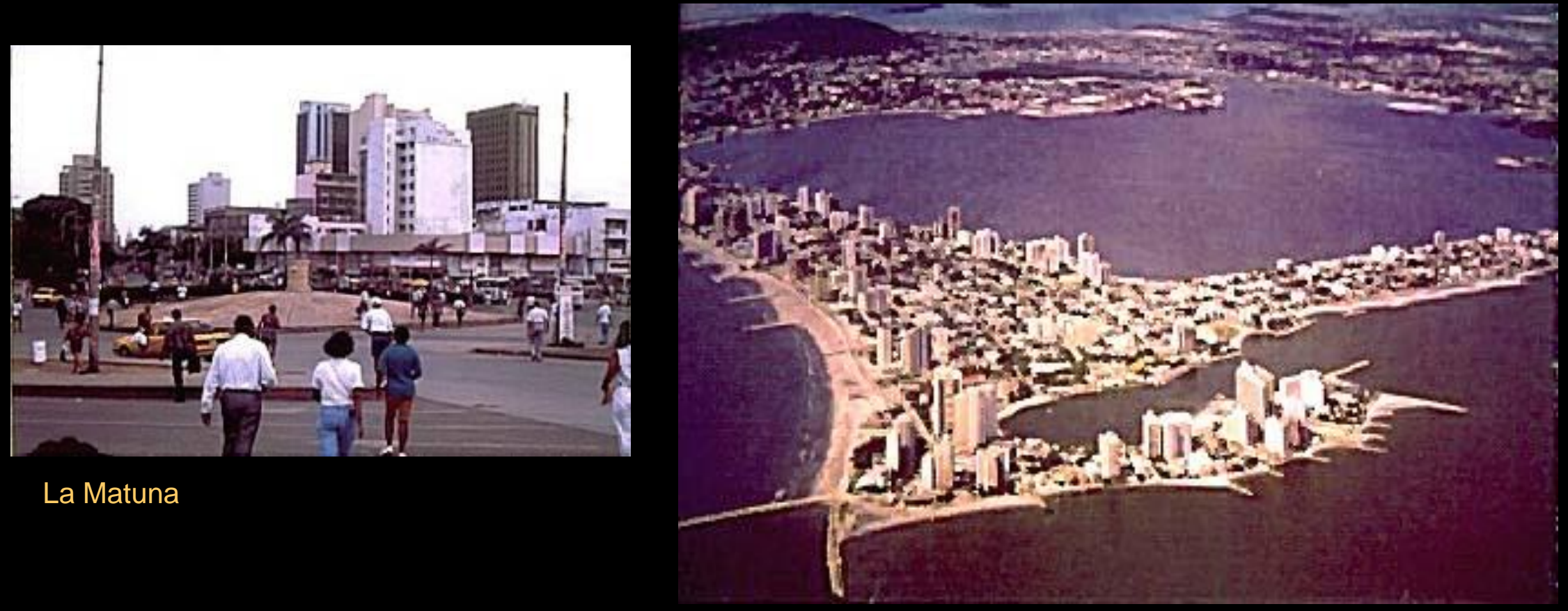

La Matuna

El Laguito
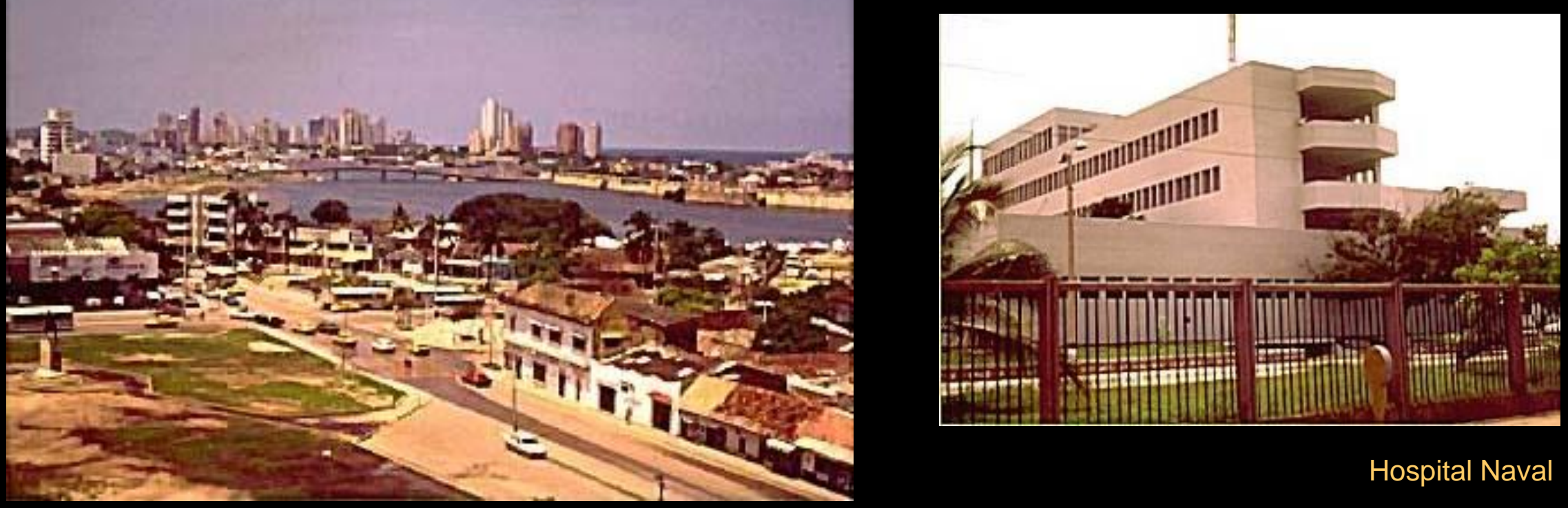

Barrio Pie del Cerro

Hospital Naval 


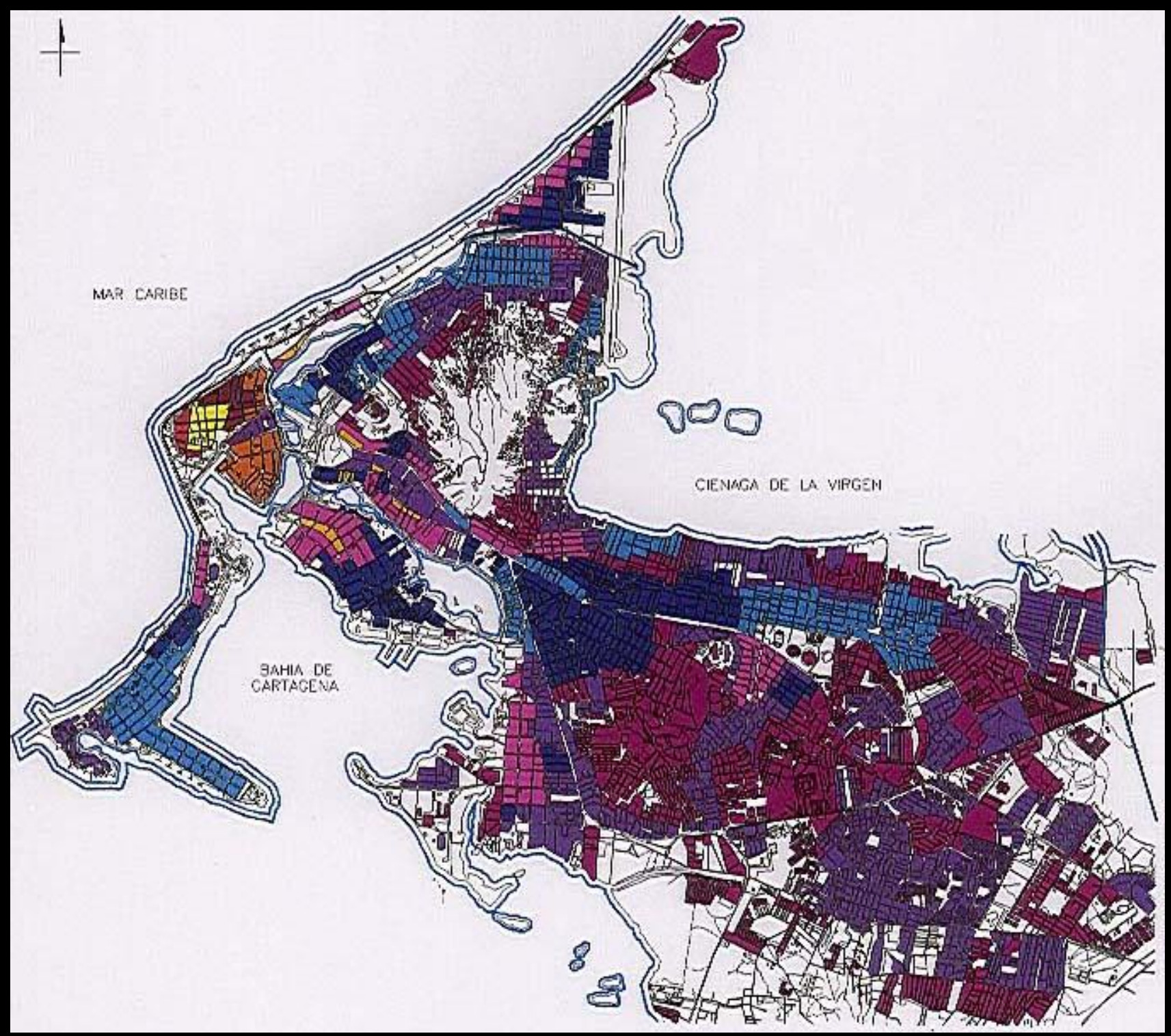

\section{EXPANSIÓN URBANA SIGLO XX}

El territorio continuó su proceso de densificación con grandes zonas de tugurios en áreas de gran potencial ambiental. 


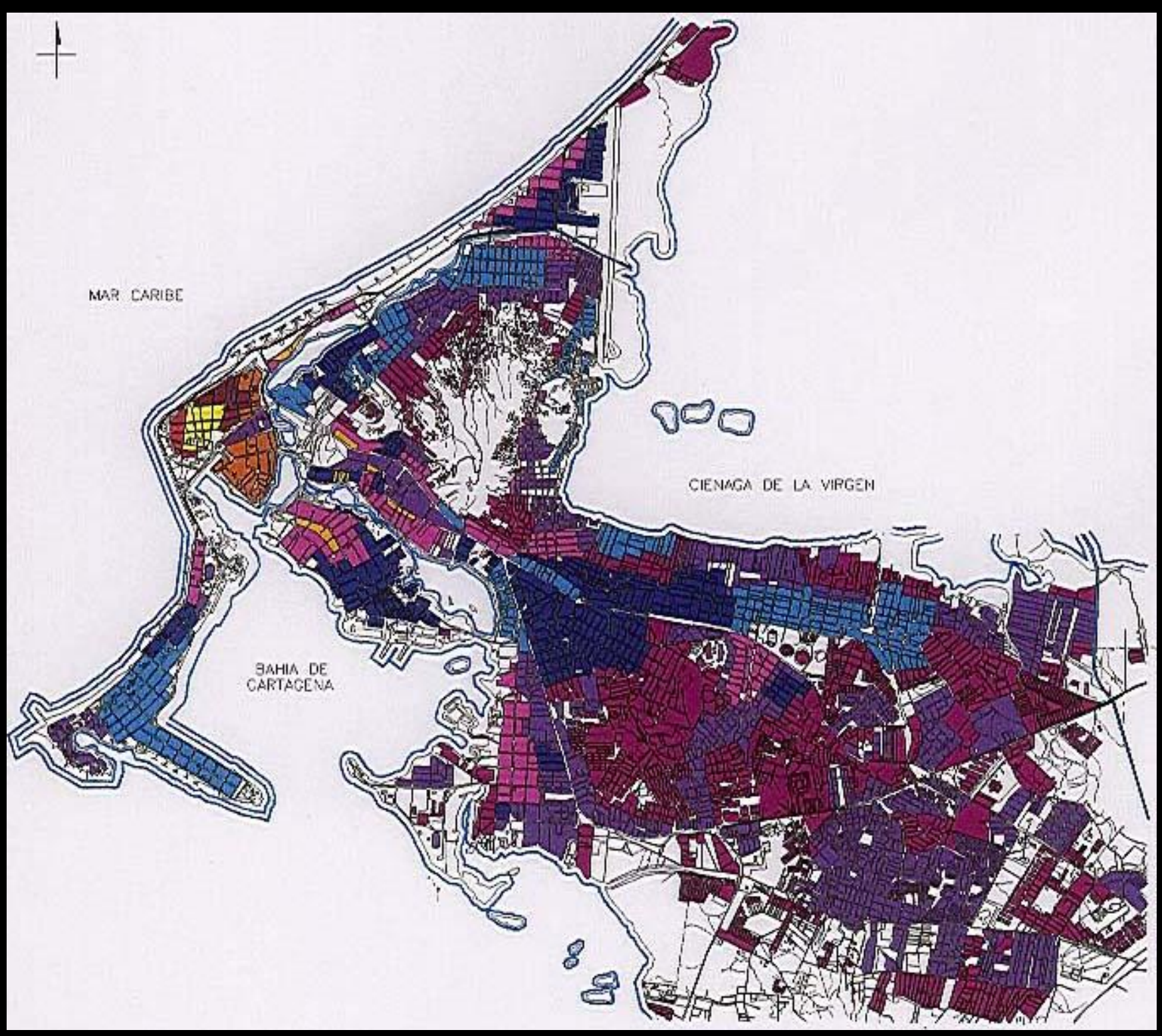




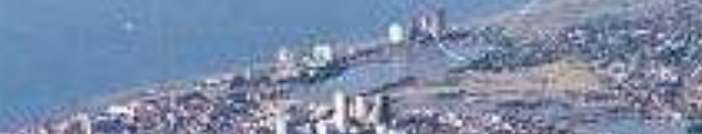

7. 3 ,

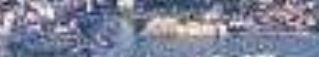

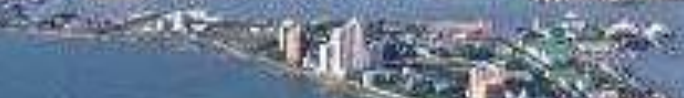

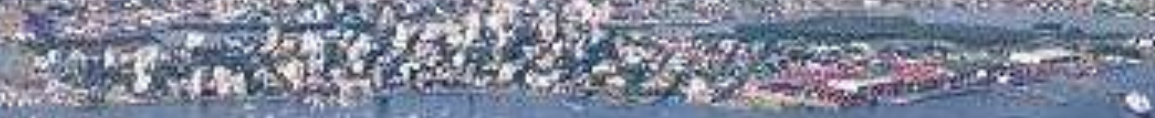

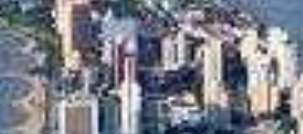

I.

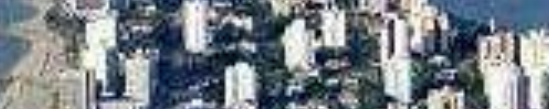

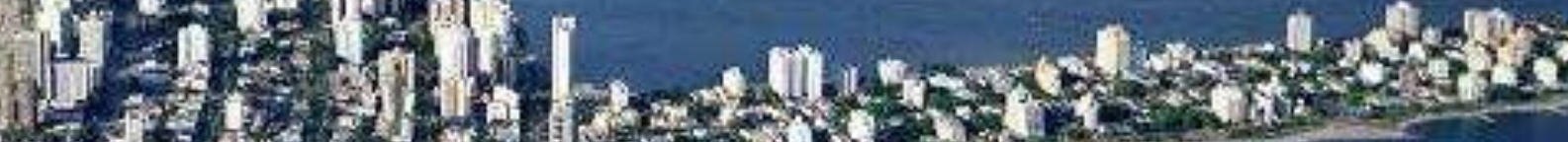
1 (10.0.

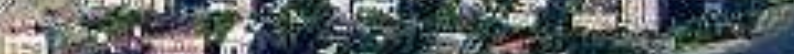
(1)

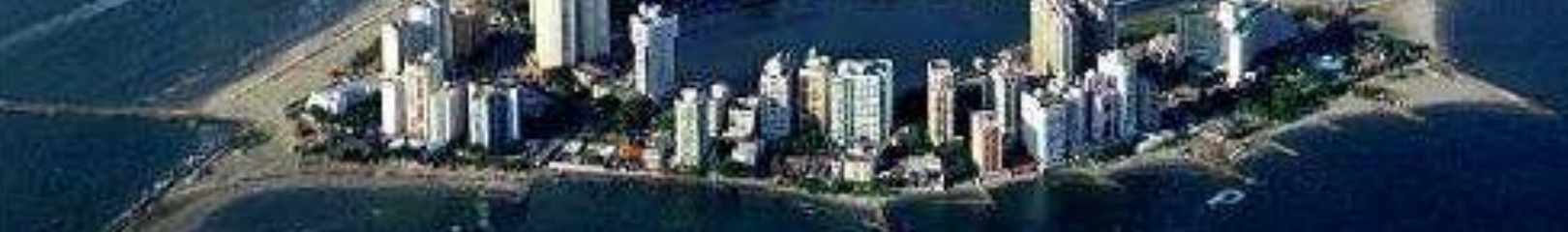




\section{MODELO DE EXPANSIÓN}

Al final del siglo, sce resume la expansión como :

- 1er. Período

un proceso de tipo lineal

- 2do. y 3er.Período una mezcla del modelo lineal y de compactación.

- 4to. Y 5to.período una marcada tendencia a la compactación.

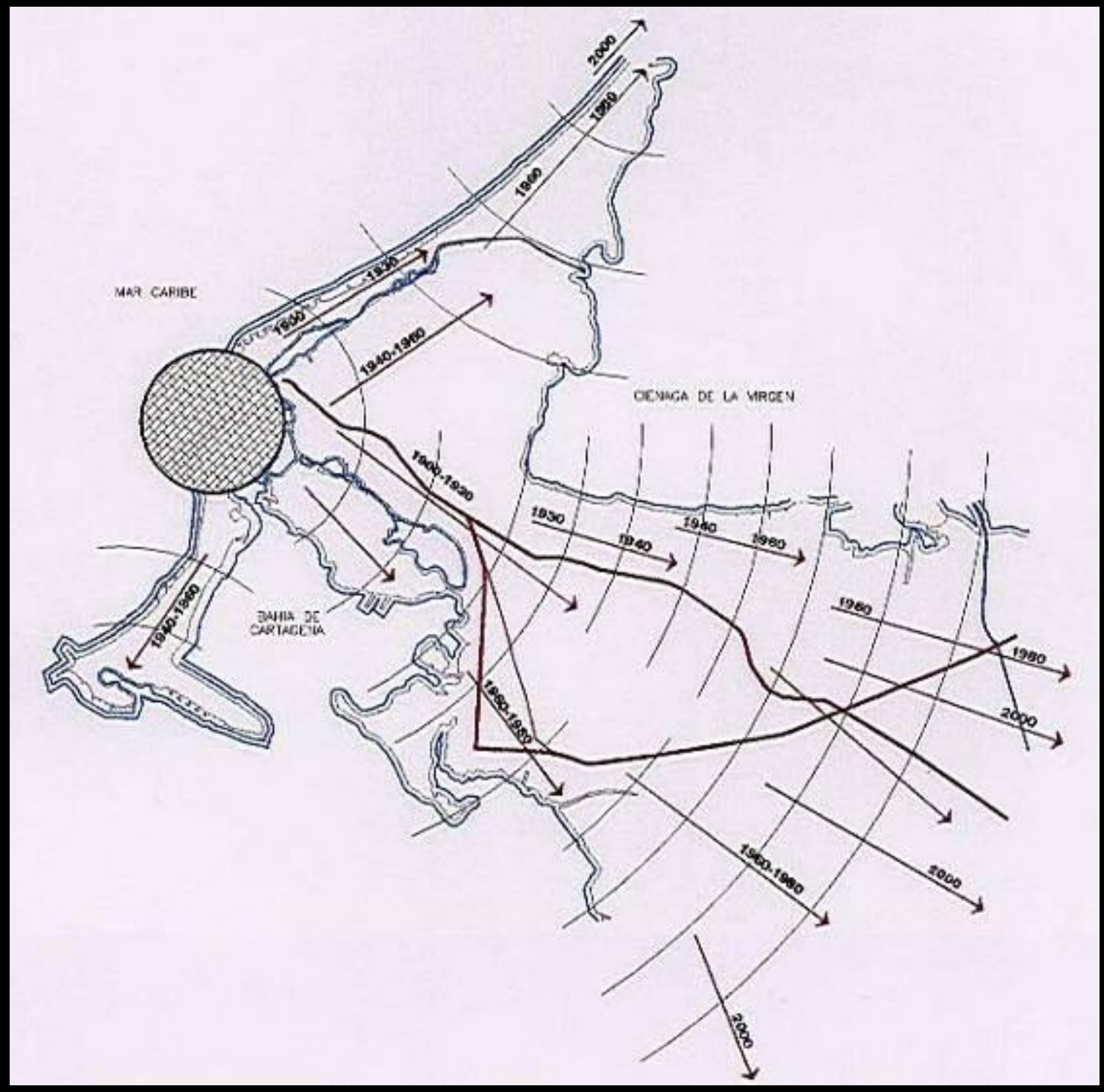




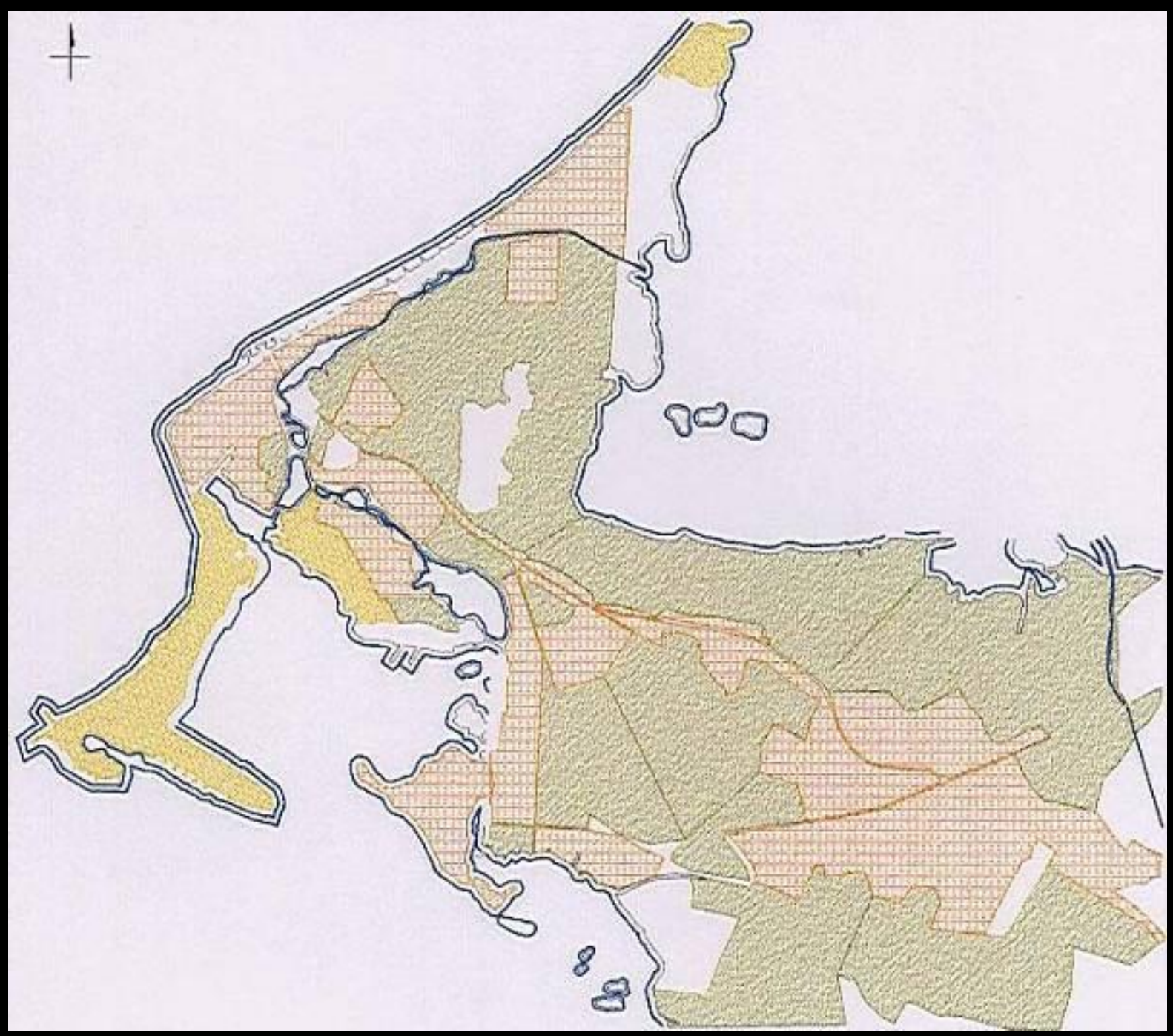

\section{MODELO DE APROPIACIÓN DEL ESPACIO URBANO}

Los sectores pobres de la población ocupan el mayor porcentaje de suelo urbano propiciando el deterioro ambiental de extensas zonas con gran potencial recreativo, turístico y paisajístico. 

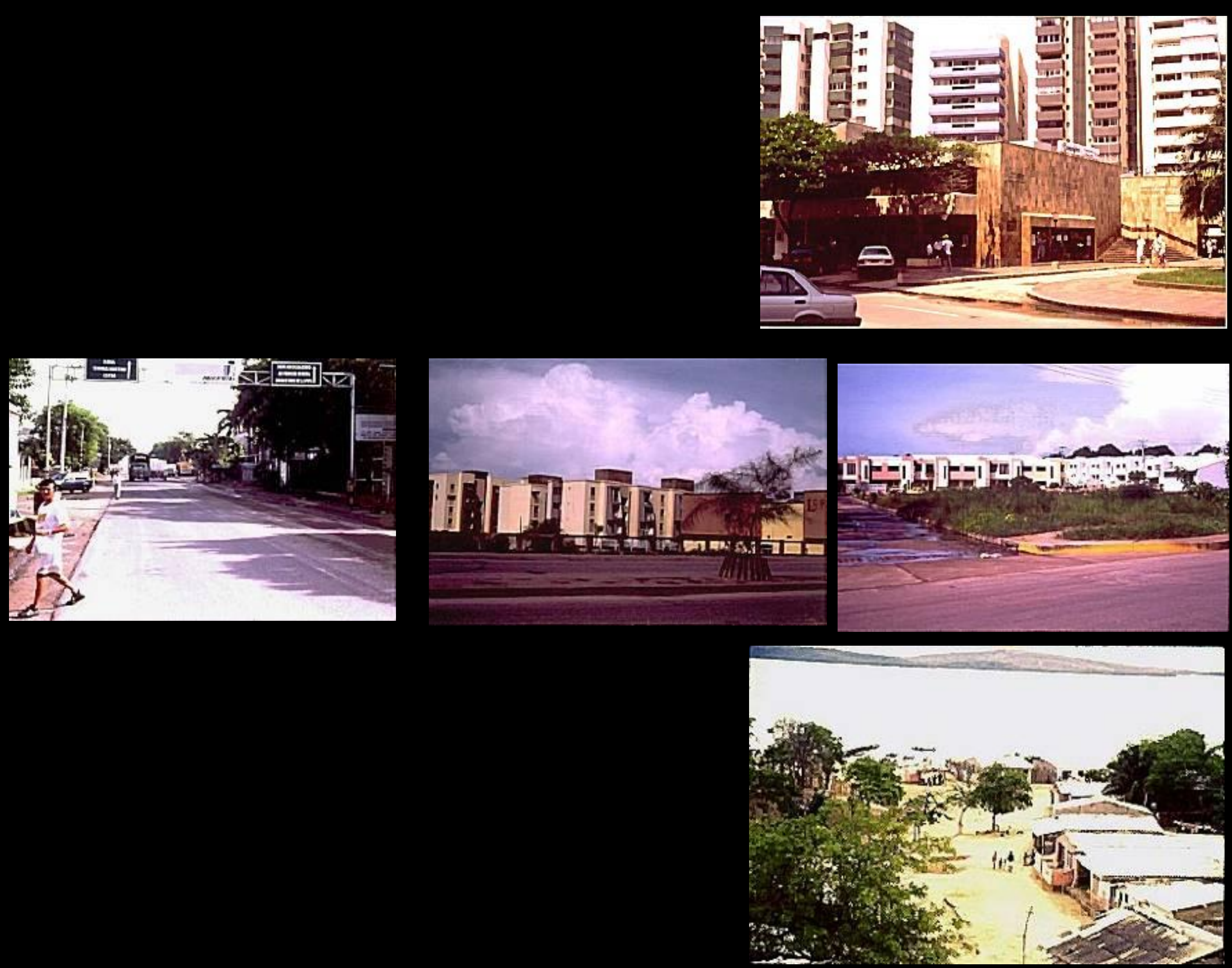


\section{ESTRUCTURA VIAL}

Precedió a la expansión y condicionó el modelo de urbanización ajustándolo a las pautas de las vías del tren y caminos en un entorno de islas y canales que generaban dificultades en la estructura.

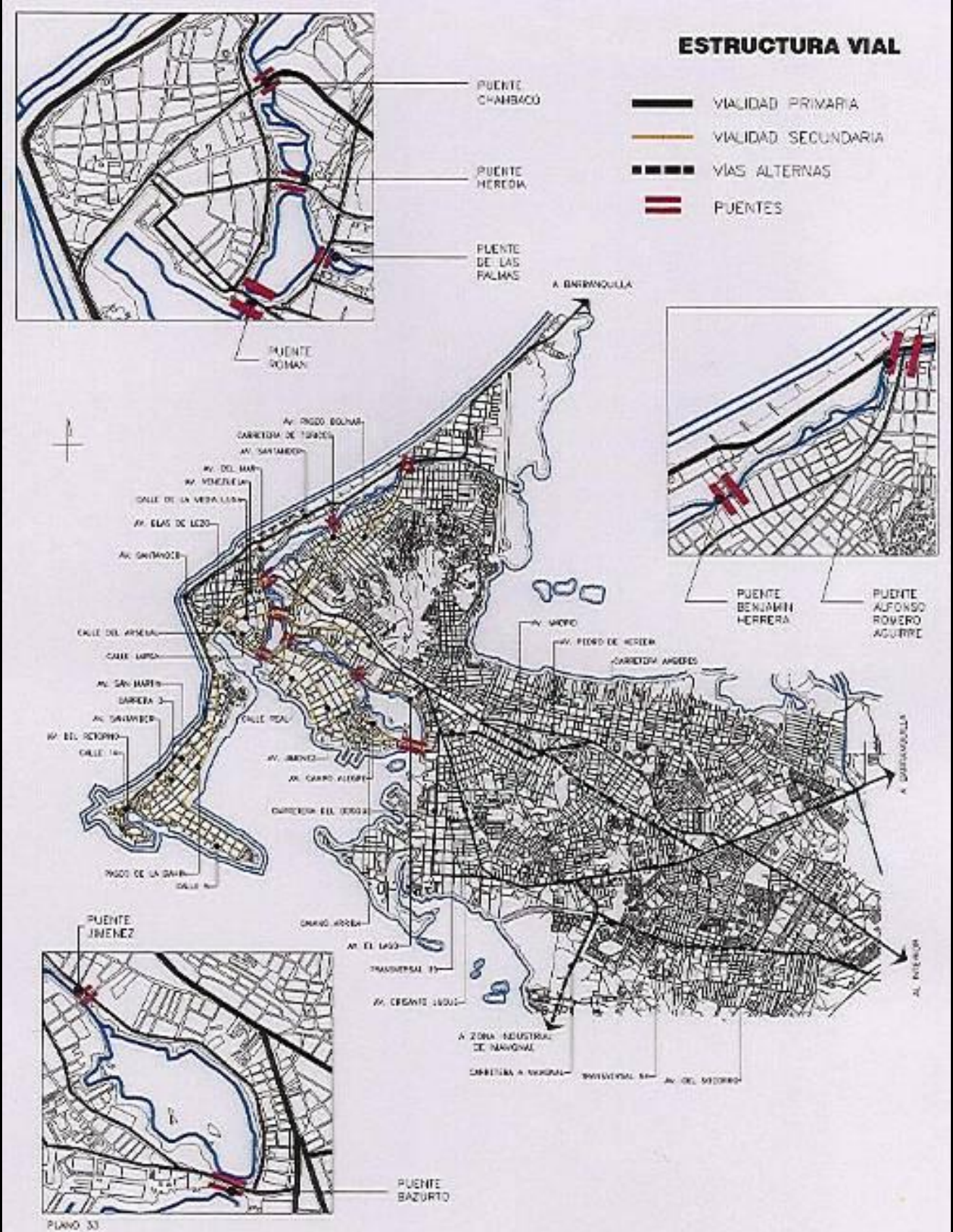




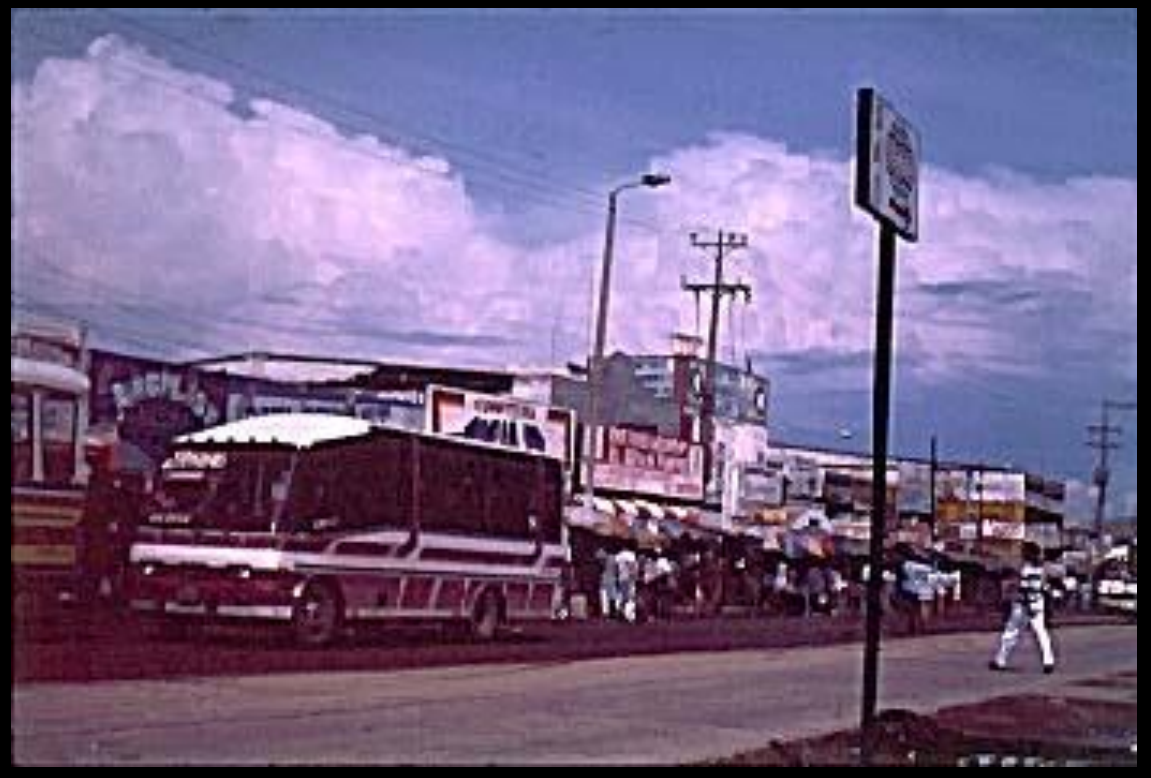

Av. San Martín

Av. Pedro de Heredia
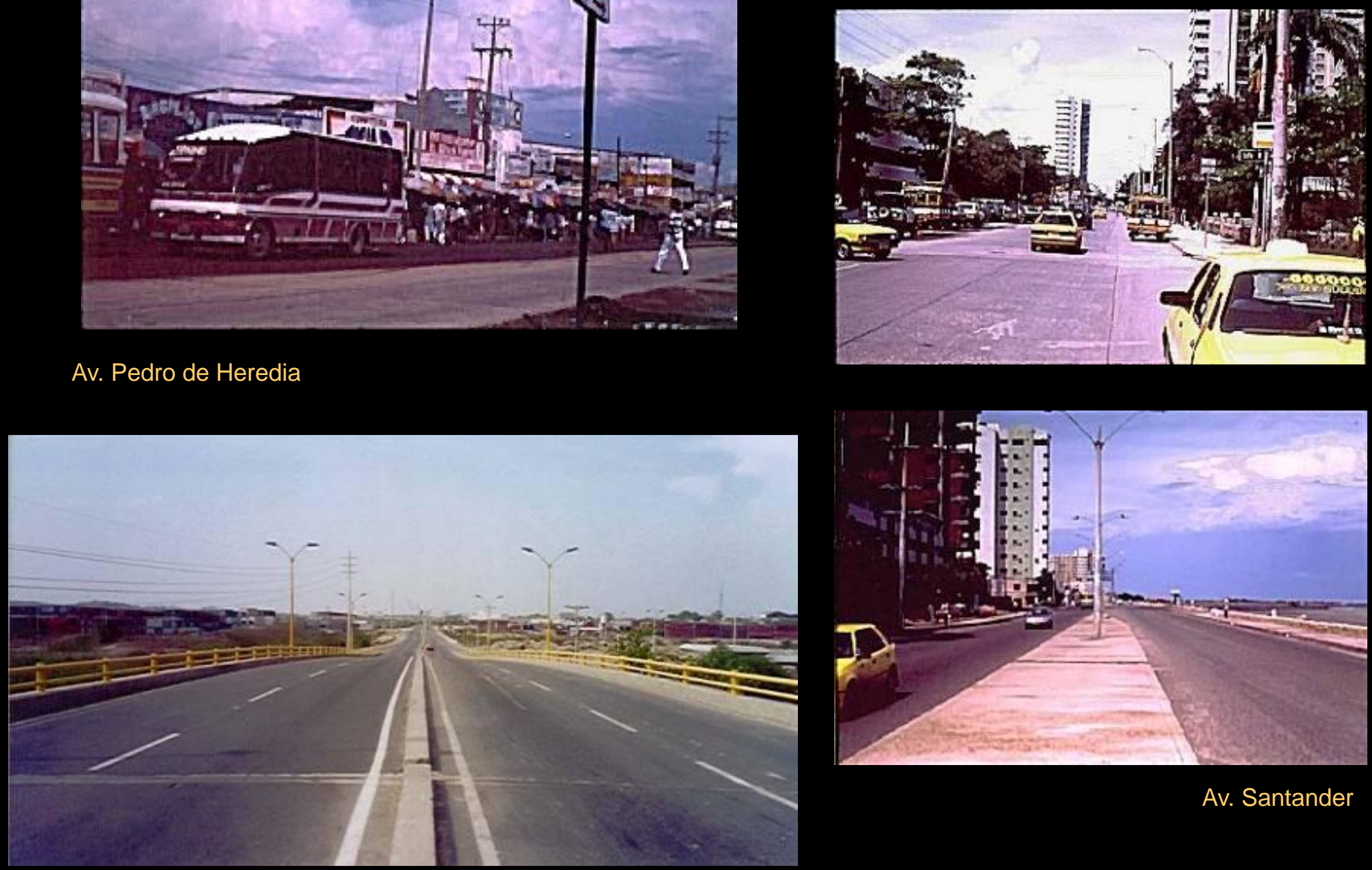

Av. Santander

Nuevo Corredor de Carga 


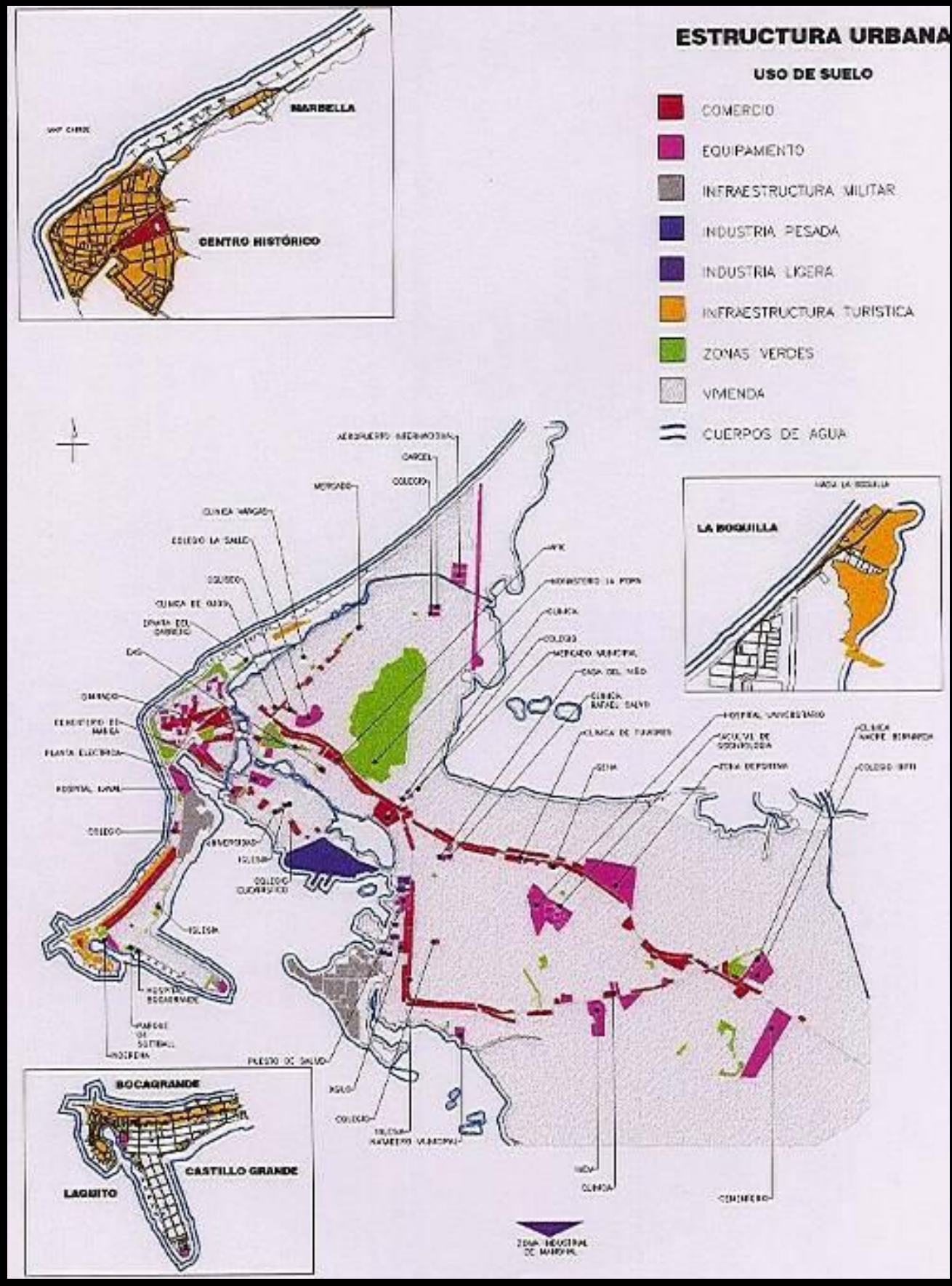

\title{
ESTRUCTURA URBANA
}

\author{
USO DEL SUELO
}

Los diferentes usos se apropiaron del espacio de manera dispersa. El uso habitacional ocupa la mayor parte del suelo del territorio. El equipamiento se diversificó ubicándose en las redes principales de circulación. 

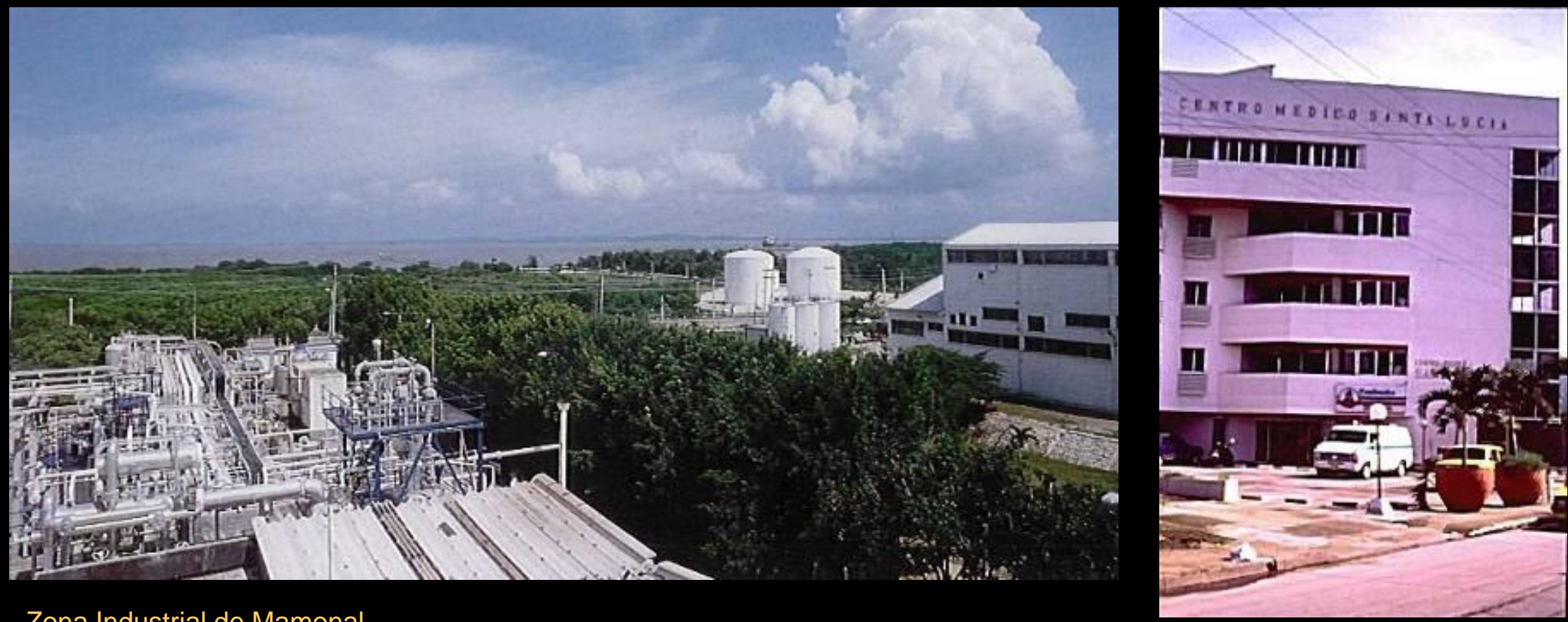

Zona Industrial de Mamonal

Hospital privado

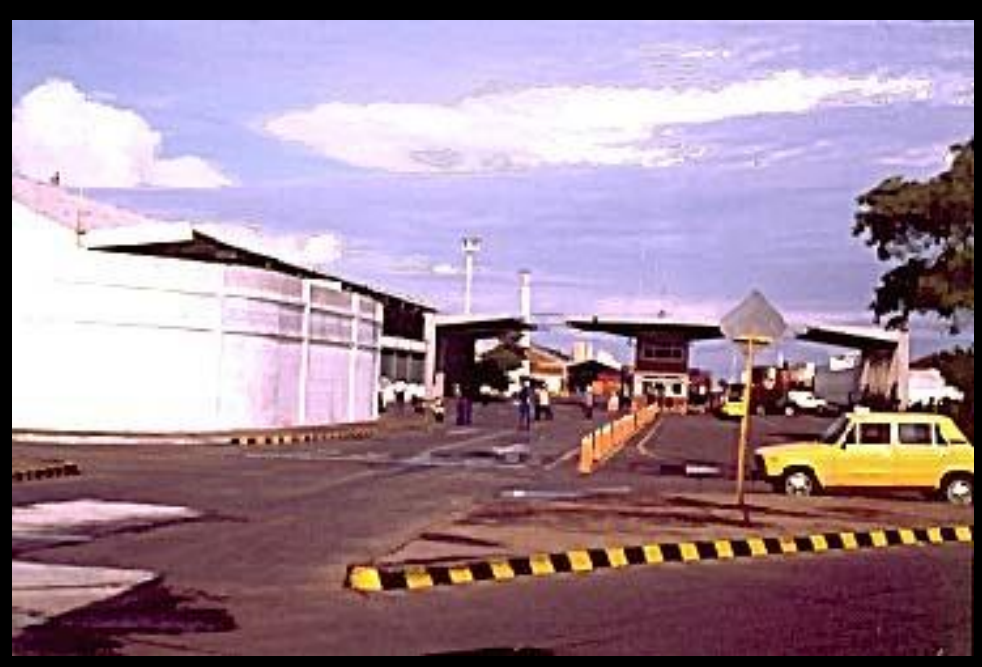

Terminal Marítimo

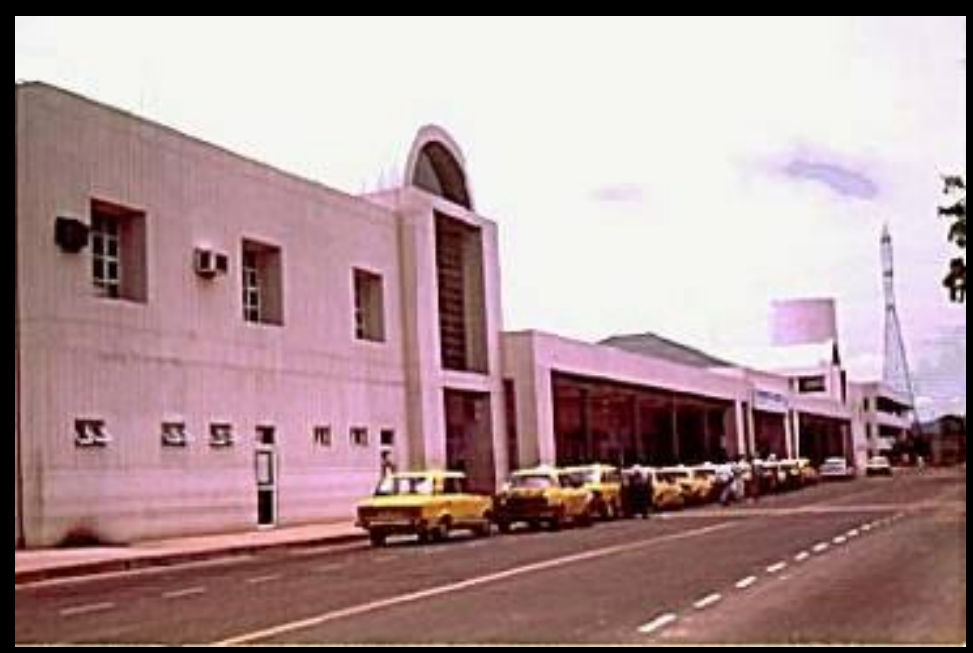

Terminal de autobuses 


\section{MODELO DE DISTRIBUCIÓN DE CENTROS COMERCIALES Y URBANOS}

Predominio del modelo lineal sobre la red principal tendiendo hacia una organización multinuclear de Centros Urbanos.

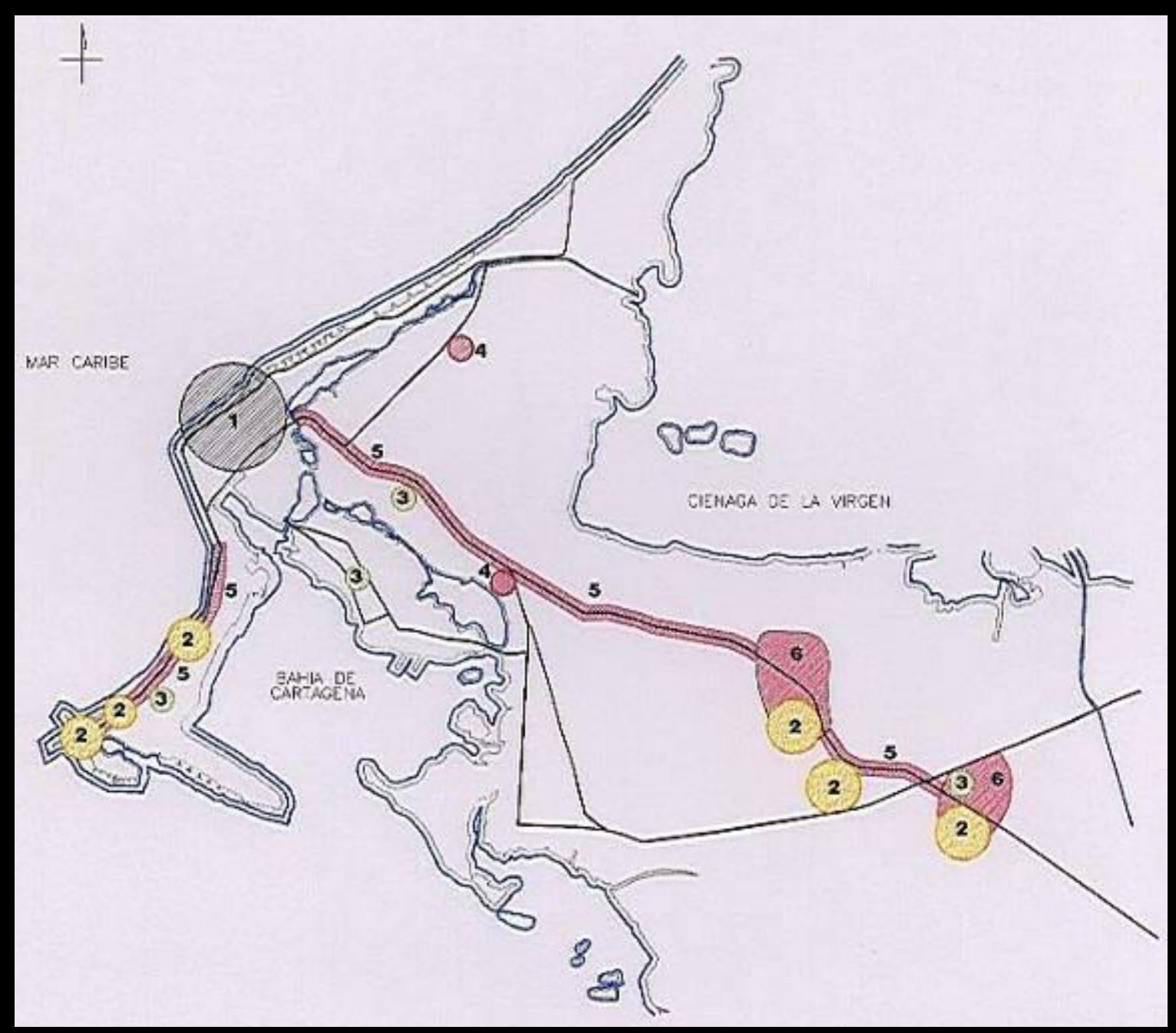




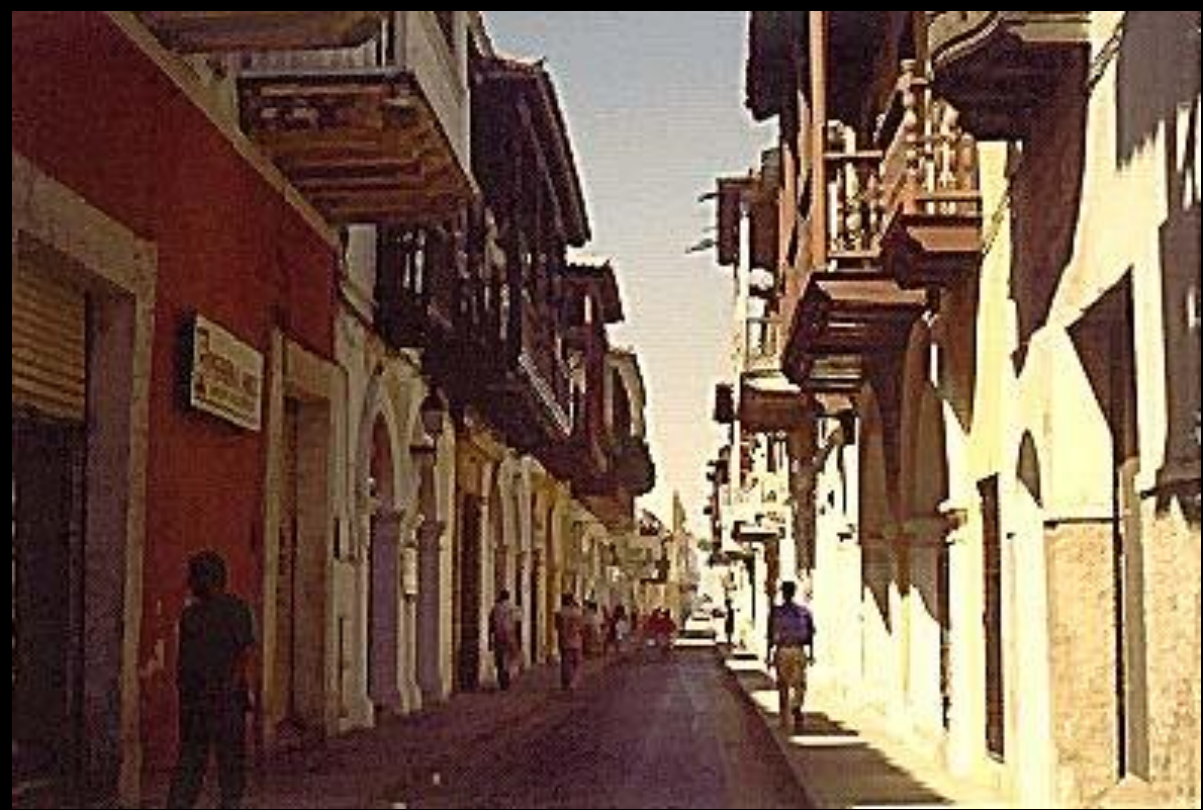

Comercio en el Centro Histórico

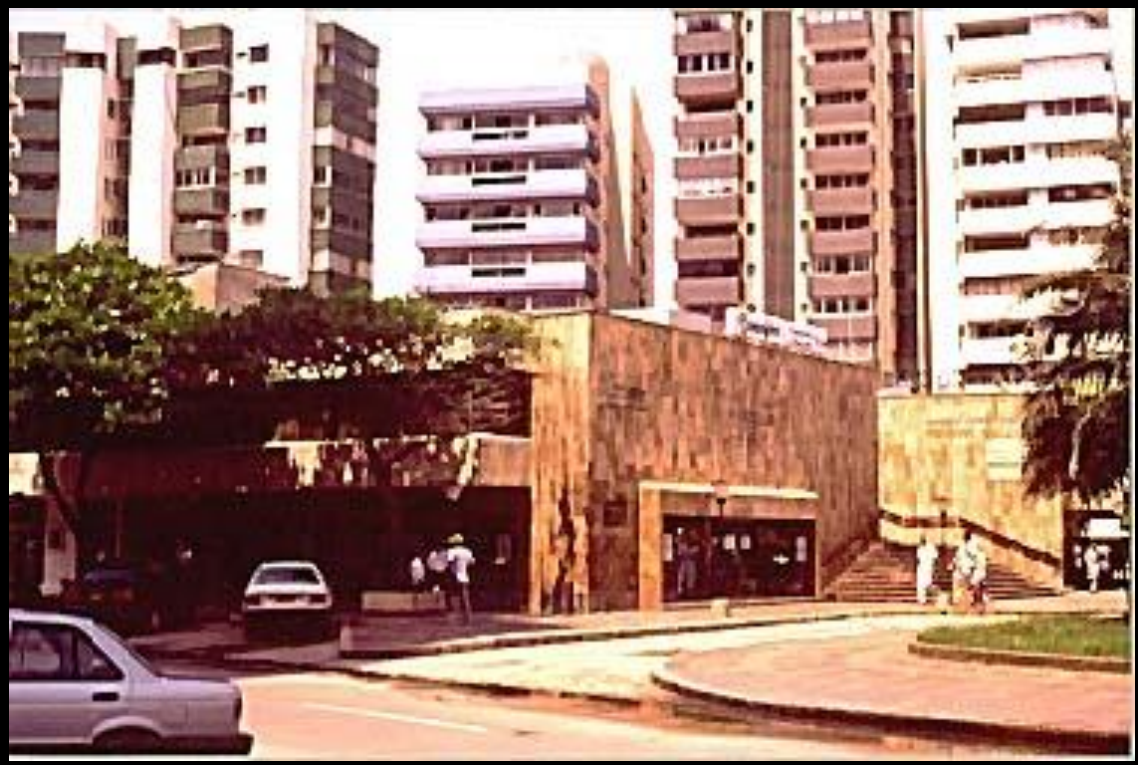

C. Comercial Pierino Gallo

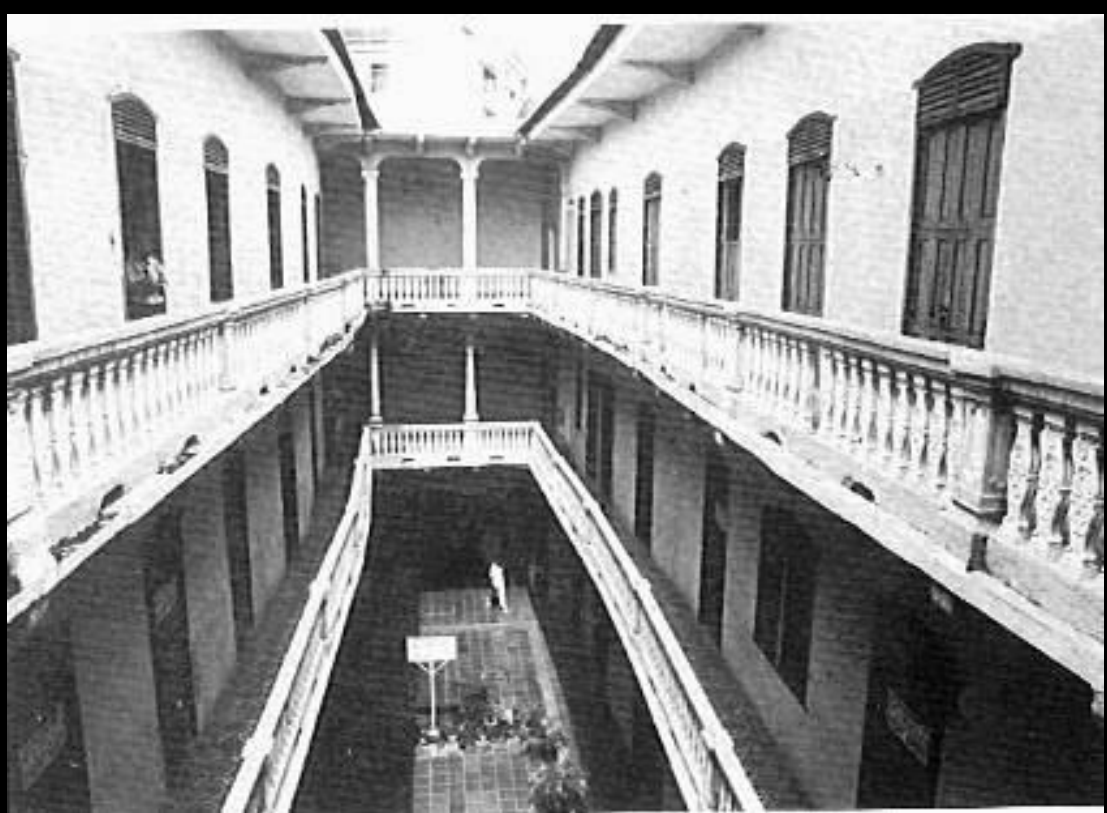

Pasaje Comercial Dager

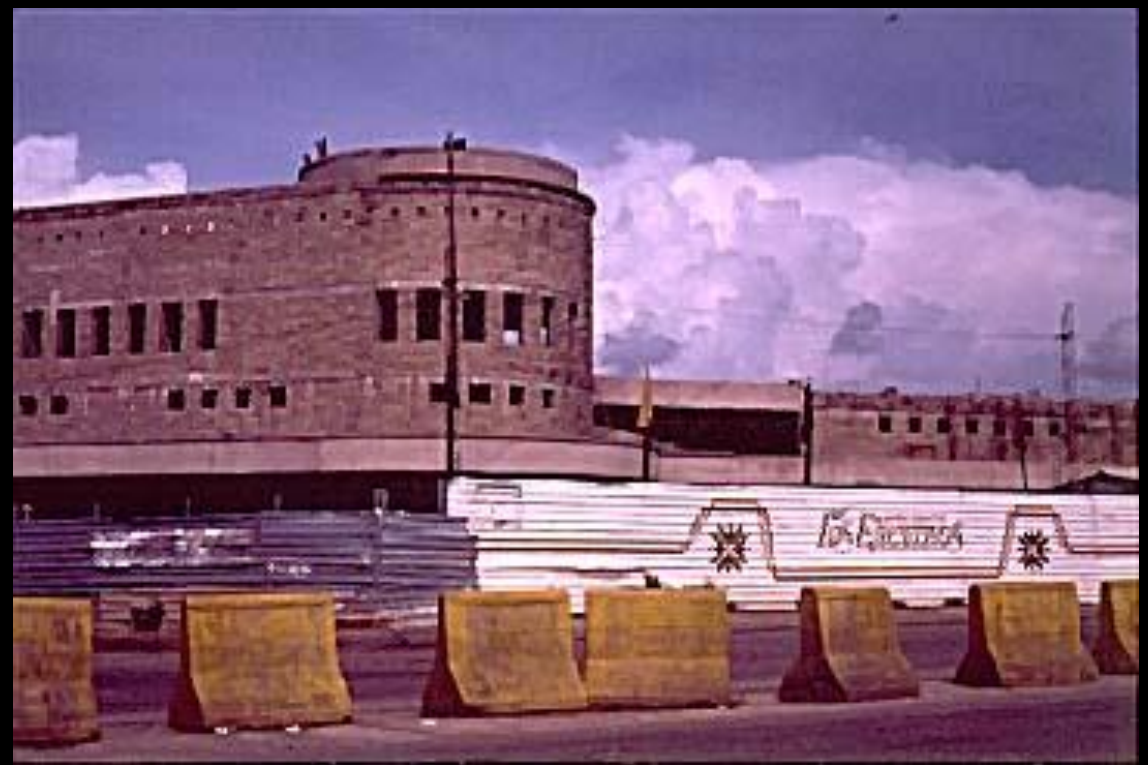

C.Comercial Los Ejecutivos 


\section{CONCLUSIONES}

DESARROLLO URBANO
- colONIA

- CAMBIO Y

TRANSICIÓN

${ }^{\circ}$ MODERNIDAD
Esplendor siglos XVI, XVII y XVIII

Siglo XIX

Siglo XX

Recuperación
ELEMENTOS

\section{URBANOS}

SIGNIFICATIVOS ${ }^{\circ}$ SIGLOS XVII

DE LA

ESTRUCTURA
- SIGLO XVI

YXVIII

- SIGLOS XIX YXX
- Sistema de plazas

- Ejes primarios

- Infraestructura Militar

- Murallas y Baluartes

- Ejes de comunicación

- Puntos Fijos (Puertas) 


\section{PROBLEMÁTICA ACTUAL}

- DEFICIENTE RED VIAL

- deterioro de los cuerpos de agua

- CARENCIA DE SERVICIOS PÚBLICO Y COMUNITARIOS

- BAJA CALIDAD DE VIDA

- CARENCIA DE ORDENACIÓN Y PLANIFICACIÓN URBANA

- ESTRUCTURA URBANA DESARTICULADA

\section{RECOMENDACIONES}

\section{VISIÓN ESTRATÉGICA}

GRANDES TEMAS

\section{POLÍTICA DE ACTUACIÓN URBANÍSTICA}

- CONSERVACIÓN - CONSOLIDACIÓN

- MEJORAMIENTO INTEGRAL - RENOVACIÓN URBANA

- REESTRUCTURACIÓN - DESARROLLO

- desarRollo socio -económico

- ORDENACIÓN DEL TERRITORIO Y ASPECTOS AMBIENTALES

- estructura uRBana

- IMAGEN URBANA 